\title{
Towards Foodservice Robotics: a taxonomy of actions of foodservice workers and a critical review of supportive technology
}

\author{
Débora Pereira, Arianna Bozzato, Paolo Dario, and Gastone Ciuti
}

\begin{abstract}
Foodservice workers perform several burdensome, tedious, and unsafe tasks that risk their health and well-being. This could be mitigated or even more avoided by using autonomouslyactuated machines. Therefore, this article aims to build the foundation to support the development of a new field of robotics research dedicated to foodservice and with a human/workercentered framework. As so, we introduce a two-level taxonomy of basic actions that compose the physical tasks of foodservice workers; it can guide future studies to design bio-inspired control models for foodservice robots. Actions are clustered in $\mathbf{1 6}$ categories according to their purpose and to the handled food. Furthermore, authors make a critical review of single-action equipment (SAE) and advanced equipment (AE) currently available for foodservice, which allowed us to identify opportunities for research. As a result, authors found some categories of actions rarely automated, aimed at i) separating solid-solid food parts, ii) moving food between workstations or independent appliances in the kitchen, iii) introducing food into another solid food or recipient, and iv) other specific actions, e.g. sewing food. In addition, authors discuss the applicability of collaborative robotics and human-robot collaboration to different contexts in foodservice, and show how artificial intelligence is improving the capabilities of $\mathrm{SAE}$ and $\mathrm{AE}$ and what else it could improve in this context.
\end{abstract}

Note to practitioners - This paper was motivated by a critical need in foodservice: the ability to produce consistent and highquality meals ad-hoc, without overloading the workers or harming their health. Robotic and autonomous systems are promising technologies to solve this. However, there is not a unified framework in robotics research focused on the professional foodservice environment. This paper provides two tools for researchers and engineers in this field: (i) a taxonomy of basic actions that foodservice workers perform during their physical tasks; and (ii) a systematic review of mechatronic systems being developed or already in use in foodservice. The taxonomy can be immediately useful to divide research and development by the classes of actions. In addition, we found specific categories of actions that have been rarely automated so far and need further investigation. The results of our review can be readily applied in industry, too: presently, most equipment is a custom-built machine with limited adaptiveness; when systems include industrial robots, cobots are being preferred; the implementation of collaborative operations between humans and robots is not common yet and its applicability may be suitable only for certain contexts; finally, we identify scientific publications introducing

D. Pereira, P. Dario and G. Ciuti are with The BioRobotics Institute, Scuola Superiore Sant'Anna, 56127 Pisa, Italy (e-mail: d.pereira@santannapisa.it; paolo.dario@santannapisa.it; g.ciuti@santannapisa.it).

A. Bozzato is with the Dipartimento di Scienze Agroalimentari, Ambientali e Animali, University of Udine, 33100 Udine, Italy (e-mail: arianna.bozzato @electroluxprofessional.com) adaptive control strategies and movement policies for some actions that can be implemented today to achieve a more robust actuation.

Index Terms - taxonomy of actions; professional appliances; food service automation; foodservice collaborative robots; intelligent systems

\section{INTRODUCTION}

耳' OODSERVICE (FS) is the leading employer sector of hospitality industry [1]. For instance, currently, restaurants in U.S. employ about 15.3 million people, which is $10 \%$ of the overall U.S. workforce [2]. On the other hand, FS typically shows high turnover rates [3] [4], having reached (together with the accommodation sector ${ }^{1}$ ) $74.9 \%$ in 2018 [5].

Indeed, some conditions of working in FS are often uncomfortable for the staff and, thus, pointed causes to the high turnover rate, i.e. part-time work [6], unsocial ${ }^{2}$ [6] [3] and long working hours [3], job overload [7], among others. Some of these are not only uncomfortable but also unhealthy. For example, unsocial and long working hours, as well as job overload, are work stress factors [8] [9]. In turn, prolonged stress deteriorates mental health, e.g. with anxiety or depression [8], and leads to physical problems [8], e.g. increased frequency of injuries due to burns and cuts [10]. Another example is the excessive noise. Past studies assessed the noise levels in kitchens of canteens, verifying it was a main cause of discomfort at work [11] or even exceeded the recommended limits reported by the National Institute for Occupational Safety and Health [12]. In FS businesses, such as restaurants or catering, where the work usually lasts the entire day, workers are exposed to this excessive noise even longer. Finally, the high turnover in restaurants is also explained by the fact that its workforce heavily relies on teenagers [13], since a long time [14]. These are usually untrained and inexperienced workers, with higher turnover intentions than older staff [3] [14].

The workplace should be continuously improved to alleviate stress, promote the workers well-being [15] [16] and allow them to be active and creative [17]. Training the workers to cope with stress seems not be the solution, as it has no benefit in long-term [18]. While several studies have suggested that

D. Pereira and A. Bozzato are also with The Research Hub, AD\&T, Electrolux Professional, 33170 Pordenone, Italy.

\footnotetext{
${ }^{1}$ The Bureau of Labor Statistics does not report data for FS alone.

${ }^{2}$ Unsocial working hours regard, for example, mealtimes.
} 
managerial measures could reduce some stress factors [3] [7], only a few have actually implemented an autonomous management system [19] and demonstrated an improved workflow. Yet, this improvement was evaluated in reduction of service time (i.e. consumers' benefit) and food waste (i.e. business benefit), rather than improved work conditions (i.e. workers' benefit). Moreover, recalling that several physical tasks require close contact with heat, potentially dangerous tools and noisy machinery, even good staff management cannot eliminate the exposure of workers to such conditions. Thus, it looks evident that FS workers need additional support in their physical tasks and, for that, more autonomous actuated equipment should be at their disposal. This equipment could be used to $i$ ) compensate for missing workforce, collaborating with the retained people to reduce their workload, and ii) replace the workers in unsocial or excessive working hours, and in tasks that risk their health. Additionally, more autonomous equipment facilitates the job of less experienced employees (e.g. teenagers). Definitely, advanced automation and robotics are promising fields of study to accomplish this.

The adoption of robotic systems in food manufacturing (FM) industry is known to be growing and expected to reach $\$ 3.1$ billion by 2025 [20]. It is not easy, however, to find statistics on robots adopted in FS. Data provided by the International Federation of Robotics (IFR) concerning FS includes only robots used for "Public-relations and joy rides" [21], but not for tasks in professional kitchens. Past reviews of robots for food manipulation mainly focus on FM [22] [23] [24] [25] [26] rather than FS. Some even examine technology for both industries together [23] [26], disregarding their remarkable differences. FM and FS have in common, generally, high productivity demands. However, contrarily to FM, demand in FS occurs at peak times of the day, and the workers' tasks may be modified daily, monthly, or yearly, depending on the events [27, pp. 1-2]. Moreover, in FS (especially full-service and fine dining restaurants), the community cares about the workers' creativity and artistic ideation [28]. Other researchers discussed FS robotics and household robotics together [29]. However, a distinction is necessary because professional appliances are subject to more intensive use than domestic ones and, thus, have higher requirements of performance and reliability [30]. Other articles address robotics in the overall hospitality industry, counting with accommodation and entertainment besides FS. Moreover, their analysis is essentially centered on human-robot interaction and social acceptance [31] [32] [33].

Thus, scientific literature seems to miss a focused review of FS technology including recent robotic solutions. Such a review is important to identify technological gaps and opportunities for research. However, literature on FS businesses also does not report a thorough enumeration of the workers' tasks, that would be fundamental to analyze, systematically, the existing technologies and understand which tasks could not be automated up to now.

This article aims to close those gaps in the literature, contributing with:

i) a taxonomy of the physical actions of FS workers;

ii) a critical review of existing technology to support those actions, from manual utensils to autonomous robots.

These can be the first tools to create a new research field of robotics dedicated to FS. Hence, Foodservice Robotics would be oriented by a human-centered framework, within which robots could be designed aiming to reduce physical effort and creating greater work conditions to FS employees.

In Section II, we explain the creation of the proposed taxonomy. Its usefulness is immediately shown, as we apply the taxonomy to guide the subsequent technology review and the discussion. In Section III, we perform a critical review of $(i)$ manual utensils, (ii) actuated appliances for a single action, and (iii) multi-action or autonomous equipment (including robots), proposed by literature or companies for FS. In Section IV, we discuss the capabilities and current limitations of both singleaction and advanced equipment. We identify the gaps in the research for this field, recognizing the actions that are rarely automated. Lastly, we reason on the usefulness of Artificial Intelligence and the applicability of collaborative robots in FS.

\section{A. Definitions}

Relevant terms used throughout this article are defined here.

- Foodservice, or food service (FS): following the North American Industry Classification System (NAICS), which is commonly used in the hospitality industry [34], FS is a set of businesses that "prepare meals, snacks, and beverages to customer order for immediate on-premises and off-premises consumption. [...] Some provide food and drink only; while others provide various combinations of seating space, waiter/waitress services and incidental amenities, such as limited entertainment" [35]; among them are caterers, limited-service restaurants (e.g. quickservice, casual and family restaurants), full-service restaurants, FS contractors (e.g. in airlines, hospitals, schools, entertainment or sports facilities), truck vendors, cafeterias, buffets, and bars [35].

- Tasks: activities of FS workers that involve movement (physical actions); activities not directly compelling any movement, but only observation and decision-making are not included here (e.g. menu planning, inventory control, usually done by executive chefs [36, p. 35] or kitchenmanagers [19]).

- Utensils: tools intended to support manual food handling; food handling is understood, here, as any task dealing with raw, cooked or leftover food; hence, in this article, utensils include the so-called kitchen-utensils but also tools to clean food dirt (e.g. scraper, sponge) or to move food between rooms or workstations, such as trays or trolleys; contrarily, instruments for mere measurement (e.g. thermometers, scales) are not included.

- FS appliances: machines designed for FS businesses, also called professional or commercial kitchen appliances [30] [37]; some are passive to the workers' physical actions, because they simply create the ambient conditions (temperature, humidity, confined space) to control a solid/liquid/gas state transformation of the food (e.g. freezer) or a chemical reaction (e.g. oven, refrigerator); 
other appliances automate some of the workers' physical actions, thus, they provide an active support; passive appliances may also integrate accessory actuated mechanisms for active support (e.g. automatic basket lifting systems in fryers); this article addresses just active appliances/mechanisms.

- Single-action equipment (SAE): the actuated machines most commonly used in FS perform only one action (see Section III.B); other equipment can perform multiple actions but only with the contribution of human staff to manually exchange the end-tool (e.g. blade, whisk); SAE is a term used, here, for both type of equipment.

- Advanced equipment (AE): we use this term for machines that automatically execute multiple actions without human intervention, even if pre-programmed ${ }^{3}$, or adaptive systems that execute one or more actions, adapting them to inputs from the environment (see Section III.C).

- Robot: this article refers only to the classical definition of robot ("actuated mechanism programmable in two or more axes" [38]), that includes physical robotic machines, but not software robots.

- Cobot (collaborative robot): a type of "industrial robots designed specifically to work alongside humans in a shared workspace $[\ldots]$ with a variety of technical features that ensure they do not cause harm when a worker comes into direct contact" [39]. Such features include rounded corners, lightweight materials, padding and sensors [39].

\section{TAXONOMY OF ACTIONS IN FOODSERVICE}

Knowing the spectrum of tasks executed by FS workers helps to identify missing supportive technology. However, FS workers perform numerous and business-variable tasks, making it impractical to enumerate all the existing ones. Still, all tasks are based on a set of methodologies, related to the transformation of food into customer meals, that rely on the repetition of more basic actions [36]. Then, instead of the tasks, these actions could be enumerated more easily.

In fact, researchers of different fields typically break down task-related movement in hierarchical levels [40] [41] [42] [43] [44]. Tasks of FS workers can also be mirrored in this scheme. As depicted in Fig. 1, a task is performed as part of a wider operation of the FS business [45] [46]. Conversely, any task is a purposeful composition of shorter actions with even more specific goals [41] [44]. For example, one could observe that washing dishes is a task composed by, at least, the actions of scraping food dirt, rubbing and rinsing. Actions result from the coordinated execution of more elementary parts, usually called motion primitives (MP), without visible transition between them [41]. MP can be simple gestures, e.g. pressing, lifting, reaching, or even unnamed ones [44]. MP have been recognized in other tasks by analyzing kinematics [47] [48] or dynamic

\footnotetext{
${ }^{3}$ We refer to pre-programmed actions as scripted sequences of pre-set commands, not adaptive to the environment. "Without human intervention" does not account the input of process parameters through a user interface, like the selection of ingredients by customers or definition of settings, such as temperature or time, by workers.
}

data [49], muscular activity [50] [51], or video [44] [52]. Note that MP in Fig. 1 are merely illustrative, as this motion has not been analyzed in the past. Moreover, it is not the aim of this work to find such detailed level in FS tasks, but only their underlying actions.

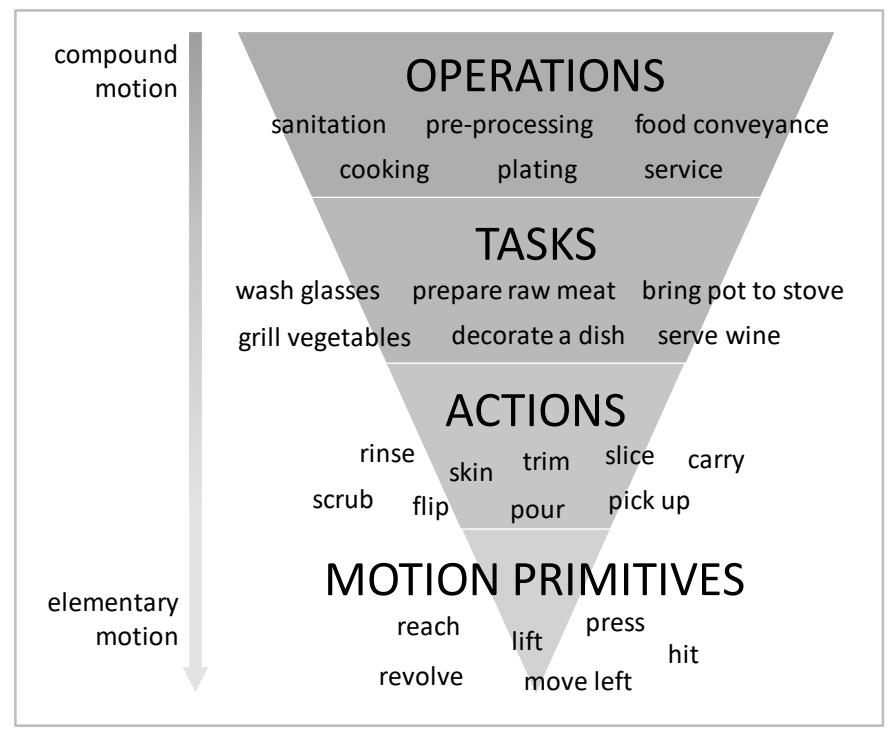

Fig. 1. Hierarchical decomposition of the motion of FS workers, from compound to elementary movements.

\section{A. Method: actions identification and classification}

The authors propose to identify the actions within FS tasks by searching movement-related verbs in books/documents about the work of FS professionals. Indeed, other researchers extracted a list of culinary verbs from text [53] [54] [55] [56] [57]. However, they have not made available the complete list of verbs they found (or the links are outdated), so we cannot use them here. Only [56] reports an extensive list, but exclusively with cutting verbs. Moreover, these works included not only verbs related to an action (movement-related verbs), but also those expressing a cooking process (e.g. fry, roast) or very generic verbs (e.g. add, divide) that do not explicit the underlying action but rather its purpose. Additionally, these studies relied on recipes, which are an incomplete representation of the work in FS: usually, recipes indicate only preparation and cooking tasks, not e.g. cleaning. Instead, other researchers [58] directly inquired professional cooks and reported a more inclusive list of FS "tasks" counting with serving, dish washing and cleaning. However, they list both elementary and compound movements (i.e. actions and tasks) and verbs referring to cooking processes. Therefore, neither of the past works meet our goal.

Hence, movement-related verbs were methodically retrieved from three books about professional culinary fundamentals of different cultures: Japanese [59], Italian [60] and a global one [36]. These books were selected for being cited significantly by previous literature ${ }^{4}$, or frequently used to teach culinary arts'

\footnotetext{
${ }^{4}$ Searching for "Japanese cooking" in Scopus (Secondary documents), [59] is the most cited. Few articles refer to [60] (e.g. [302] [303]), but no other book on Italian cooking was found cited by scientific literature.
} 
professions [61] [62]. Contrarily to recipe books, the selected ones address tasks from all FS operations, including sanitation, service, or food conveyance.

The verbs in each book were found using the following method [63]: all words were extracted and identified as noun, verb, letter or digit; verbs were picked and normalized to the infinitive form; verbs with less than 2 letters or more than 15 , as well as those occurring less than 5 times, were excluded; finally, the list was manually corrected to remove wrong classifications and discard the following verbs:

- explicitly not associated to movement (e.g. define, think);

- referring to a process or a type of food transformation, e.g. bake, boil, braise, freeze, grill, melt, etc.;

- with its meaning depending on the word immediately after (e.g. pull, put, bring, cut, remove) - e.g. put together (mix), put in a position (place), cut in slices (slice), remove fat (trim);

- with a broad meaning (e.g. coat, add, garnish, discard) for which specific meanings are already listed (e.g. breading is a specific case of coating);

- related to a general operation (e.g. cook, serve, prepare $)^{5}$.

Following this, the definition/description of the verbs was obtained complementarily from the glossary in [36, pp. 1-23], an online glossary [64] and the Oxford American Dictionary [65]. The appropriateness of the definitions was, then, confirmed by manually searching the usage of each verb in the books. The definitions were firstly used to distinguish verbs expressing an action from those expressing a task. Although this distinction is not straightforward [42] [44], we considered that a verb would express a task if its definition indicated a composition of smaller movements by including other verbs already classified as actions. For instance, knead was considered a task because it means "working a dough to develop gluten" [36] " ... by stretching, folding and pushing" [64], being "stretch" and "fold" two actions.

\section{B. Results: the taxonomy structure}

In total, 53 actions were found.

In addition to enumerating actions of FS workers, it is useful to agglomerate and classify them as it facilitates the analysis of equipment to support these actions. Therefore, a taxonomy can be created. From the definitions of all the retrieved verbs, two criteria were defined to classify the actions:

- the action purpose - first level of the taxonomy (colored boxes in Fig. 2);

- a relevant characteristic/status of the food involved in the action - second level (light-brown boxes in Fig. 2).

Nine purposes were identified by keywords in the verbs' definitions:

1. separate - identified in keywords like e.g. "remove liquid component", "cut away unwanted parts";

2. reduce size - e.g. "separate into pieces", "reduce to small particles";

\footnotetext{
${ }^{5}$ The verbs were retrieved using the functions of Text Analytics Toolbox of MATLAB 2019b. The code for the whole procedure is publicly available at https://github.com/deborapereira/actions of fs workers. It lists all discarded
}

3. cover - e.g. "coating", "scatter over";

4. move-e.g. "cause a liquid to flow", "turn over", "throw";

5. mix - "mixing method";

6. clean - e.g. "remove dirty";

7. introduce - e.g. "put into liquid", "place into";

8. close - "fasten", "close";

9. shape - e.g. "flatten", "bend".

Each verb was placed in the taxonomy according to its associated purpose (Fig. 2, in black). However, exceptionally, the verb "shake" was found associated to multiple purposes. It is mostly intended as separating components, e.g. shake off flour excess covering another food, or shake the pan or basket to induce stuck food pieces to get separated. Less commonly, "shake" is an alternative action to "stir", e.g. in preparing drinks, or to "sprinkle", e.g. shaking a container of salt or spices to season a dish. Thus, "shake" was included in the taxonomy only as the most common action, i.e. to separate components.

For verbs with identical meaning (e.g. mill/grind, pit/core, shell/shuck), one verb is indicated in the taxonomy, or two for better comprehension.

A second level was added to the taxonomy, because the verbs' definitions provided indications of differences among actions with a same purpose. Such differences were related to the food involved in the action. For example, actions such as peel or strain are both intended to separate components from a given food. Yet, the first refers to removing a solid component (the peel) while the second refers to removing liquid (serum or water). Another example lies among mixing actions: while blend or stir are intended to evenly distribute ingredients in a mixture, beat or whip are executed in a way that modifies the mixture, either by allowing to incorporate air (in mixtures with eggs) or to develop gluten (in dough). Thus, the food is just "distributed" or "modified", respectively. The same reasoning was applied to subdivide the actions with other purposes, when evident in definitions - actions intended to shape and close were not subclassified. This process resulted in 16 classes of actions (black boxes in Fig. 2).

In the literature, we found other three criteria used in classification systems related to FS activities: (i) the type of FS business (e.g. the classes in NAICS [35] or [34]), (ii) the type of food flow system [45] [27], and (iii) the role of FS workers, e.g. the classical kitchen brigade and the waiters staff hierarchy [36, pp. 35-37]. However, one can observe that many actions are performed in common by workers in different FS businesses [46] and are also part of different types of food flow systems [46]. Moreover, despite each chef/kitchen-worker being responsible for specific tasks, each role does not necessarily characterize a single type of task/action. They are assigned tasks of a same cooking method, equipment or food type [36, pp. 35-37], which may require similar actions. Therefore, neither of these three criteria can discriminate the actions of FS workers, thus, actions were no further subcategorized.

verbs and respective justification. The repository also includes the definitions of retained verbs that were used here. 


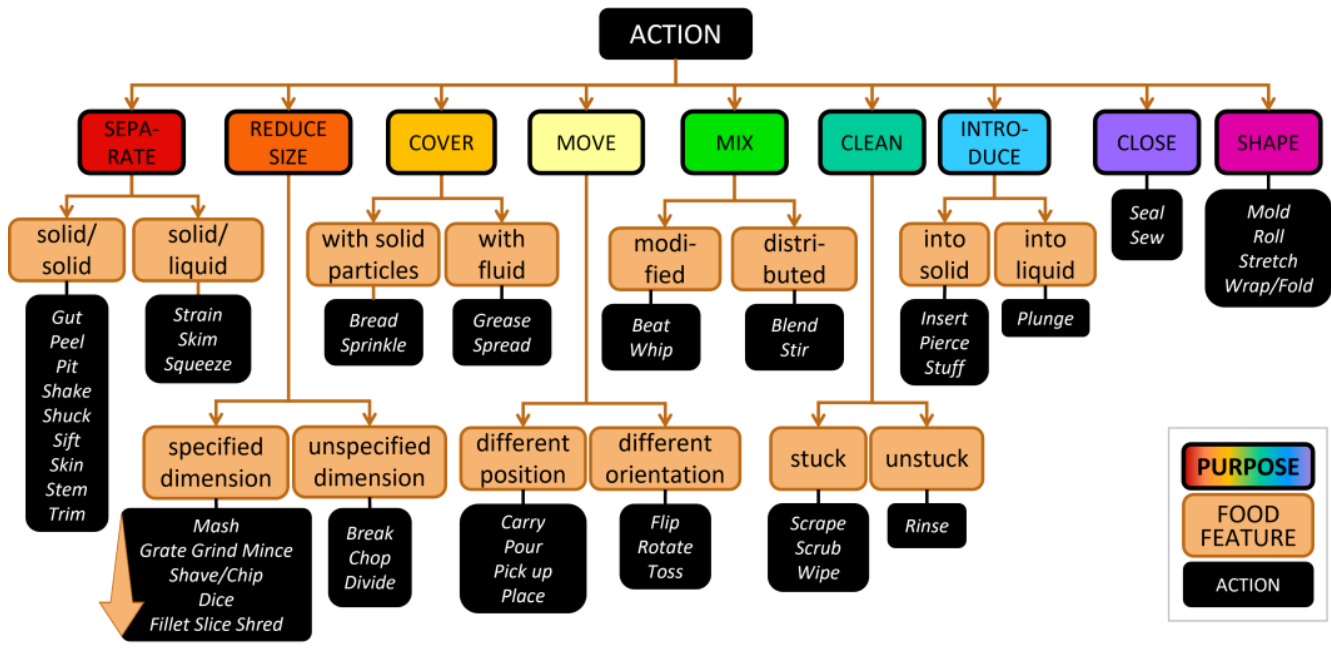

Fig. 2. Taxonomy of actions of FS workers, with two levels of classification: action purpose and status/characteristic of the food involved.

\section{CRITICAL REVIEW OF FOODSERVICE TECHNOLOGY}

FS workers perform numerous actions manually and with the help of different utensils. In addition, over the years, several electromechanical devices have been created to automate, fully or partially, some of these actions. Utensils and equipment commonly used in FS are reviewed, here, as well as novel solutions to further automate the work in FS.

\section{A. Search protocol}

Many utensils and equipment are tailored to specific needs of FS businesses by manufacturers [30]. Thus, several tools have been created over the years [66]. We address the most common utensils in FS, i.e. stated in our reference books [36] [59] [60] and confirmed by, at least, 4 of the 10 chefs that we surveyed $^{6}$. In addition, given the few studies describing FS technology [67], we screened the products list of well-known manufacturers of FS appliances, in their official websites, to find SAE typically used in $\mathrm{FS}^{7}$. Since many years, FS suppliers lead the innovation in FS equipment [68] [67], becoming the most reasonable reference. Finally, we searched novel SAE and $\mathrm{AE}$ in online news and in scientific literature (in Web of Science and Scopus), until June 2020, using the following keywords: kitchen robot; robotic kitchen; restaurant robot; robotic restaurant; cooking robot; waiter robot; robotic chef; foodservice/"food service" robot; foodservice/"food service" automation; automatic cooking; automatic food preparation ${ }^{8}$.

For literature, we excluded conference reviews, books, and book chapters, and retained journal/conference articles, short surveys, and reviews, written in English. The total 1033 scientific articles found, excluding duplicates, were inspected to keep only studies on a novel machine/system $(i)$ intended to automate physical actions in FS, and (ii) tested in a FS-like realistic scenario. Only 6 studies remained, on waiter robots [69, 70, 71, 72] or Chinese food cooking machines [73, 74].

\footnotetext{
${ }^{6}$ Survey available at https://www.smartsurvey.co.uk/s/NL4S7/.

${ }^{7}$ Suppliers that were searched: Electrolux Professional SpA, Sirman SpA, Rational AG, Convotherm Elektrogerate GmbH, Tecnoinox Srl, MKN GmbH \& Co. KG, Henny Penny Corp, Kenwood Ltd., Robogbo Srl, Robot Coupe USA
}

News and scientific articles on food manufacturing (FM) machines and domestic appliances were not considered for this review. This is because FS equipment is subject to distinct operative conditions from those of domestic or FM. For this reason, FS equipment is often developed by specialized suppliers (e.g. Rational AG, Electrolux Professional SpA, Sirman $S p A$, etc.). Compared to domestic, FS appliances are exposed to more extreme conditions, such as larger food quantities (e.g. roasting up to $200 \mathrm{~kg}$ of food [75]), long hours of continuous productivity, and recurrent exposure to food chemicals and detergents [30]. Thus, FS appliances are designed to ensure continuous performance (e.g. in food quality [76] [77] [78] and energy consumption [79]), as well as reliability, i.e. to withstand many and long working cycles [30]. In particular, reliability is very impactful in FS, because the failure of an appliance carries a high direct cost: big quantities of food waste and service stop. Instead, compared to FM, FS businesses normally have higher task's turnover (e.g. daily, hourly), variable productivity over time (e.g. depending on the customers flow), smaller spaces, and higher food variability to handle [27]. Therefore, many solutions created for FM are not adapted to the space or usage needs of FS businesses.

Information shared by the companies with the authors via email, in their website or in the news (often available only in video), as well as their patents, was used to describe the technologies they implemented. Patents were searched by the name of the assigned company, in Espacenet [80].

\section{B. Utensils and single-action equipment (SAE)}

Most of the automated apparatuses present in FS, today, are SAE. By performing a single action, they can be perceived as an automatic alternative to manual utensils. So, this section analyzes both utensils and SAE that were found for FS (see Table 1 and Appendix A). Normally, utensils are designed for one (or few) specific purpose(s) [36, p. 83], hence, Table 1 is

Inc., HotMix (Vitaeco Srl), Hobart Corp, Nemco Food Equipment Ltd, Alto Shaam Inc., Meiko Maschinenbau GmbH \& Co. KG, Nilma SpA.

${ }^{8}$ Search string example used in Web of Science: TS=(robotic NEAR/255 chef). Equivalent in Scopus: TITLE-ABS-KEY (robotic W/255 chef). 
organized by the purpose-level of the taxonomy proposed in Section II. Knives, forks, and spoons appear in multiple rows because, exceptionally, they are used for various purposes.

Table 1 shows that a variety of utensils and SAE are available nowadays to improve productivity and save labor to FS workers. Still, these tools do not cover all actions, as one can observe that many are yet performed solely by hand. Additionally, actions performed with utensils still convey many inconveniences. In fact, in the survey distributed to the chefs, they could indicate difficulties of using utensils and several ones were enumerated. The main issue reported in common to various utensils was the difficulty and time wasted for cleaning them. Often, knives are used instead of more specific tools (e.g. mandoline, pastry cutters, egg slicer), possibly because the subsequent cleaning action is easier. Furthermore, some utensils are incompatible with the productivity needed (e.g. manual pasta press, manual grater, meat mallet, silicon-made grease brush) and chefs use the automatic solutions, if available, or pre-processed packed foods (e.g. pre-washed and cut fruits and salads). Utensils to reduce size, in turn, can be dangerous, scratch surfaces and need to be sharpened often. Scrapers, too, need their blade to be replaced manually, which is also dangerous. Other utensils were reported to break easily (e.g. pastry cutters, nutcracker, hand salad spinner) or to deform with some food (e.g. scoop, with hard ice cream). Some utensils, such as pastry cutters, are small and tend to be lost. Other utensils are reported to cause high losses of product (e.g. garlic press) or to heat the food in the process (hand meat grinder).

For the automatic equipment, chefs reported difficulties in cleaning as well. Moreover, the (dis)assembly of the blades in size-reduction equipment (e.g. vegetable cutters, slicer machine, immersion blenders) is considered dangerous and difficult to perform. They also reported that sharpening the blades must be performed quite often such as with the manual utensils. Finally, they underlined the negative impact of the equipment dimensions. Given that almost each action requires a different machine of considerable footprint, automating all desired actions becomes costly and difficult to manage in space. In fact, as one can observe in Table 1, several actions are either not automated or automated only for some foods. Appliances to move, introduce, shape, reduce size and clean exemplify the drawbacks of SAE, as explained next. To easily compare and to better understand the functioning of SAE, they are represented in Fig. 3 (grouped by similarity of components and actuation). Moreover, technical details of all the appliances are available in Appendix A, with links to videos of the machines in operation.

\section{1) Move}

Moving food between containers, workstations or rooms is recurrent in $\mathrm{FS}^{9}$. As aforementioned, the quantity of food is notable, thus, carrying it is arduous. Occasionally, the operators carry themselves the recipients with heavy loads, hot food or liquids [58] - one of the causes for falls and burns in the kitchen [81] [58]. Even though, trolleys (where trays, dishes or pots can be carried) are commonly available. There are trolleys that hold

\footnotetext{
${ }^{9}$ In fact, this was evident in the extraction of verbs from the culinary books, because move-related verbs were found highly frequent.
}

up to $20 \mathrm{GN}^{10}$ trays of food (e.g. [82]). Furthermore, ovens and blast chillers are designed so that trolleys can be inserted inside (see Fig 4. C), to cook or chill the food. Yet, these big and often full trolleys need to be pushed by hand.

In 1958, rotating conveyor belts were created for sushi FS businesses [83]. Kaitenzushi ("rotating sushi"), invented by Yoshiaki Shiraishi [84], allows to automatically carry dishes from the kitchen to the customers table, continuously and unidirectionally. The belt is usually a chain of plates with curved edges that allows movement not only in straight but also circular paths (Fig. 4. A). Likewise, institutional FS (i.e. canteens) often use a conveyor to carry trays of finished meals to the dishwashing area (see e.g. [85]). An equivalent technology, present in some sushi restaurants [86], was invented to carry dirty plates back to the kitchen through a hidden conveyor [87]. The dishes are inserted by the client in a slot at the table [88]. Nevertheless, none of these or other solutions seem to be used to automatically move loads across workstations in the kitchen, as a replacement of trolleys. Moreover, rotating conveyor belts are not so common in other than sushi businesses, possibly, because it is not suitable for all dish types, such as hot food (that can cool down in the way) or saucy dishes as well as drinks (that may spill). Even the existing vending machines of fresh food do not avoid carrying items. For example, Automats [89] display food to customers, placed in windows and prepared by kitchen workers. Clients select and pick a warm or cold dish themselves, but the food still needs to be carried by the kitchen workers to the windows. Sally, by Chowbotics [90], also dispends ingredients for salads and grain bowls, selected by the customer, but, like Automats, ingredients must be carried and placed in its containers. At least, Sally frees the workers from picking up and placing ingredients in the plate of each customer and dispenses precise quantities.

Automatic solutions also exist to move liquids, because notable volumes are used in FS, such as $22 \mathrm{~kg}$ of frying-oil (typical capacity of a single fryer [91, p. 4]). Optional systems are offered e.g. in large-scale fryers or pans, to fill them (by pumping) and to pour the liquid to another container (by automatic tilting); see an example in Fig. 4. B. Frequently, these mechanisms can be controlled for the desired quantity.

To move small amounts of food, some utensils facilitate pouring (e.g. funnel, pitcher) and others avoid direct contact of the hands with food (e.g. spatula, tweezers). This reduces hygienic issues and injuries (when food or surfaces are hot). Instead, automatic equipment could completely eliminate these issues, but few machines exist. A significant and unique example is the actuator created by L2F Inc. [92] to pick plates or trays (from a trolley) and place them in a conveyor oven, upon remote request from an operator. Being a manipulator of three rotational joints and one translational vertical joint, its structure is versatile, so it could be studied for a wider use in different pick and place actions. For instance, plating for a catering event is a repetitive, long-time standing task mainly consisting of picking, placing, and spreading prepared ingredients on plates (see Fig. 6. A).

${ }^{10} \mathrm{GN}$ means gastronorm. It is a standard system for the dimensions of containers, trays, and equipment, regulated by the norm EN 631 [299]. 
TABLE 1. UTENSILS AND SINGLE-ACTION EQUIPMENT (SAE) BEING USED IN FOODSERVICE.

\begin{tabular}{|c|c|c|c|}
\hline PURPOSE & ACTIONS & MANUAL UTENSILS & AUTOMATIC SAE \\
\hline \multirow[t]{2}{*}{$\begin{array}{l}\text { SEPA- } \\
\text { RATE }\end{array}$} & $\begin{array}{l}\text { Gut } \\
\text { Peel } \\
\text { Pit } \\
\text { Shake } \\
\text { Shuck/Shell } \\
\text { Sift } \\
\text { Skin, Stem } \\
\text { Trim }\end{array}$ & $\begin{array}{l}\text { Peeler, Zester. } \\
\text { Corer, Pitter. } \\
\text { Oy } \\
\text { Oyster/Clam knife, Nutcracker. } \\
\text { Sifter, Sieve. } \\
\text { Knife, Scissors. }\end{array}$ & $\begin{array}{l}\text { N/A } \\
\text { Vegetable peeler machine (e.g. [93] [94, p. 40]). } \\
\text { N/A } \\
\text { N/A } \\
\text { N/A } \\
\text { Automatic flour/crumbs sifting in breading stations (e.g. [95]). } \\
\text { N/A } \\
\text { N/A }\end{array}$ \\
\hline & $\begin{array}{l}\text { Strain } \\
\text { Skim } \\
\text { Squeeze }\end{array}$ & $\begin{array}{l}\text { Colander, Strainer, Salad spinner. } \\
\text { Skimmer. } \\
\$, \text { Hand juicer. }\end{array}$ & $\begin{array}{l}\text { Automatic filtering in fryers (oil recirculation pump and filters [96, p. 7]), } \\
\text { Vegetable dryer (e.g. [94, p. 45]). } \\
\text { N/A } \\
\text { Juice machine, Pulp extractor (e.g. [97]). }\end{array}$ \\
\hline \multirow[t]{2}{*}{$\begin{array}{l}\text { REDUCE } \\
\text { SIZE }\end{array}$} & $\begin{array}{l}\text { Mash } \\
\text { Grate, Grind } \\
\text { Shave, Dice } \\
\text { Fillet, Slice, } \\
\text { Shred }\end{array}$ & $\begin{array}{l}\text { Food mill, Mortar and pestle. } \\
\text { Grater, Meat grinder. } \\
\text { Knife, Mandoline. } \\
\text { Knife, Pizza cutter. }\end{array}$ & $\begin{array}{l}\text { Food processor, Immersion blenders (see Fig. 6. B). } \\
\text { Meat mincer machine, Grater machine, Ice crusher (e.g. [98]). } \\
\text { Food cutter machine (e.g. [99]). } \\
\text { Vertical/gravity slicer (rotating saw and automatic moving tray, e.g. [100]), } \\
\text { Bread slicer [101], Shredder machine (strips cutter), e.g., [102]. }\end{array}$ \\
\hline & $\begin{array}{l}\text { Break } \\
\text { Chop } \\
\text { Divide }\end{array}$ & $\begin{array}{l}\text { Knife, Scissors. } \\
\text { 극 }\end{array}$ & $\begin{array}{l}\text { N/A } \\
\text { Pasta divider (e.g. [103]), Sushi rolls cutter (e.g. [104]). }\end{array}$ \\
\hline \multirow{2}{*}{ COVER } & $\begin{array}{l}\text { Bread } \\
\text { Sprinkle }\end{array}$ & $\begin{array}{l}\text { Salt/spices shaker. } \\
\text { Saㄱ. }\end{array}$ & $\begin{array}{l}\text { Automatic breading machine (e.g. [105]) } \\
\text { N/A }\end{array}$ \\
\hline & Grease, Spread & Brush, Spray, Spoon. & N/A \\
\hline \multirow{3}{*}{ MOVE } & $\begin{array}{l}\text { Carry } \\
\text { Pour }\end{array}$ & $\begin{array}{l}\text { 帚, Tray, Trolley. } \\
\text { Pitcher, Funnel. }\end{array}$ & $\begin{array}{l}\text { Conveyor belt (see Fig. 4. A). } \\
\text { Automatic water/oil filling and tilting mechanisms in braising pans and } \\
\text { kettles (see Fig. 4. B). }\end{array}$ \\
\hline & $\begin{array}{l}\text { Pick up } \\
\text { Place }\end{array}$ & $\begin{array}{l}\text { Spatula, Spoon, Tongs, Scoop, } \\
\text { Fork, Ladle, Tweezers, Shovel. }\end{array}$ & 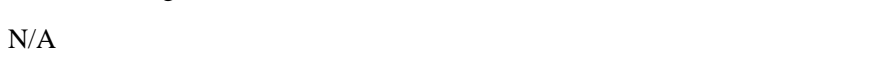 \\
\hline & $\begin{array}{l}\text { Flip } \\
\text { Rotate, Toss }\end{array}$ & $\begin{array}{l}\text { Spatula, Tongs, Fork, Chopsticks. } \\
\text { 클 }\end{array}$ & $\begin{array}{l}\text { N/A } \\
\text { Rotisserie with rotating spit (e.g. [106]), Pizza rotating deck oven [107]. }\end{array}$ \\
\hline \multirow{2}{*}{ MIX } & $\begin{array}{l}\text { Beat } \\
\text { Whip }\end{array}$ & $\begin{array}{l}\text { Rubber spatula, Spoon, Paddle. } \\
\text { Whisk, Paddle, Cream whipper. }\end{array}$ & $\begin{array}{l}\text { Kneader machine, Spiral dough mixer. } \\
\text { Planetary mixer. }\end{array}$ \\
\hline & Blend, Stir & Spoon, Drinks shaker. & $\begin{array}{l}\text { Boiling pans' rotating spatula (e.g. [108, p. 19; 27]), Drinks mixer (e.g. [109]). } \\
\text { Automatic stirring system for woks [74] }\end{array}$ \\
\hline \multirow[t]{2}{*}{ CLEAN } & $\begin{array}{l}\text { Scrape } \\
\text { Scrub/rub } \\
\text { Wipe }\end{array}$ & $\begin{array}{l}\text { Scraper. } \\
\text { Sponge, Brush. } \\
\text { Cloth. }\end{array}$ & N/A \\
\hline & Rinse & Tap hose, Water nozzle/shower. ${ }^{\text {a }}$ & $\begin{array}{l}\text { Dishwasher, Vegetables washer (e.g. [94, p. 44]), Appliances self-cleaning } \\
\text { mechanisms (e.g. [110, p. 52]). }\end{array}$ \\
\hline \multirow[b]{2}{*}{$\begin{array}{l}\text { INTRO- } \\
\text { DUCE }\end{array}$} & Plunge & 急, Basket. & $\begin{array}{l}\text { Automatic immersion and lifting system in fryers and rice/pasta cookers (see } \\
\text { Fig. 4. D). }\end{array}$ \\
\hline & $\begin{array}{l}\text { Insert }^{b} \\
\text { Pierce } \\
\text { Stuff }\end{array}$ & 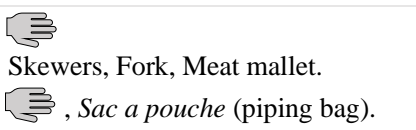 & $\begin{array}{l}\text { N/A } \\
\text { N/A } \\
\text { Meat stuffing machine (for sausages). }\end{array}$ \\
\hline CLOSE & $\begin{array}{l}\text { Seal } \\
\text { Sew }\end{array}$ & $\begin{array}{l}\text { Pooth , Manual pump and sealer. } \\
\text { Toothicks, Butcher's twine, } \\
\text { Trussing needle. }\end{array}$ & $\begin{array}{l}\text { Vacuum/aired sealer machine (e.g. [111]). } \\
\text { N/A }\end{array}$ \\
\hline SHAPE & $\begin{array}{l}\text { Roll, Wrap } \\
\text { Stretch }\end{array}$ & $\begin{array}{l}\text { Ice-cream scoop, Melon ball cutter, } \\
\text { Piping bag, Squeeze bottle, Spoons, } \\
\text { Pastry cutters/molds. } \\
\text { Rolling pin, Manual pasta press. }\end{array}$ & $\begin{array}{l}\text { 3D food printers (see Fig. 5. C), Rice balls press machine (for sushi nigiri, } \\
\text { e.g. [104]). } \\
\text { Japanese Maki wrapper (see Fig. 5. A). } \\
\text { Dough/rice sheeter (e.g. [104] [112]). }\end{array}$ \\
\hline
\end{tabular}

The icon indicates that the action is commonly done by hand, without a utensil. N/A stands for not available. The colors in the first column signal the colors in the first level of the taxonomy.

${ }^{a}$ These are usually integrated in a sink or appliance and one can consider them utensils as they are handheld and follow the definition in Section I.A.

${ }^{\mathrm{b}}$ For example, insert food in bags, insert fat strips into another meat [36, p. 321], or insert trays in the supports of an oven. 

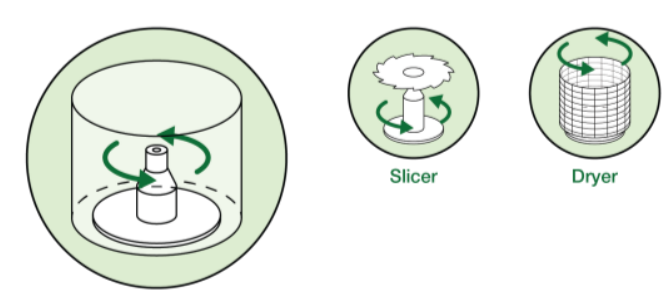

Mechanism type \#1
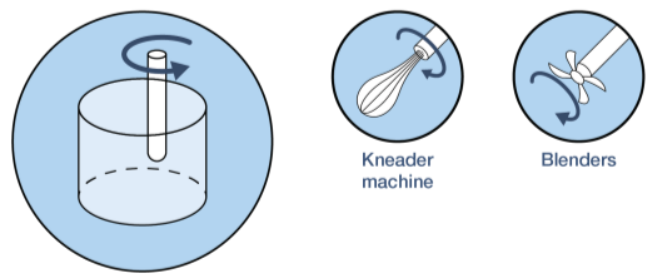

Mechanism type \#2
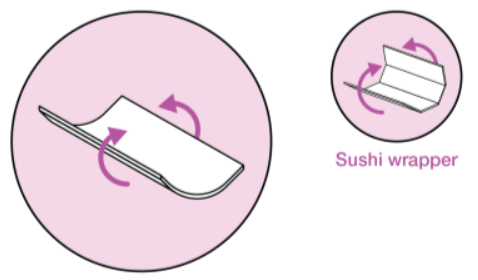

Mechanism type \#4
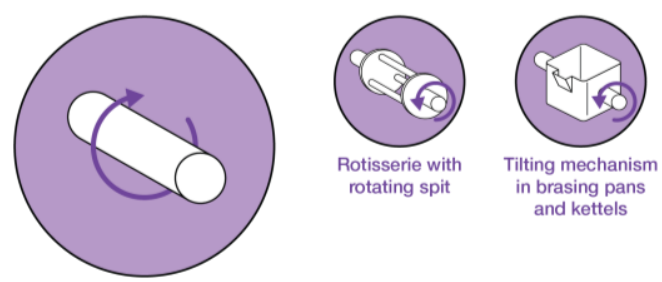

Mechanism type \#6
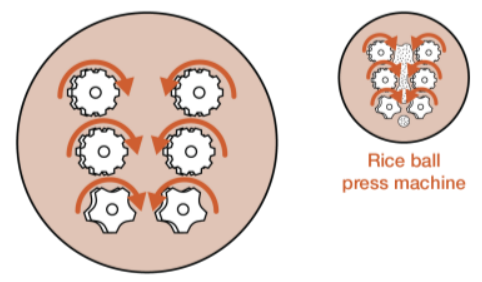

Mechanism type \#8
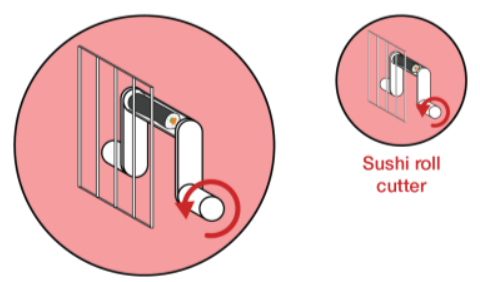

Mechanism type \#10
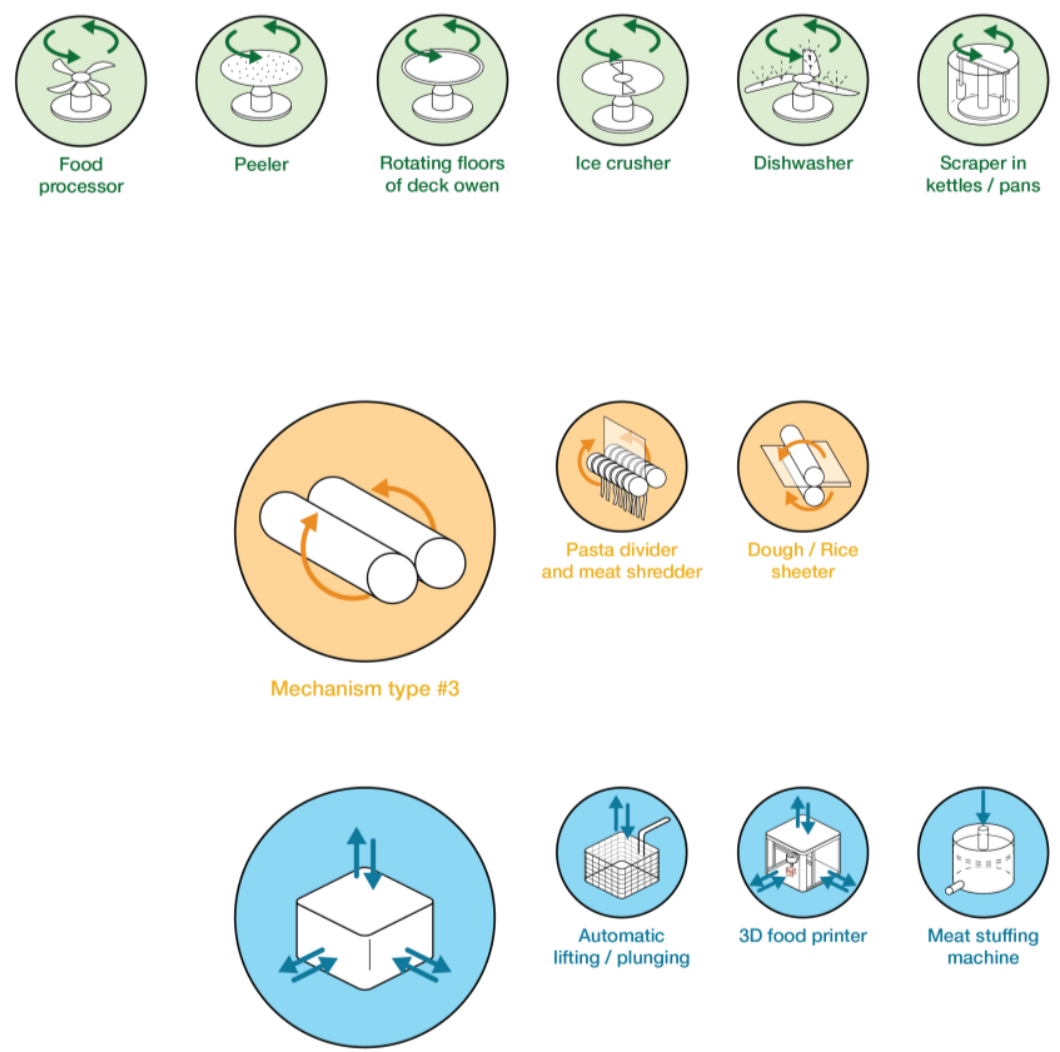

Mechanism type \#5
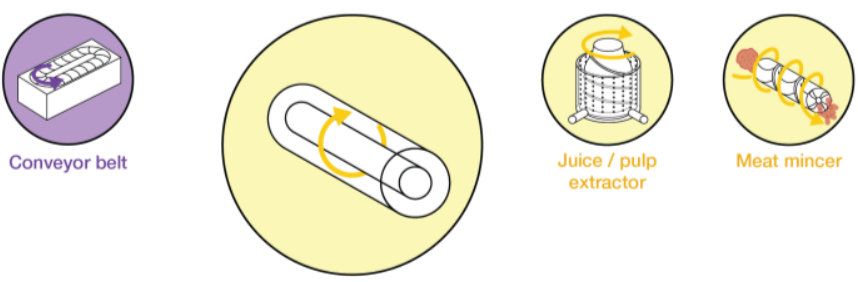

Mechanism type \#7
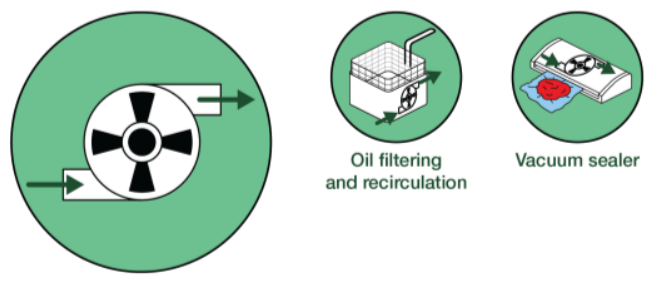

Mechanism type \#9 and recirculation

Fig. 3. Actuated mechanisms of single-action equipment (SAE), here presented in groups (type 1 to 10), for their similarity in actuation and components. Next to each mechanism type, there are examples of SAE that use it, with a more specific representation of their respective mechanism. In Appendix A, there is an indication of the mechanism type for all the SAE present in Table 1. The arrows in the figures highlight the motion of the actuator. 

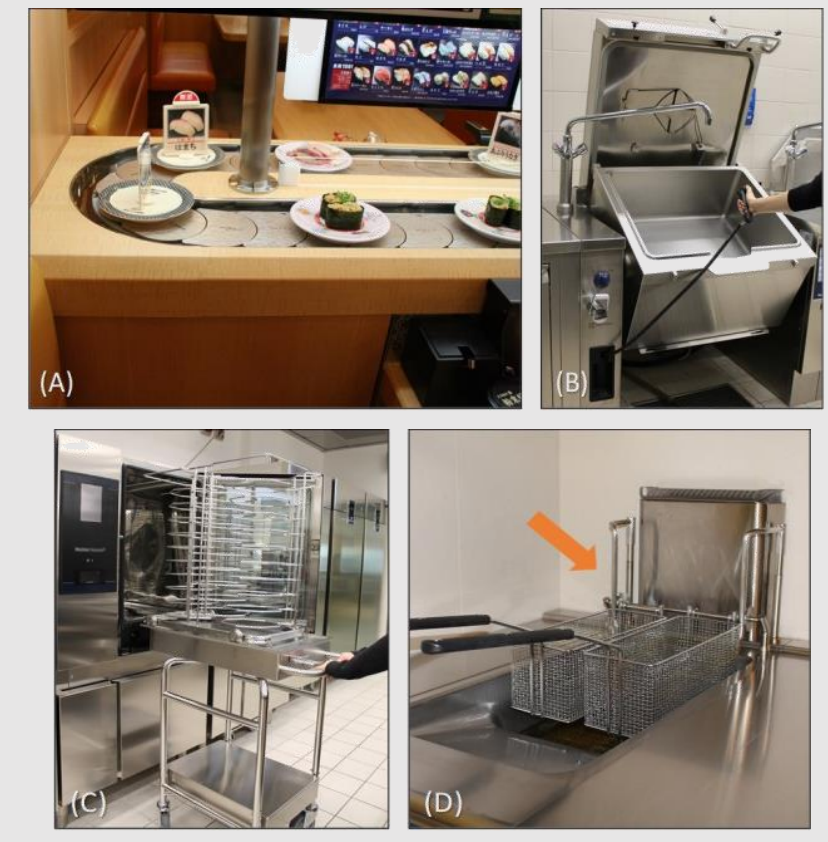

Fig. 4. Examples of tools currently used in FS to support move-intended actions: (A) conveyor belts, (B) tilting mechanisms and (C) trolleys. One of the few equipment available for introduce-intended actions: (D) automatic baskets lifting/immersion system (arrow) for fryers.

(C) (A) Nippon Bill (Photographer) (2008) [digital image], available at https://en.wikipedia.org/wiki/Conveyor belt sushi\#/media/File:Sushi conyey or_chain_3.jpg, with CC BY-SA 3.0 license; (B-D) courtesy of Electrolux Professional SpA.

\section{2) Introduce}

Concerning actions of introducing food into liquids or solids (i.e. other food or containers), automatic mechanisms are also scarce. Some suppliers created immersion/lifting systems in fryers and pasta/rice cookers (Fig. 4. D) to automatically plunge and raise the baskets with food into oil/water. To introduce food in solid materials, solutions come down to few stuffing machines, e.g. for sausages. They help the action but still require substantial hand-work.

\section{3) Shape}

Shaping food requires skilled manipulation of both food (from soft pastes to frozen items) and utensils (e.g. the sac-apouche, molds, or spoons).

For large quantities, only a few automatic equipment is available, mostly for standardized preparations, such as sushi [83]. There are machines to shape rice in balls or sheets, and to wrap sushi (see Fig. 5. A-B). Some rice sheeters (e.g. [104]) allow flexibility in desired thickness, compression, length, and position of the rice sheet. The machine adjusts itself to the specified sheet characteristics, by tuning the forming-rollers inter-distance and rolling speed ${ }^{11}$.

Small volumes of complex geometries (e.g. sculptures of ice/chocolate, or molded food pastes) are typically produced manually. However, since 2001 [113], this could be achieved with high repeatability using $3 \mathrm{D}$ printing techniques. Several professional-grade 3D food printers are available in the market, such as Foodini [114] (Fig. 5. C), 3D Culinary Studio [115], Focus [116], Choc Creator V2.0 Plus [117], Procusini ${ }^{\circledR ~[118], ~}$ or Deco-Pod [119]. 3D food printing (3DFP) not only brings benefits to consumers (in health and customization) [120] [121], but also supports FS workers, especially pastry chefs, by automating laborious shaping tasks. For example, instead of chocolate sculptures being hand-carved (a skillful task [36, p. 974;1200]), chocolate can be extruded in layers (by Robocasting) or its powder fused by heating (by Selective laser sintering - SLS) to create elaborated figures [122] [121]. Furthermore, 3DFP and other digital fabrication tools (e.g. laser cutters, CNC milling machines, and 3D scanners) have been proposed as mediators of creativity: with the food CAD models, chefs can control ingredients' proportions and conditions of chemical reactions in order to manipulate structure, taste and aesthetics of dishes [123]. However, this technology is not widespread in FS yet, due to restrictions in usable ingredients and final food textures [121]. These drawbacks have been addressed by several recent research works [124] [121] [125] [126] [127].
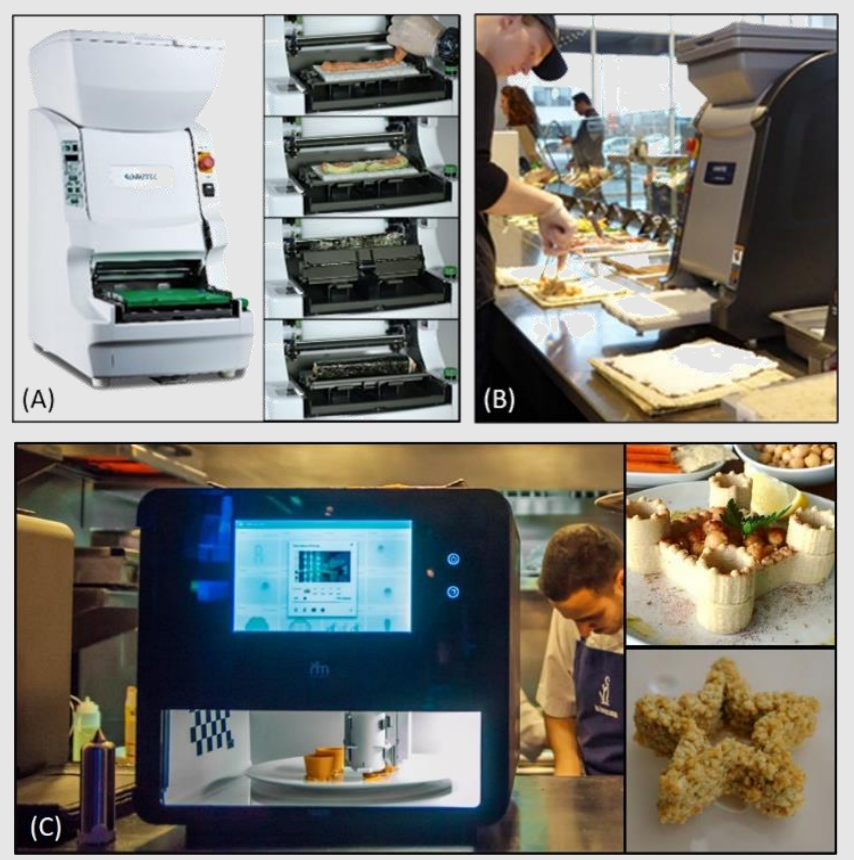

Fig. 5. Examples of equipment currently available to support shaping actions in FS: (A) a sushi Maki wrapper machine (top left), its wrapping mechanism (right) and the alternative manual action with the bamboo rolling mat; (B) a rice sheeter machine; (C1) Foodini, a 3D food printer, (C2) examples of food shaped by Foodini. (C) wrapper and sheeter machines - courtesy of Autec Inc.; Foodini pictures - Natural Machines Inc. (press kit); bamboo rolling mat - Dennis van Zuijlekom (Photographer) (2012) [digital image] Available at https://www.flickr.com/photos/dvanzuijlekom/8300627300, with CC BY-SA 2.0 license.

\section{4) Reduce size}

Food processors have been created to automatically slice, chop, grind, puree, grate, dice, or execute another preprocessing action to large food quantities. For example, vegetable peelers can process batches of 1.5 to $25 \mathrm{~kg}$ of food

\footnotetext{
${ }^{11}$ Technical information was shared by Autec Inc. via email.
} 
with a production of 80 to $400 \mathrm{~kg} / \mathrm{h}$ of peeled vegetables $(e . g$. [94, p. 40]). Vegetable cutters can work at 2500kg/h [94, p. 16], meat mincers up to $300 \mathrm{~kg} / \mathrm{h}$ and cheese graters up to $130 \mathrm{~kg} / \mathrm{h}$ [94, p. 49]. Vegetable cutters perform more than one cut type, but the worker must exchange the blade manually. Different machines were even created to execute the same action but under different conditions, such as different volumes. For instance, immersion blenders are commonly handheld (Fig. 6. $\mathrm{B}$, right) and inserted inside a container (e.g. pot) containing the food to be reduced in size. For larger volumes, there are bigger models of immersion blenders with a movable arm that stay on the floor (Fig. 6. B, left). Both blenders are bulky, and the immersion ones are heavy (1.4-4kg [94, pp. 24-27] [128]) for a handheld device.

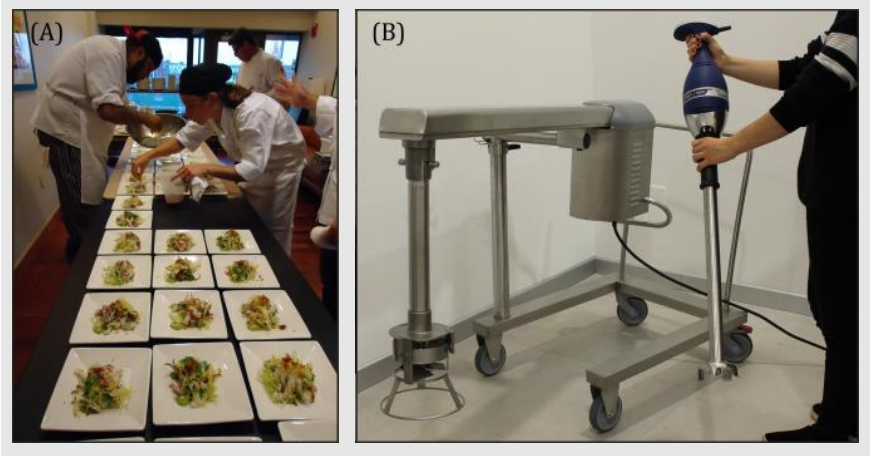

Fig. 6. (A) Example of plating for numerous customers, performed manually by chefs; (B) Professional-grade immersion blender (at right) and floor blender (at left). (C) (A) Breville USA [digital image], available at https://www.flickr.com/photos/breville/ 8702695188/, with CC BY-SA 2.0 license; (B) courtesy of Electrolux Professional SpA.

\section{5) Clean}

Many components of FS appliances are detachable and dishwasher-compatible because dishwashers are largely spread today. In addition, the chamber of many appliances have selfcleaning mechanisms and, in our survey, chefs reported that tilting systems, e.g. in large-scale pots, help the manual cleaning. Still, the external surfaces of appliances and working tops lack an automatic cleaning mechanism.

Professional cleaning detergents already reduce actions of pre-scrubbing/scrapping serviceware. These are further reduced in dishwashers that actively pump food leftovers from its wash tank [129]. Still, large food pieces need to be manually discarded from dishes. Moreover, sorting serviceware is done by hand in most FS businesses, i.e. picking up and placing dishes, glasses, or cutlery, in their respective basket, before entering the dishwasher.

\section{Advanced equipment (AE): adaptive and multi-action automatic systems}

A few companies and academics are working on adaptive and/or multi-action systems for FS - we call them advanced equipment. Being adaptive or multi-functional, these systems greatly reduce the efforts of FS workers, because they can complete full tasks in a workstation (e.g. the counter, grill, fryer) or an entire room (e.g. dishwashing room) that usually have a negative impact on the workers well-being, such as long- time standing, smoke breathing, noise, falls and injuries.

Table 2 summarizes the features of the AE that was found. Most equipment was found in online news, only a few in scientific literature. Some solutions are custom-built machines integrating various actuators (e.g. manipulators, appliances, conveyors). Others are partially custom-built, as they include an industrial manipulator (i.e. a robotic arm commercially available alone). Finally, a third type was found, in which robots (one or more industrial arm or mobile robots) were equipped with the proper sensors and end-effectors to autonomously work with appliances and worktables already installed in a FS house (i.e. standard professional griddles, fryers, serving counters, etc.) - we call them add-on robots.

\section{1) Custom-built machines}

Our search identified one research group [73] and six companies developing custom machines for multiple actions: Spyce Inc. (Somerville, USA), Creator Inc. (San Francisco, USA), Picnic (Seattle, USA), Meiko Maschinenbau GmbH \& Co. KG (Offenburg, Germany), Dishcraft Robotics Inc. (San Carlos, USA) and Wilkinson Baking Company LLC (Walla Walla, USA).

Spyce Inc.'s kitchen [130] is an autonomous machine with innovative mechanisms, that replaces cooking stations with stove or braising pans. The system integrates various containers of ingredients (hoppers), cups to collect portions of ingredients to cook, a sliding carrier (runner), seven induction-heated cooking pots (woks) and automatic water nozzles to wash the woks [131]. The machine (Fig. 7) was designed for quick service restaurants (QSR), so, it cooks a dish in up to 3 minutes. Yet, each dish is prepared in one pot individually [131], hence, the real waiting time is limited by the available pots to the number of meals being requested.

To collect the required ingredients for a dish, the runner slides towards the corresponding hoppers and a collecting cup is positioned below the dispensing module of the hopper, facing upwards. The ingredient is dropped into the cup which measures its weight using load cells. This information is used to adapt the cooking parameters (e.g. time, temperature) to avoid under or overcooking [131]. The collecting cup is, then, moved by the runner to a position above the wok that was automatically selected for that dish. The wok is oriented upwards and the collecting cup pours the food into the wok, by rotating $180^{\circ}$ downwards at a speed that, due to the centrifugal force, ensures the ingredients do not fall from the cup in the way. The wok is, then, tilted forward and starts cooking. In SAE, like e.g. large-scale kettles, automatic mixing on cooking is commonly achieved with an accessory that is rotated inside the machine. With the system of Spyce Inc., the pot itself spins and its interior surface has a salience against which the food collides and is turned, being stirred [131]. Furthermore, the induction element is placed, vertically, adjacent to each pot rather than beneath the pot [130]. This allows the pot to be tilted freely, keeping the heating element static. Once cooking is finished, the meal is automatically poured to a bowl, under the pot. Finally, the pot is tilted downwards to be automatically rinsed and sanitized by the water nozzle [131]. So far, not all 
cleaning actions are automated, since the staff must regularly remove and sanitize all components in the refrigerator that touch food. Likewise, the staff must restock the hoppers, up to 3 or 4 times a day, according to the demand ${ }^{12}$.

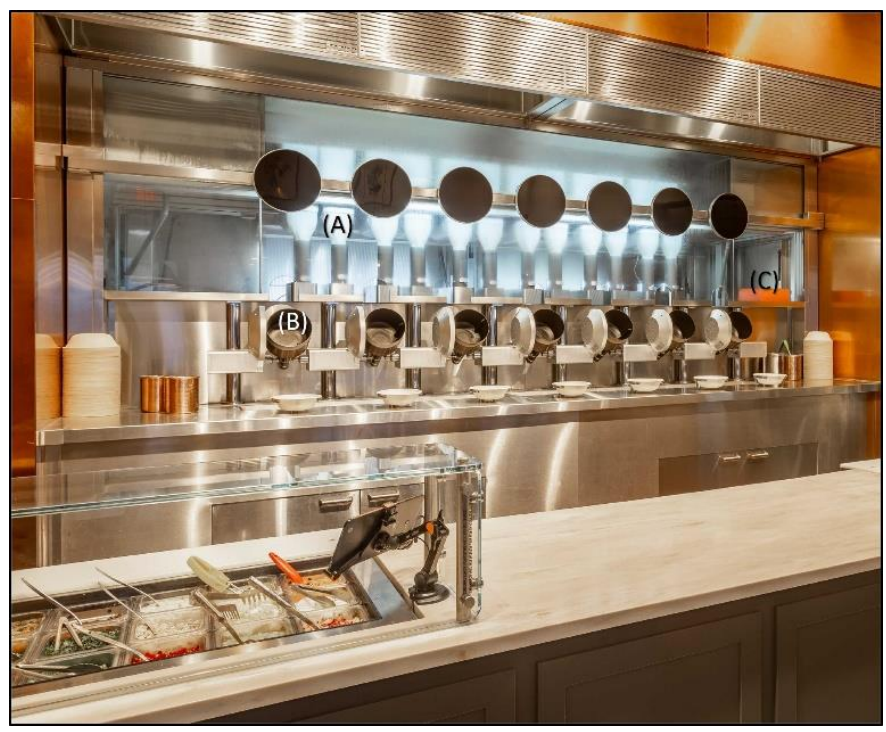

Fig. 7. The kitchen of Spyce Inc.: (A) hoppers with ingredients; (B) automatic cooking pot (wok); (C) runner (distributor of ingredients in the woks, collected with cups). (C) Chris Sanchez (Spyce Inc. press kit).

This system is certified to work in FS, by NSF (National Sanitation Foundation) and UL (Underwriters Laboratories) [132] and is being used in their own restaurants in the USA ${ }^{13}$.

The gas-burning machine created by [73] is intended to cook Chinese dishes (stir-fried, braises, stews and soups). Its structure resembles that of Spyce Inc.'s system for also having a dispenser of ingredients, a moving wok, and nozzles to rinse [73]. The dispenser has five vessels that slide horizontally on a rack, in linear bearings, and are positioned over the wok by a belt-transmission system; they automatically rotate to pour an ingredient in the wok [133]. The wok can be tilted to pour ready food or to drain liquids out, as well as shaken and moved along an elliptic curve, horizontally, to stir food [73]. A fork-shaped component is fixed in the inner face of the wok lid, to stir ingredients and prevent their conglutination [134]. Finally, although the actuators' control is pre-programmed, the researchers implemented a teaching-playback method for a cook to guide the machine while the sequence of actions, motion parameters (e.g. speed, acceleration), and selected temperatures, are recorded to be reused in automatic [73].

In turn, the machine of Creator Inc. [135] (formerly called Momentum Machines) automates, almost completely, the production of hamburgers, similarly to a manufacturing line. All actions are automatic except those for the preparation of sauces, peeling or washing vegetables (e.g. pickles, tomato or onion), and closing the final sandwich. The actuators are adaptively controlled with 20 computers that receive inputs from 320 sensors, such as temperature and distance sensors

\footnotetext{
${ }^{12}$ Information shared by Spyce Inc. via email.

${ }^{13}$ Since 2021, they have a modified version of the original machine [130].
}

[136] [137]. The system of Creator Inc. was evaluated by UL and NSF to operate in a foodservice facility ${ }^{14}$.

The system of Creator Inc. is, at present, installed in a QSR in USA, where hamburgers are prepared in about 5 minutes [135]. To maximize freshness, all the automatic actions involved in the preparation of each hamburger begin only when the order is made: meat is ground and, while being grilled, it is compressed (to mold the hamburger patty); the bun is sliced, buttered and toasted; sauces are dispensed and spread (by a dispenser with a movable tip - Fig. 8. B); toppings are sliced, cheese is grated and melted; and all is placed on the bun. For this, the machine integrates custom appliances (such as slicers and graters), as well as original technologies. One innovative mechanism is their modular conveyor (Fig. 8. K): a chain of paddles, each driven by an individual motor-gear assembly that rotates the paddle axis [138]. Each paddle pushes a hamburger box to move forward, independently of others. This way, several hamburgers can be prepared almost asynchronously.

Another invention is the automatic method to create the hamburger locally: a grinding unit minces the quantity of raw meat in accordance with the patty size and meat blend specified by the client, and an actuator places the minced meat directly onto the griddle [136]. Note that, typically, QSRs use pre-made fresh or frozen patties, instead [139]. Furthermore, the grilling unit of the machine has several griddles [136], so multiple hamburgers are grilled concurrently.

Each griddle includes a top and a bottom hotplate, to grill both faces of a patty simultaneously [136]. Each griddle also cooks one patty independently, thus, its doneness level can be tailored for each hamburger, which can be achieved by $i$ ) monitoring the hotplates temperature and controlling the power of the induction-based element, and ii) controlling the bottom/top hotplates inter-distance and, thus, the pressure applied on the patty [136]. Finally, the method for placing the hamburger on the bun is also unusual, using a custom manipulator with a spatula (Fig. 8. H) and a passive structure (Fig. 8. J): the spatula moves the hamburger against that structure such that it is dragged off the spatula and falls on the bun [136]. These mechanisms, in fact, can be applied to a variety of food, including vegetables or meat in geometries other than minced [136]. Other unusual actions that Creator Inc. automated are the bun slicing, spreading of butter on the sliced face and toasting (Fig. 8. A). To automatically butter the bun, a set of paddles compress the sliced face of the bun against a perforated surface, through which liquified butter is sprayed/leaked [137]. Then, the bun slides down and is compressed against a vertical heated surface to toast [137].

All the machines of [73], Spyce Inc. and Creator Inc. prevent injuries associated to manual work. The staff avoids carrying loads from one workstation to another, because the systems automatically transfer the food between processes, and avoid burns from handling hot food. With that of Creator Inc., they even avoid the hot environment (near the griddle) and smoke breathing, for that unit is encapsulated (Fig. 8, H).

\footnotetext{
${ }^{14}$ The numbers and certifications were shared by Creator Inc. via email.
} 
TABLE 2. SUMMARY OF ADVANCED EQUIPMENT (AE) BEING DEVELOPED FOR FOODSERVICE.

\begin{tabular}{|c|c|c|c|c|c|c|}
\hline \multirow{2}{*}{$\begin{array}{c}\mathbf{A E} \\
\text { (year a: launch }-\mathrm{L}, \\
\text { or first invention - I) } \\
(\mathrm{V}-\text { video of the } \mathrm{AE})\end{array}$} & \multirow[b]{2}{*}{ ACTIONS } & \multicolumn{5}{|c|}{ SYSTEM CHARACTERISTICS } \\
\hline & & & $\begin{array}{c}\text { Solution type 国 } \\
\text { and list of actuators }\end{array}$ & Control & $\begin{array}{l}\text { Collaboration } \\
\text { and social skills }\end{array}$ & Workers avoid: \\
\hline $\begin{array}{l}\text { Creator Inc. } \\
\text { machine }[135] \\
(2015 \text { I) }(\underline{V})\end{array}$ & $\begin{array}{l}\text { Grind, grate, slice } \\
\text { Grease, sprinkle, } \\
\text { spread } \\
\text { Carry, pick up, place } \\
\text { Mold }\end{array}$ & & $\begin{array}{l}\text { Automatic slicers, spreader, } \\
\text { dispensers, grater, toaster, } \\
\text { grinder, double-side griddle, } \\
\text { press, and butter sprayer; } \\
\text { - modular conveyor; } \\
\text { - custom arm with spatula. }\end{array}$ & Adaptive & N/A & $\begin{array}{l}\text { - The grill - hot, burns, } \\
\text { smoke breathing; } \\
\text { - carrying heavy loads. }\end{array}$ \\
\hline $\begin{array}{l}\text { Picnic }^{\mathbf{T M}}[140] \\
(2017 \mathrm{I})(\underline{\mathrm{V}})\end{array}$ & $\begin{array}{l}\text { Slice } \\
\text { Spread } \\
\text { Place, carry }\end{array}$ & 䀦 & $\begin{array}{l}\text { - Conveyor belt; } \\
\text { - automatic dispensers; } \\
\text { - automatic slicer. }\end{array}$ & Adaptive & N/A & $\begin{array}{l}\text { - Repetitive, long-time } \\
\text { standing tasks. }\end{array}$ \\
\hline $\begin{array}{l}\text { Dishcraft Robotics } \\
\text { Inc. machine [141] } \\
(2016 \text { I) ( } \text { V) }\end{array}$ & $\begin{array}{l}\text { Pick up, place, carry } \\
\text { Rinse, scrub }\end{array}$ & 圆 & $\begin{array}{l}\text { - } \text { Rotating scrubber; } \\
\text { - } \text { rotating carriage; } \\
\text { - two custom articulated arms } \\
\text { with a magnetic gripper. } \\
\end{array}$ & Adaptive & N/A & $\begin{array}{l}\text { - (Partially) the } \\
\text { dishwashing room - } \\
\text { noise, humidity; } \\
\text { - } \text { repetitive task. } \\
\end{array}$ \\
\hline $\begin{array}{l}\text { Fully automatic } \\
\text { dishwashing by } \\
\text { Meiko GmbH \& Co. } \\
{[142]\left(2014^{b} \mathrm{~L}\right)(\mathrm{V})}\end{array}$ & $\begin{array}{l}\text { Carry } \\
\text { Rinse }\end{array}$ & 䰙。 & $\begin{array}{l}\text { - Horizontal and vertical } \\
\text { conveyor belts; } \\
\text { - magnet to "pick" cutlery; } \\
\text { - } \quad \text { automatic water showers. }\end{array}$ & $\begin{array}{c}\text { Pre- } \\
\text { programmed }\end{array}$ & N/A & $\begin{array}{l}\text { - The dishwashing room - } \\
\text { noise, humidity, falls; } \\
\text { - repetitive task. }\end{array}$ \\
\hline $\begin{array}{l}\text { BreadBot [143] } \\
\text { by Wilkinson } \\
\text { Baking Company } \\
\text { LLC }(2005 \mathrm{I})(\underline{\mathrm{V}})\end{array}$ & $\begin{array}{l}\text { Carry, pick up, place } \\
\text { Blend, beat } \\
\text { Rinse } \\
\text { Mold } \\
\end{array}$ & 圖 & $\begin{array}{l}\text { - } \text { Conveyor belts; } \\
\text { - } \text { automatic mixer; } \\
\text { - custom cartesian robotic arm } \\
\text { with fork-shaped EE. }\end{array}$ & $\begin{array}{c}\text { Pre- } \\
\text { programmed }\end{array}$ & N/A & $\begin{array}{l}\text { - } \text { The oven - hot, burns; } \\
\text { - carrying heavy loads; } \\
\text { - } \text { repetitive, long-time } \\
\text { standing tasks. }\end{array}$ \\
\hline $\begin{array}{l}\text { Cafe X by Cafe X } \\
\text { Technologies Ltd. } \\
{[145](2015 \text { I) (V) }}\end{array}$ & $\begin{array}{l}\text { Pick up, place, pour } \\
\text { Stir }\end{array}$ & 圖 & $\begin{array}{l}\text { - Automatic expresso machines, } \\
\text { drinks, ice and cream } \\
\text { dispensers; } \\
\text { - articulated robot; } \\
\text { - EE: (fixed) 2-finger gripper. }\end{array}$ & $\begin{array}{c}\text { Pre- } \\
\text { programmed }\end{array}$ & $\begin{array}{c}\text { C: Cobot; } \\
\text { method - none. } \\
\text { S: expressive } \\
\text { gestures }(e . g . \\
\text { waving) }\end{array}$ & $\begin{array}{l}\text { - Repetitive, long-time } \\
\text { standing tasks. }\end{array}$ \\
\hline $\begin{array}{l}\text { OctoChef [146] by } \\
\text { Connected Robotics } \\
\text { Inc. } \\
(2018 \text { I) () }\end{array}$ & \begin{tabular}{|l} 
Shake \\
Grease, spread \\
Pick up, pour, rotate \\
Scrape \\
Plunge \\
\end{tabular} & 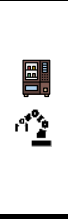 & $\begin{array}{l}\text { - Shaking grill for Takoyaki; } \\
\text { - automatic liquids dispensers; } \\
\text { - articulated robot; } \\
\text { - EE: (fixed) custom clamp } \\
\text { gripper (can grasp custom } \\
\text { spatula, funnel, stick). }\end{array}$ & Adaptative & $\begin{array}{l}\text { C: Cobot; method } \\
\text { - power and force } \\
\text { limiting. } \\
\text { S: none. }\end{array}$ & $\begin{array}{l}\text { - Repetitive task; } \\
\text { - hot, burns, humidity. }\end{array}$ \\
\hline $\begin{array}{l}\text { Makr Shakr }^{\circledR}[147] \\
\left(2013^{\mathrm{c}} \mathrm{I}\right)(\underline{\mathrm{V}})\end{array}$ & $\begin{array}{l}\text { Shake } \\
\text { Mash, slice } \\
\text { Place, pour } \\
\text { Stir } \\
\text { Rinse }\end{array}$ & 圖国 & $\begin{array}{l}\text { - Automatic fruit cutters, ice } \\
\text { muddler, dispensers, and water } \\
\text { showers; } \\
\text { - } \quad \text { two articulated robots; } \\
\text { - EE 1: (fixed) cocktail shaker; } \\
\text { - EE 2: (fixed) cups holder. } \\
\end{array}$ & $\begin{array}{c}\text { Pre- } \\
\text { programmed }\end{array}$ & $\begin{array}{l}\text { C: Cobot; } \\
\text { method - } \\
\text { (information not } \\
\text { available). } \\
\text { S: none. }\end{array}$ & $\begin{array}{l}\text { - Repetitive, long-time } \\
\text { standing tasks; } \\
\text { - } \text { musculoskeletal } \\
\text { disorders. }\end{array}$ \\
\hline $\begin{array}{l}\text { Pazzi [148] } \\
\text { by EKIM } \\
(2016 \text { I) }(\underline{V})\end{array}$ & $\begin{array}{l}\text { Divide } \\
\text { Spread, sprinkle } \\
\text { Pick up, place, rotate, } \\
\text { carry } \\
\text { Stretch }\end{array}$ & 圆国 & $\begin{array}{l}\text { - Automatic press, ingredients } \\
\text { dosing, and rotating oven; } \\
\text { - linear actuators, conveyor; } \\
\text { - three articulated robots; } \\
\text { - EE: (fixed) 2-finger gripper } \\
\text { (grasps bottles, ladle, cutter, } \\
\text { fork-shaped shovel) }\end{array}$ & $\begin{array}{l}\text { Pre- } \\
\text { programmed }\end{array}$ & $\begin{array}{l}\text { C: Cobot; } \\
\text { method - } \\
\text { (information not } \\
\text { available). } \\
\text { S: none. }\end{array}$ & $\begin{array}{l}\text { - The baking oven - hot, } \\
\text { burns; } \\
\text { - repetitive, long-time } \\
\text { standing tasks. }\end{array}$ \\
\hline
\end{tabular}




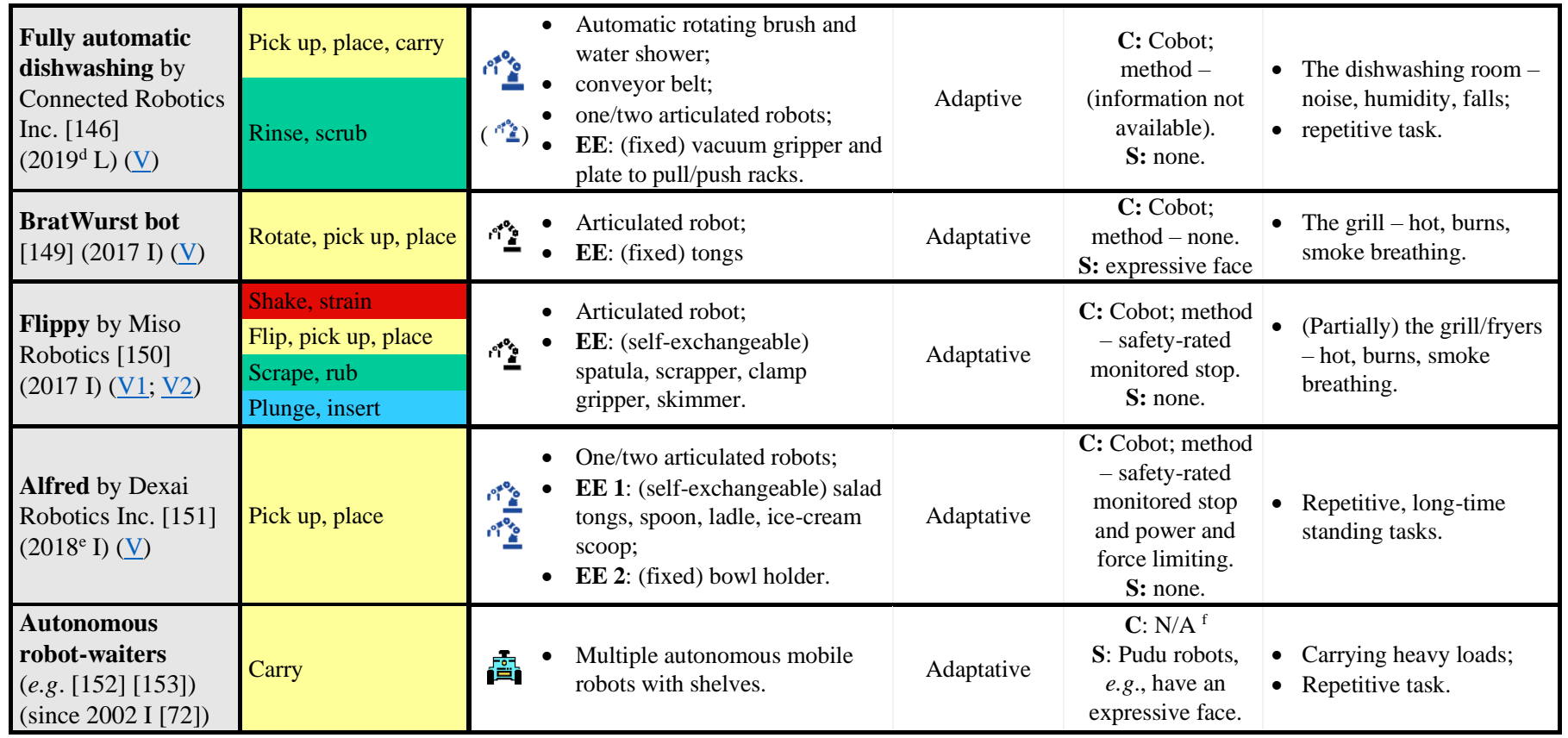

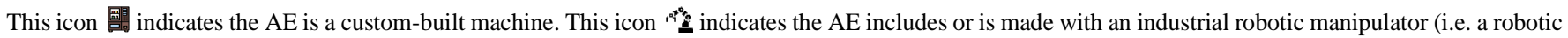

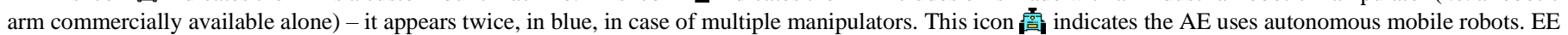
stands for robot end-effector. The column "collaboration and social skills" applies when a manipulator is present. N/A stands for not applicable, i.e. no robot is present. "None" indicates that no collaborative operation was implemented (even if a cobot is present). The method refers to the type of collaborative operation implemented, according to ISO/TS 15066 [154]; if the company did not share their method, "information not available" is stated.

${ }^{a}$ When available, the year of the invention was obtained from the patent: earliest priority. ${ }^{b}$ Year estimate: demo publication. ${ }^{c}$ Source: http://senseable.mit.edu/ (laboratory of the original developers/researchers of Makr Shakr's project). ${ }^{\mathrm{d}}$ Year estimate: demo publication. ${ }^{\mathrm{e}}$ Year estimate: $\underline{\text { demo publication. }}$

${ }^{\mathrm{f}}$ Autonomous mobile robots are not addressed by the ISO/TS 15066 [154], even if they move around people to collaborate with them. Instead, there are a few standards specifying their safety requirements, i.e. the ANSI/ITSDF B56.5-2019 [155] and the ISO 3691-4:2020 [156]. Nevertheless, "neither standard fully addresses the current state-of-the art of robot mobility", as stated by IFR [157], so, more applicable standards are in revision [157] [158].

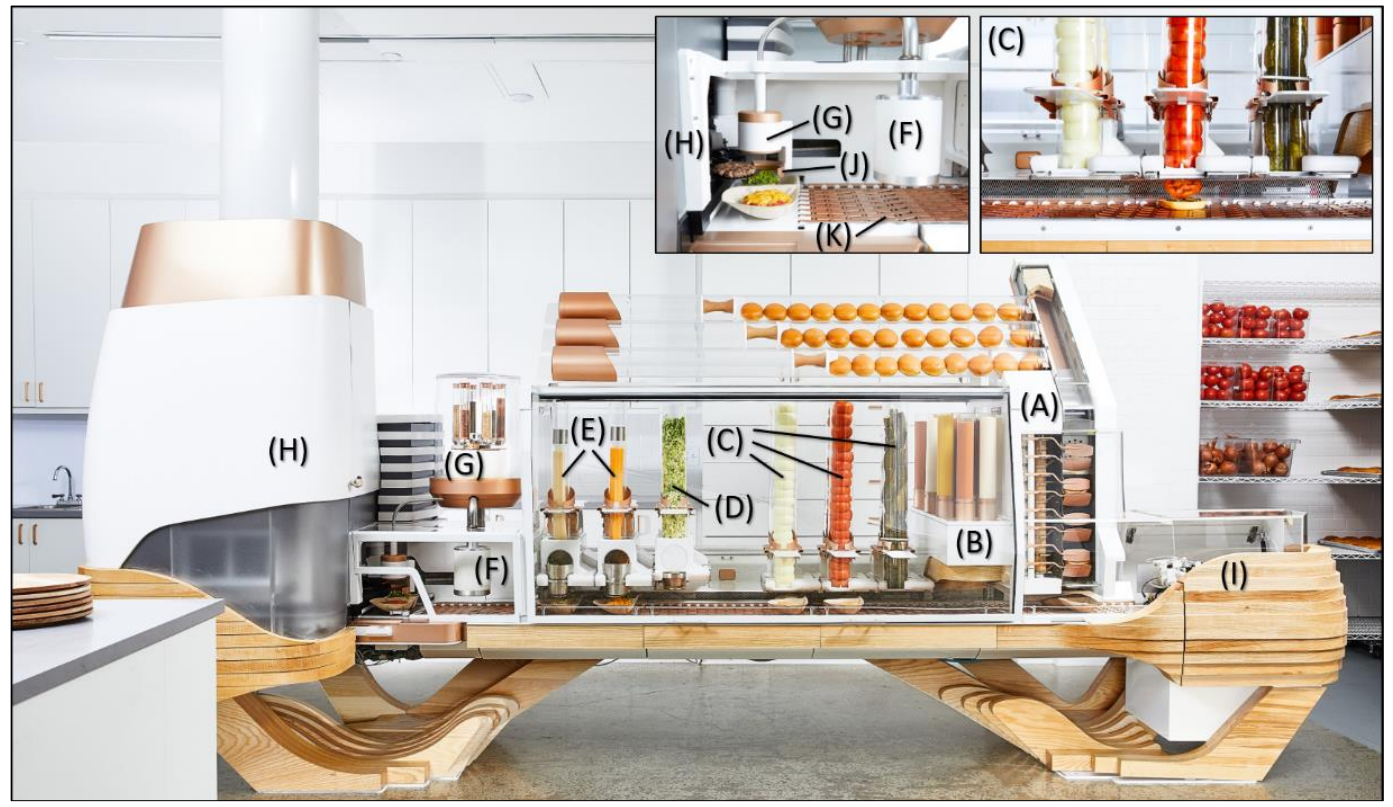

Fig. 8. The machine of Creator Inc. to prepare hamburgers: (A) bun slicer, toaster and butter, (B) sauce dispenser with movable tip, (C) toppings slicer (pickles, tomato, onion), (D) lettuce dispenser, (E) cheese graters and dispensers, (F) cheese melter, (G) spices dispenser, (H) meat grinder, patty press, griddle, automatic spatula to place hamburgers on the sandwiches, (I) unit where the hamburger boxes are flipped open side up to catch the sliced and toasted buns, (J) fixed structure to support the spatula movement, (K) modular conveyor. (C) Aubrie Pick (Creator Inc. press kit).

Like Creator Inc., Picnic [140] (former Vivid Robotics Inc.) made an apparatus resembling an assembly line [159] (Fig. 8) but dedicated to automate the application of toppings on pizzas. It is a sequence of electromechanical modules placed side by side. The dough is moved from one module to another on a conveyor belt. The modular structure of the machine allows it to be adapted to different FS businesses because different modules can be combined. The available actuated units include: 
sauce dispenser and spreader; granular ingredients spreader (for pre-grated cheese, pre-diced vegetables or meat); and oven loader [140]. Placing and spreading granular toppings on the dough is executed by moving a link forward and backward (one translational axis) and by simultaneously running a narrow conveyor belt that is embedded in the link. Likewise, a link moves forward and backward to spread sauce being poured (Fig. 9. C). Similar to the previous inventions, precise amounts of each ingredient are measured and dispensed, which can be customized per pizza [140]. In addition, a slicer (e.g. for pepperoni) or an additional dispensing element can be added to a unit. Storage modules can also be accommodated besides the actuated ones, like a dough rack [140]. Each automatic unit may be replaced by another one. Once added, that unit connects to the control system and communicates its operating space, position, and components, so that operating instructions are adapted to it [159]. The dough is placed by the staff in a first passive unit where the dough size, shape and position are estimated, by Computer Vision. This way, actions of the following units are adjusted accordingly [140]. Artificial intelligence is also used to support the staff in planning by tracking ingredients usage, predicting inventory needs and optimizing operations [140].

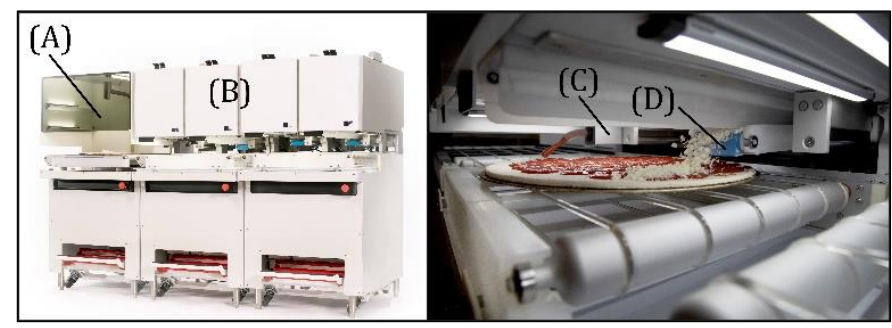

Fig. 9. Picnic ${ }^{\mathrm{TM}}$, a machine for the automatic application of toppings on pizzas: (A) loading unit with Computer Vision; (B) actuated units to place and spread ingredients; (C) actuator to dispense and spread sauce; (D) actuator to drop granulated ingredients. (C) Picnic (press kit).

Another AE that was found under the category of custom machines is the solution of Dishcraft Robotics Inc., to automatically rinse and scrub serviceware, before sanitation in a separated commercial dishwasher [141]. Indeed, the pre-step of rinsing, scrubbing, and sorting serviceware in racks is, nowadays, performed manually, being the major reason for requiring a human present in dishwashing rooms. Currently, the system that Dishcraft Robotics Inc. implemented (Fig. 10) can handle the dishes and bowls that are customized by Dishcraft Robotics Inc. with a small disk of ferromagnetic material fixed in their bottom face [160]. This is necessary as their machine uses magnetic grasping to pick the dishes to scrub and to hold them while scrubbing [160]. Still, the concept of Dishcraft Robotics Inc. could be adapted to other non-ferromagnetic materials by mechanical engaging [161], as shown also by past academic studies [162] [163] [164].

The machine starts its process when the staff inserts a cart with dishes/bowls at the entrance, that were manually presorted and pre-stacked in the cart [141] [165]. Inside the machine, an arm lifts the dishes up to a level that a custom 2axis manipulator, holding a magnetic gripper, can pick a dish.
The manipulator, then, places the dish on the surface of a rotating mechanism [161] that transfers the dish between processes: first, the dish is brought above a rotating scrubber that, with a water jet, rubs the dish surface to eliminate stuck dirty; then, the rotating conveyor brings the dish in front of an inspection system that determines the presence/absence of dirty and its location, based on Computer Vision [166]. In particular, this system uses Convolutional Neural Networks (CNN) to localize and segment dirt in the images of the dish, and to classify the level of dirtiness [166]. If that level is not satisfactory, the dish is re-cleaned [166]. This is one of the few implementations existing, today, to scrub automatically. The structure of the machine allows only to scrub the internal face of a dish, but not its back [167]. Still, normally, only the internal face usually retains stuck residues of food that require scrubbing. Furthermore, the system does not handle cups, glasses, or silverware, but, once more, this serviceware rarely requires being scrubbed [167]. For FS businesses where this would, anyway, be required, the possibility of exchanging brushes or using a reconfigurable brush to adapt to the shape of cups/glasses would need to be studied. Finally, another manipulator, after the inspection system, picks the cleaned dish and places it in a rack, to enter in a dishwasher for sanitation.

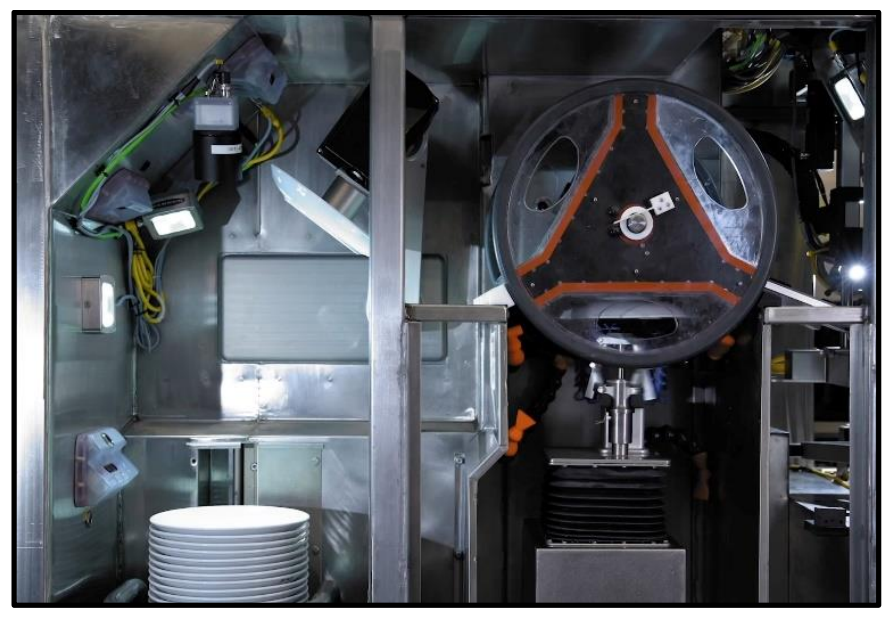

Fig. 10. The machine of Dishcraft Robotics Inc. that rinses and scrubs dishes and bowls. (C) courtesy of Dishcraft Robotics Inc.

Meiko Maschinenbau GmbH \& Co. KG, a supplier of professional dishwashing systems, also developed a solution to automatically sort and rinse dishes, bowls, silverware, and trays, before sanitation [168]. This system uses a series of conveyors to carry the serviceware along the machine. Vertical conveyors are available to carry the materials from the dining room (e.g. a canteen) to a dishwashing room, when it is located at another floor. Horizontal conveyors transport the materials along the rinsing path and into the final dishwasher. Silverware is collected from the trays to its dedicated conveyor, using a magnetic field to attract them. Dishes and bowls are collected from the trays using a "hedgehog" conveyor: an upper conveyor belt with soft pins traps the dishes and mugs by passing over them and, then, turning them upside down [168] (minute 2:42), while the trays continue their path in the previous conveyor. Dishes and mugs are separated by size: mugs fit a narrower 
passage on the conveyor that dishes do not fit. While being sorted, the serviceware is rinsed by water showers, automatically, and considerable dirt is dissolved and removed, without scrubbing. After sanitation in the dishwasher, trays are automatically stacked in a trolley. Cutlery is separated manually, and dishes are manually picked up, too [168].

Both solutions of Dishcraft Robotics Inc. and Meiko Maschinenbau GmbH \& Co. KG partially avoid the human presence in the dishwashing room, as it is needed at the beginning of the process. At least, they potentially reduce accidents and the staff does not remain constantly under the noisy and humid environment of the room.

Wilkinson Baking Company LLC developed a large-scale autonomous bread-making machine [169], BreadBot [143], that is intended to produce baked products continuously from preparation to cooking. The machine blends the ingredients and kneads the dough for 6 min [170], using an embedded mixer (Fig. 11. E). Two conveyor belts (F) are used to mold the dough to a portioned size, in about $1 \mathrm{~min}$ [170].

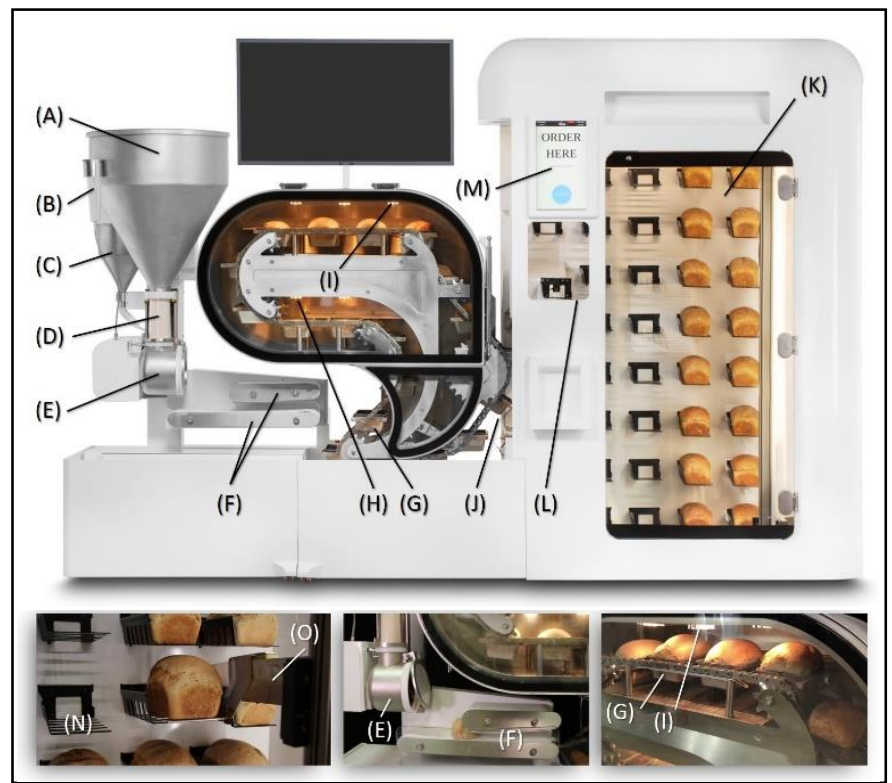

Fig. 11. BreadBot, an autonomous, large-scale bread-making machine, and its components: (A) hopper with the mix of flours, (B) water dispenser, (C) yeast hopper, (D) dosing chamber, (E) mixing pot, (F) molding conveyor belts, (G) integrated cake pans, $(\mathrm{H})$ proofing oven, $(\mathrm{I})$ baking oven, $(\mathrm{J})$ exit of finished bread, (K) cooling cabinet, (L) delivery window, (M) customer and staff interface screen, $(\mathrm{N})$ cooling basket, $(\mathrm{O})$ bread-picking manipulator. (C) courtesy of Wilkinson Baking Company LLC.

A chain drive carries the dough inside custom cake pans $(\mathrm{G})$ into the machine-integrated oven (H-I) and, then, carries the finished bread into the cooling cabinet $(\mathrm{K})$. The endless oven conveyor is programmed to translate the cake pans through the oven chamber at a rate that allows the single batches of dough to be sequentially baked [169]. Upon request from a client, a manipulator of three translational joints, integrated in the cooling cabinet, picks a bread and brings it to the delivery window (L). The manipulator has a fork-shaped end-effector

${ }^{15}$ Information on sanitation, certifications, staff-machine interfaces, and data collection was shared by Wilkinson Baking Company LLC via email.
(O) that matches the shape of the cooling-baskets (where the bread rests), so the bread can be easily picked [170]. To what concerns cleaning, the staff is involved only to wipe surfaces and vacuum any debris. The machine self-cleans its components, including the most difficult ones, that work the dough. Furthermore, the system was designed to comply with NSF, UL, and CE standards. Presently, to avoid crosscontaminations, the delivery window (L) has doors that block the access of a customer to the space of the cooling cabinet, and the window is even automatically sanitized with UV light, after each customer interaction. This solution completely frees humans from repetitive tasks, like kneading, deep cleaning and carrying heavy loads from a preparation to a cooking station, and it eliminates the human presence near a hot oven, avoiding burns. In addition, it supports the staff in management and planning, by collecting and displaying comprehensive data of all the machine units. The staff can interact with it through the screen interface (M) or remotely, using another tablet. ${ }^{15}$

\section{2) Custom-built machines with an industrial robot}

Six machines were identified as partially custom-built, for including one industrial manipulator (Blendid, Cafe $X$, and OctoChef) or several ones (Makr Shakr ${ }^{\circledR}, P a z z i$ and the fully automatic dishwashing system of Connected Robotics Inc.).

Blendid (6d Bytes Inc., USA) is an autonomous bar, that frees human staff from the long-time standing and repetitive preparation of smoothies and blends. Customers can customize the preparation of their drinks with desired ingredients and quantities in the ordering app [144]. Different actuation mechanisms work automatically and coordinately [144, p. FAQ]: food processors (to mash and stir), temperaturecontrolled dispensers, a small articulated manipulator of 6 rotational axes with a 2 -finger gripper, and a magneticallydriven carrier to slide the cup near the customer [171]. The manipulator, located at the center of the bar, is a cobot (although no human-robot collaborative operation is implemented) and it is intended to move the recipients with the ingredients from one process to another (pick up, place, pour) [144]. The pouring action is adapted in real-time to the cup position, which is monitored by Computer Vision, with a reported $99 \%$ accuracy [172]. The company indicated that Artificial intelligence is also used in the identification of the ingredients and the calibration of the robot trajectories, but the precise methods were not specified. The system is certified by NSF and is self-cleanable. Only periodically, human staff performs the equipment maintenance. ${ }^{16}$

Cafe $X$ (Fig. 12. A) is also an autonomous coffee bar (by Cafe $X$ Technologies Ltd., Hong Kong), for the preparation of cold and hot drinks, like coffee, tea, chocolate, brew, lemonade, and others. Like Blendid, a 6-axis cobot is used as connection between other automatic machines: refrigerated dispensers of ice, water, concentrates and syrups, professional expresso machines and automatic-opening delivery windows [145] [173]. The robot uses a 2-finger gripper with force sensing, to pick up and place the cups under the necessary dispensers, and

\footnotetext{
${ }^{16}$ Information regarding the use of Artificial Intelligence, certification and cleaning was shared by Blendid (6d Bytes Inc.) via email.
} 
stirs the drinks by shaking the cups with rotary movements [145]. Six drinks can be prepared simultaneously, ordered by the customers through the kiosks or the mobile app [145]. Finally, the delivery windows can also detect the presence of a human hand or objects (e.g. cups that are ready) [145].

Autonomous robotic bars are also provided by Makr Shakr $\mathrm{Srl}$ (Torino, Italia), that FS businesses can buy or rent [147]. Their platform is built for the automatic preparation of cold drinks. It includes two articulated cobots, several automatic dispensers (of ice, mint, beer, wine, sugar, fruits and cups), fruit cutters and a muddler (ice crusher). From the ceiling of the bar structure, 158 bottles hang, containing spirits, juices and sodas. They are used to prepare cocktails and mocktails (i.e. nonalcoholic cocktails), that can be pre-set or tailored by the client. Each bottle has a custom valve that is pressed by the robot to open and dispense the liquid. Currently, one of the robots has a cocktail shaker at the end-effector, and the other robot has a cups holder (Fig. 12. B). So, the first robot shakes (to thoroughly mix and partially dissolve solids, e.g. ice, with the liquids [174]), stirs (to homogenize) and pours the drinks to a glass held by the second robot.

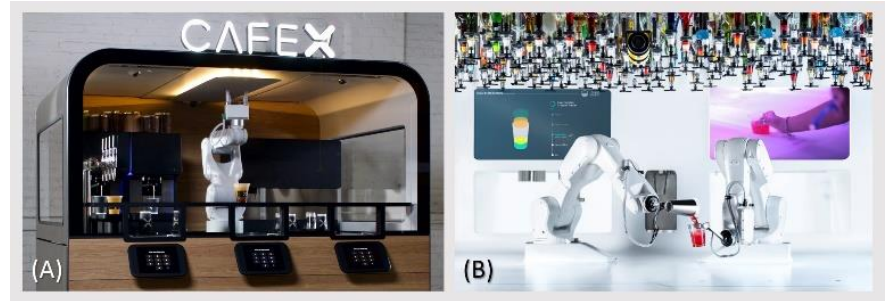

Fig. 12. Custom-built machines that include industrial robots: (A) Cafe X; (B) Makr Shakrß. () Courtesy of Cafe X Technologies Ltd. and Makr Shakr Srl.

In a previous version, tested in cruise ships [175] and land bars [176], both robots could prepare the drinks and pick up a cup (by suction) to be filled. That version included a carrier on the serving counter to slide the drink near the customer. In the newest version, the second robot simply places the cup in the serving area [147]. In addition, the cocktail shaker is rinsed and dried by the robot at an automatic water shower [177]. This is, indeed, another solution with potential to prevent long-term negative consequences for the health of bartenders. It avoids the continued manual shaking, which has been associated with a high prevalence $(88 \%)$ of musculoskeletal disorders within one year [178], in addition to the usually long time standing while performing repetitive tasks.

The robotic system of Connected Robotics Inc. (Japan), OctoChef [146], cooks the typical Japanese street food known as Takoyaki. The system integrates a multi-axial manipulator with a typical Takoyaki grill and automatic dispensers of oil and batter [179]. The robot is collaborative, has force/torque sensors in its joints, and the method of power and force limiting [154] is implemented, such that the robot stops when a person comes in contact [146]. The tools used by the robot (spatula, funnel, stick) have a perforated handle. The robot uses a custom clamp gripper with pins that fit the holes in the tools' handle, closing a grasp [146]. Although the tools need to be modified, this method can be easily adopted to robustly grasp other tools.
The surface of a typical Takoyaki grill has multiple concavities which induce a spherical shape on the batter being cooked. The innovation in the grill of OctoChef is that it is modified to shake automatically while cooking, so that the batter unsticks from the surface of the grill concavities and the forming balls are rotated to cook homogeneously [179]. This rotation is also aided by the robot using a stick at the EE (piercing and pulling the balls), like humans do [180]. The robot can also grease the grill surface, pour batter and spread it in the grill, plunge pieces of octopus and vegetables in the batter, and scrape the grill with a spatula [146]. While humans usually plunge one piece of octopus and vegetables at a time, the robot can plunge all the pieces at once. The robot control is supported by a vision system that recognizes the food and determines the actions needed, like e.g. rotate the Takoyaki balls if one side is cooked enough or correct the action of plunging if some pieces failed to fall. The cameras are over the workspace and in the robot EE [146].

EKIM (France) created an autonomous pizza-making installation, called Pazzi [148], that has been operating in France. Their invention comprises three multi-axial cobots and several custom actuated workstations: one to add toppings, another to stretch the dough, and a third to bake the pizza [181]. Two of the robots are mounted on the same base to create a dual-arm structure, that is responsible for picking, placing and carrying the pizza in preparation from one station to another. The first station includes several containers that store ingredients. In this innovative unit, a dosing device is moved in two axes (horizontally and vertically), by linear actuators, to reach the several containers and collect the amount of ingredients needed for a pizza [181], which can be selected by the client [148]. As one ingredient is collected after another, the ingredients get stacked in layers inside the dosing device. Thus, they are transferred to a distributing mechanism to be mixed, so that, when they fall on the dough, their arrangement is homogeneous [181]. The dough is brought under this distributor (inside the toppings station), by another conveyor [181], after being stretched with an automatic press. This press is made of two circular plates that compress the dough [182]. The novelty is the mechanism to unstick the dough from the bottom plate of the press, without tearing the dough apart: this bottom plate is perforated and, below, there is a third plate with pins that match the position of the perforations; when the dough is pressed, the pins are leveled with the surface of the perforated plate (forming a continuous surface); when the dough is released, the pins are automatically raised, pulling the dough off the plate [182]. This method also makes it possible for the dual-arm to pick the stretched dough: one of the robots grasps a fork-shaped shovel with teeth that match the spaces between the pins of the automatic press [183]. This robot is also able to handle a ladle to spread sauce. In the third station, multiple pizzas are baked and rotated inside a custom oven [184]. At the end, the third robot collaborates with the dual-arm to place the pizza in a box, spreads oil, sprinkles seasonings and divides the pizza in slices [181]. Each robot holds a gripper and grasps different utensils. So far, the robots work autonomously and are separated from the customers by glass [148]. EKIM did not share any 
collaborative operation has been implemented.

Connected Robotics Inc. also designed a robotic station to automatically sort serviceware in and out of a commercial dishwasher [146]. This station has been demonstrated by the company in two configurations: one uses two manipulators (a first to sort in, a second to sort out) [185], another uses one manipulator (to sort in) and a conveyor belt (to simply stack racks of washed dishes in shelves) [146]. Independently of the setup, this solution tries to eliminate the human presence in the dishwashing room. Dirty dishes and bowls of different sizes can be picked by the first robot and brought to a rotating brush or to an automatic water shower for scrubbing or rinsing, as needed - these two mechanisms are embedded in a sink that is controlled synchronously with the robot [185]. The robot places rinsed/scrubbed dishes in a rack and pulls the rack into the commercial dishwasher. Oppositely to the machine of Dishcraft Robotics Inc., the robot of Connected Robotics Inc. picks dirty dishes from the back face, which is a cleaner surface and, expectedly, easier to grab. Instead of magnetic grippers, a vacuum gripper is used here. Cameras over the workspace and at the robot end-effector are used to identify the dish type and to determine its location [146].

\section{3) Add-on robots}

Our search identified four solutions that self-adapt to the FS facility and, thus, can be installed in pre-existing rooms or workstations. Two of them rely solely on an industrial manipulator (BratWurst bot, and Flippy), that works with a professional standard appliance (griddles, fryers). Another one (Alfred) adds a custom arm to one or two industrial manipulators, to work at standard serving counters. Finally, different manufacturers are developing autonomous mobile robots to serve and collect dirty serviceware.

Researchers at the FZI Research Center for Information Technology have built a robotic system, BratWurst bot, to grill sausages autonomously [149]. A UR-10 cobot was used with standard barbecue tongs mounted on a Schunk PG-70 Gripper. The control was implemented in the ROS framework [186] (with OpenCV library for image processing), integrated with a web-based user interface displayed in a tablet, for ordering. The robot picks raw sausages from storage trays, rotates them while grilling (managing the grill space), and places the cooked sausages on plates. Two color cameras are used obliquely to the grill (to prevent blinding from vapor): one to localize the sausages and guide the picking task from the trays, and other to guide the grilling job (localize sausages and monitor the degree of browning) [149]. This is a research prototype that, if made available commercially, could avoid humans to work at the grill, continuously breathing smoke, in a hot environment and with the risk of getting burns.

Miso Robotics (Pasadena, USA) developed a movable robotic platform (Flippy) with a 6-axis cobot, to collaborate, occasionally, with humans in workstations with griddles and fryers. OSHA-compliant laser sensors detect proximity of a person [150] and the safety-rated monitored stop type of collaboration is implemented: the robot pauses its motion if a human enters the workspace and restarts after the person leaves
[38]. The system is certified by NSF and Edison Testing Laboratories (ETL Intertek) for its compliance with sanitation and safety standards for FS equipment [150]. It is designed to operate with standard professional griddles or fryers and has a washable cover, although the machine is not self-cleanable [150]. The platform is equipped with artificial vision (via 3D, color, and thermal scanners) for:

i. recognizing the food and, thus, the necessary action (e.g. exchange spatulas for raw or half-cooked meat);

ii. locating food and tools, to adapt the robot trajectory;

iii. monitoring food temperature to determine remaining cooking times [187].

At the fryer (Fig. 13. A), Flippy has a custom clamp endeffector (EE) to pick up baskets with food, plunge them into oil, shake them while frying and, when ready, raise and hang (insert in a support) the baskets to drain excess oil [188]. In between frying batches, the robot self-exchanges the EE to a skimmer, and strains particles from the oil. Humans only need to collect the fried items from the baskets, away from the fryer, where Flippy places the baskets [150]. At the griddle (Fig. 13. B), Flippy picks hamburgers, flips them, and places them in a holding counter. For the latter, Miso Robotics used a different strategy from that of Creator Inc., more human-like: the spatula is tilted causing the hamburger to slide down. In addition, while Creator Inc. uses two hotplates to grill (bottom and top), avoiding the flipping action, Flippy makes use of already installed single-hotplate griddles and has learned to flip hamburgers. The robot also rubs the spatula against its support, to clean it, and scrapes the griddle by self-exchanging its EE to a scraper [150, p. Miso AI]. The workers need to place raw food on the griddle (hamburgers and cheese over them), pick the paper covering raw hamburgers and, at the end, wrap the bun with all ingredients. This way, robot and humans collaborate to complete the task, reducing the staff workload and the need for a worker to be permanently near the griddle/fryer. As so, it partially eliminates the negative impact of this work, like the constant smoke breathing and the hot environment. Yet, the risk of burns remains. In addition to support physical actions, Flippy helps the staff in decision-making, displaying the remaining time to cook each item that is being monitored.

Dexai Robotics Inc. (Somerville, USA) integrated a collaborative 7 -axis manipulator with a custom 2 -axis arm, to automatically prepare and serve cold dishes, like salads or icecreams [151]. The first robot handles and self-exchanges different tools: ladle, spoon, or salad tongs, to pick up and place ingredients for salads, or a scoop, for ice-creams [189]. The smaller arm holds the bowl to fill [151]. Like the abovementioned robotic bars, this system, Alfred, frees humans from long-time standing and repetitive tasks. Contrarily to e.g. Blendid or Cafe X, Alfred is not closed in a pre-set space, but can, instead, be installed at a standard serving counter and it will recognize the parts to work with (e.g. hotel pans) [151].

Hence, its quick installation is another advantage for the workers. Their cobot pauses motion if anyone comes closer than $4 \mathrm{ft}(1.22 \mathrm{~m})$ [151]. The person is detected by Computer Vision. In addition, the power and force of the robotic arm are 
limited (as in the ISO/TS 15066 [154]), such that it stops operating, if the pressure is sensed too strong (e.g. due to a collision $)^{17}$. This is possible because the robot includes force/torque sensors in each joint, which are also used to control the manipulation of the tool (e.g. to adapt to soft/hard food). A camera at the end-effector is used to estimate the food quantity that is picked up [189]. Among a list of ingredients, Alfred can recognize each ingredient in the hotel pans, independently of the pan position on the counter [151]. From the ingredient identification, the necessary action is immediate, and the quantities on the pans are continuously tracked. Dexai also offers a two-robot option, for many ingredients, in which the bowl to fill is passed between robots that reach different pans [151]. The system is NSF-certified as food service equipment, has a splash-proof cover wipe down compatible, and all accessories are easy to remove and dishwasher-friendly [151]. Finally, data is collected for order analytics and inventory management, as well as to improve the accuracy of Alfred in food manipulation and weight picking [151].
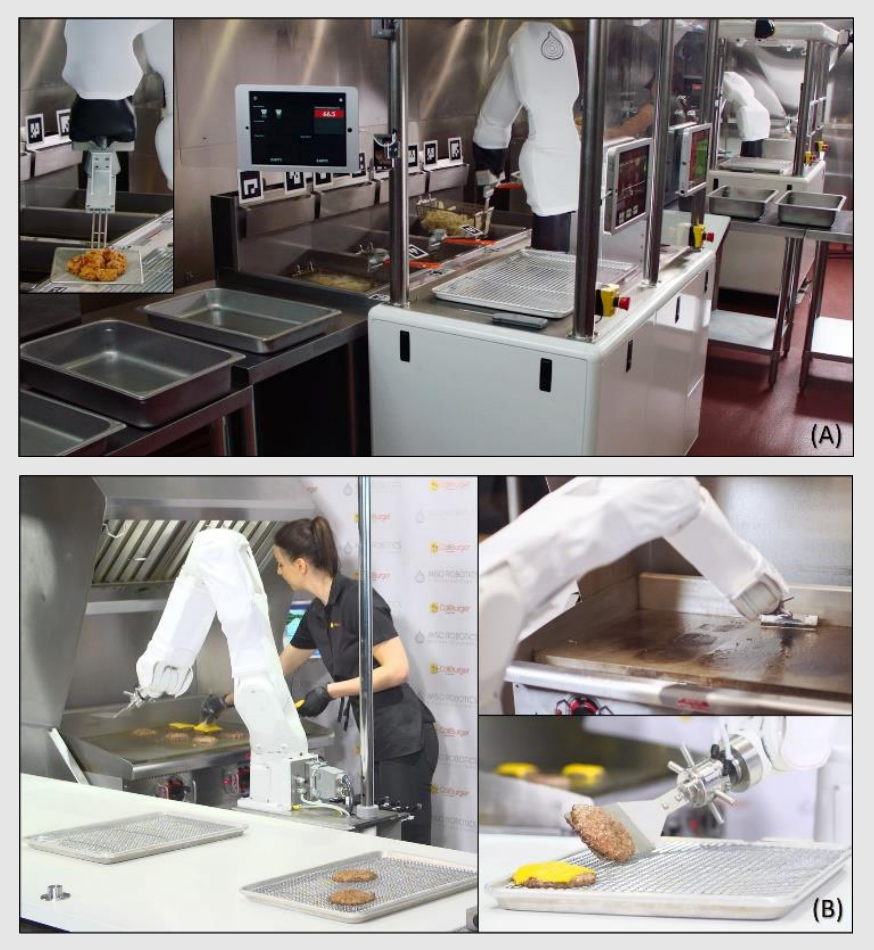

Fig. 13. Flippy: intelligent, collaborative robotic platform for frying (A) and grilling (B), developed by Miso Robotics. @ Miso Robotics

Some companies and academics are developing robotwaiters for the front-of-the-house ${ }^{18}$, with autonomous mobile robots (AMRs). They eliminate the manual action of carrying loads (food, dirty dishes, etc.) between the kitchen or dishwashing room and the dining room, preventing the usual accidents associated to it [58], besides supporting the business in staff shortage [190]. Although robot-waiters are not multi-

\footnotetext{
${ }^{17}$ The method to detect people and the collaborative operation implemented was shared by Dexai Robotics Inc. via email.

${ }^{18}$ Front and back-of-the-house are commonly used to refer to "areas of a restaurant where customers and employees interact" and "areas of a restaurant
}

action, they are also not equivalent to pre-programmed, singlepath conveyor belts, because their path is re-programmable for each service and for adaptation to obstacles in the real-time environment. Indeed, the first attempts to implement a robotwaiter employed a rather simple and poorly adaptive method based on following dark lines on the floor [191] [192]. Today, some companies, such as e.g. Pudu Technology Co. Ltd (Shenzhen, China) [153] or Bear Robotics Inc. (Redwood City, USA) [152], provide intelligent indoor mobile robots with redundant SLAM systems (Simultaneous Localization and Mapping), collision avoidance and multi-robot coordination.

For example, Penny, by Bear Robotics Inc., uses 3D cameras, to avoid collisions, and a LiDAR sensor (Light Detection and Ranging) for mapping and navigation [193]. Penny is versatile in the sense that trays can be exchanged between adapted trays for dishes or for bottles/glasses, and bins can be added to collect trash and dirty serviceware [152]. This AMR has a payload of $30 \mathrm{~kg}, 8-12 \mathrm{~h}$ of battery life and up to 3 levels/shelves for carrying materials [152].

Pudu Technology Co. Ltd provides, among other robots, separated AMRs for dish-delivery (PuduBot) and dish-return (HolaBot) [153], see Fig. 14. This allows them to have customized solutions for both tasks: HolaBot can be called by the staff, has a IPX5 waterproof inner cabin and a big payload (maximum total load of $120 \mathrm{~kg}$ ), to clear as many tables as possible at once; PuduBot has lower payload (maximum total load of $40 \mathrm{~kg}$ ), but a centimeter-precision positioning and autonomous planning, to ensure delivery at the right table. PuduBot uses sensor fusion to navigate efficiently in the environment: VSLAM (Visual SLAM - with RGBD camera) [194], LiDAR-based SLAM, inertial odometry (IMU sensors), UWB (ultra-wideband radio technology) and the motors encoder [153]. Obstacle avoidance is achieved by applying methods of Computer Vision to the images from the 3D stereo cameras [153]. In addition to being a support for physical tasks, these robots collect data to generate usage reports, as well as failures and maintenance records that can aid the staff in managing their activities [152] [153].

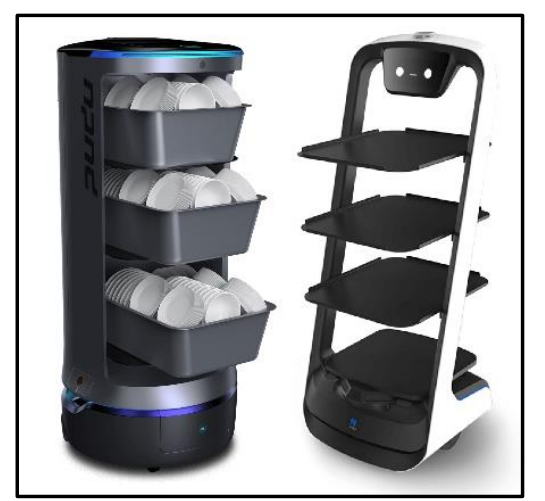

Fig. 14. Example of autonomous robot-waiters being used in FS, developed by Pudu Technology Co. Ltd:: HolaBot (at left), a dish-return robot, and PuduBot (at right), a dish-delivery robot. (C) Pudu Technology Co. Ltd.

that customers normally do not see: the kitchen, storage, offices, and dishwashing" [298]. 
In academia, several researchers have been developing robotwaiter prototypes with different sensors and navigation methods $[69,70,71,72]$. Furthermore, since some years, researchers have been addressing the waiter motion problem ${ }^{19}$ [195] [196], by creating balance methods to carry liquids in open containers [197] [198], control strategies to balance bottles/glasses [199] [200], as well as collision-avoidance approaches for ARMs to move near humans [201].

\section{DISCUSSION}

\section{A. Applicability of the proposed taxonomy}

So far, a common framework was absent in the development of robotics for FS, and the spectrum of FS actions was never made explicit in a structured way, even in literature on FS businesses. The proposed taxonomy can be of great use to Foodservice Robotics, especially to:

- identify more study cases for automation and robotics in FS, among the classes of actions in the taxonomy;

- study how FS workers execute their actions (to guide the development of control strategies for FS robots), dividing the studies by the classes of actions.

Particularly regarding the second point, we expect the actions in a same class of our taxonomy to have common characteristics in their execution, since they have a related goal (purpose) and characteristics of the food involved in common. Hence, the research on control strategies for FS robots is expected to be accelerated with our taxonomy.

Nevertheless, one must acknowledge the limitations of the procedure used to create the taxonomy. First, the method of Section II.A fails to catch exceptional actions ${ }^{20}$ that are not identifiable by a specific verb: e.g. opening packages, cans, or bottles are common actions in FS, because several ingredients arrive to FS businesses in them [46]. However, the verb "open" per se does not express what is the action, unless the context is specified. For this reason, general verbs such as open could not be systematically included in the taxonomy. Hence, for a thorough identification of all actions, complementary methods may be necessary. Second, new culinary techniques may be invented and one cannot foresee whether the actions in the taxonomy or different/new ones will be used in those techniques. Therefore, although the proposed taxonomy extensively enumerates several actions of FS workers, it may need to be updated in the future.

\section{B. "Curriculum" of SAE}

Automation can benefit FS workers with labor-saving, improved safety, and more time for creativity. Although increasingly more SAE is invented, humans still put efforts in several actions. That is visible by the blank spaces in Table 1, which indicate that, for those actions, no SAE was ever

\footnotetext{
19 The waiter motion problem: "moving a non-fixed object time-optimally from an initial pose to a final pose while preventing the object to slide, lift or tip over." [223]

${ }^{20}$ It is important to acknowledge this as those could be additional actions to consider for automation (e.g. the use of corkscrews or can openers)
}

invented or the invented ones were rarely adopted by FS businesses (and, thus, were not reported in the table).

In fact, some machines are not widespread in FS. They are only adopted by minority businesses (e.g. specialized catering services or hotels). For instance, there is equipment to automatically wrap food in transparent film (e.g. [202]), tenderize meat (e.g. [203]), or wash shells (i.e. rinse, rub; e.g. [204]), automatic oil disposing systems (e.g. [205] [206]) and clamshell griddles/grills (e.g. [207]). However, the cost of those systems, the extra space, energy consumption or required modifications to the kitchen are not worthy to only automate these actions, unless for FS businesses where the action is recurrently repeated [36, p. 82]. For example, clamshell grills are mainly used by fast food chains like McDonald's [208, p. 1], to avoid flipping hamburgers ${ }^{21}$.

Furthermore, it seems that no SAE has been created for some actions that are not complex (e.g. sprinkle or shake) as well as for actions that are already characterzed in literature (e.g. grease $^{22}$ or toss [209] [210]). This may be because those actions alone do not entail a sufficiently negative impact on the business or the workers for being done manually and, thus, does not seem to raise interest in automating only them.

Finally, one can observe that the most remarkable characteristic of SAE, that often makes its adoption or implementation unworthy, is its general inflexibility:

- lack of versatility: inability to execute other actions, in case its intended action is no longer needed or a priority (a blender can only blend, a sealer machine can only seal);

- lack of autonomy: inability to exchange tools by itself (e.g. autonomously change blades to execute a different cut).

\section{C. "Curriculum" of AE and foodservice robots}

Many novel mechanisms were described in Section III.C that may be an inspiration to develop other machines for FS in the future. One can observe, from Table 2, that various AE are becoming available to FS businesses. Nonetheless, the vast majority of FS automation, today, still consists in SAE, as indicated by the higher number of solutions in Section III.B than in Section III.C. Moreover, most AE is not being massively produced. It is under the first market tests (e.g. Flippy or Alfred) or being improved after the first feedback of the market (e.g. Spyce Inc.'s kitchen [211]). Some are not even available for sale (e.g. Spyce Inc.'s kitchen [130, p. FAQS]).

The majority of the AE is being developed by companies (most of which startups) rather than academics. Thus, the technical details of their methods are not always fully disclosed even if the technology is patented, because often the invention is not entirely implemented. This way, for an accurate technology review, information had to be collected also from previous online interviews to the companies or by directly contacting them. Still, companies often need to keep their methods/mechanisms in secrecy, thus, limiting the comparative

\footnotetext{
${ }^{21}$ The clamshell eliminates the action of flipping food by having a top lid with an additional heat source. That lid is automatically lowered/raised.

${ }^{22}$ Grease by spraying could be comparable to spraying ink, an action previously studied [301] [300], commonly automated e.g. in the automobile industry, and already applied by the AE of Creator Inc. [135].
} 
analysis that one can perform.

Nonetheless, the available information already allows a few observations. One can note that, at present, most $\mathrm{AE}$ is a custom-built machine. This means that, even if they entail a great benefit for FS workers, they imply modifications to the FS house, that may or not be affordable to the business. On the other hand, it can be a solution for a new business to open (as occurred with the restaurant of Spyce Inc.'s or Creator Inc.). Moreover, these machines suffer from a similar issue to that of SAE: being custom-built for the specific actions of one business, it is difficult to deploy them in a different business. On the contrary, add-on robotic manipulators are much more flexible, especially, articulated ones.

Indeed, articulated robots (with 6 or 7 axes) are the most common robot type used both in custom-built as in add-on AE. Observing the type of AE ordered in time (by year of invention or deployment, as in Fig. 15, Appendix B), there seems to be a trend: companies and researchers went from designing mostly custom-built machines to integrating robotic arms in those and, then, to developing add-on robotic platforms. Another evident trend is that collaborative robots have been preferred over cell robots (typical industrial robots) since companies started including robots in solutions for FS. As a matter of fact, this occurred while "Collaborative Robotics" was being gradually recognized (2012-2016) as a viable new class of robots by many robot manufacturers [212] and, shortly after (2016), when standard specifications and guidelines were finally published by ISO for a collaborative environment [154]. Even if only few AE (as reported in Table 2 - "collaboration" column) was actually used for a collaborative operation (i.e., for workers/client-robot cooperation), this feature, if necessary, can eventually be added in the future because, at least, a cobot is already installed.

To what concerns the classes of automated actions, it is visible in Table 2 that moving and cleaning actions are the most common. In fact, all $\mathrm{AE}$ that performs or connects various processes (i.e. the systems of Spyce Inc., Creator Inc., Dishcraft Robotics Inc., Meiko GmbH \& Co. KG and Connected Robotics Inc., as well as Picnic ${ }^{\mathrm{TM}}$, BreadBot, Blendid and Pazzi) includes a mechanism to carry the materials from one process/station to another, such as conveyors, rotating or sliding carriers, or a robot. This is the most commonly implemented action, along with pick and place. These are, in fact, basic actions very common in other industries, too [213]. In addition, several companies try to avoid the need for humans to clean their machines, implementing self-cleaning programs, like many SAE have as well. For this reason, other solutions beyond those dedicated to dishwashing also rinse, scrub or scrape.

One can also note that, at least, in some contexts, current $\mathrm{AE}$ executes a few more actions over SAE, aimed at separating food components (shake), covering (spread, grease, sprinkle) and cleaning (scrape, scrub). Some of them were expected, for the state-of-the-art in automation or the action simplicity, as discussed in Section IV.B. Still, like SAE, many other actions of separating food components were never automated, apart from shaking or straining, which are the least complex in this category. Surprisingly, although many SAE exists to automate actions aimed at reducing the food size, they are performed by very few AE. For example, the kitchen of Spyce Inc., Alfred, Picnic $^{\mathrm{TM}}$, or OctoChef take food already pre-cut.

To what regards food characteristics, there is AE that can handle liquids and solid food, in standard or variable dimensions, but it depends on the context. Some can manipulate soft and particulate food, like Alfred and BreadBot, with ice cream, dough, cereals and food pieces. A lot of AE manipulates liquids (Cafe X, Blendid, OctoChef, Makr Shakr ${ }^{\circledR}$ ). A few handle food in standard dimensions (Flippy, BratWurst bot). Finally, in dishwashing, all solutions did not show, so far, any ability to deal with big food leftovers.

As previously explained, AE can execute complete tasks in a workstation or room and, consequently, eliminate their dangers and negative effects on the workers' well-being. The most frequent benefit offered by the $\mathrm{AE}$ that we found is the avoidance of hot and humid environments, like at the grill, fryer or stove, and the dishwashing room.

Furthermore, AE is expected to benefit the business with consistency (uniform portions, precise quantities), better hygiene, easier business monitoring (data collection), and costs reduction e.g. in staff training or food waste. Indeed, bridging benefits for the business with those for the staff is important for the adoption of the machine in FS, as shown in Section IV.B.

Nevertheless, currently, not all AE that was found seems to guaranty increased efficiency/productivity and less waste over manual work. Some robots and mechanisms that were found merely replicated the human movements, which not always shows to be the most efficient or sustainable method. For example, OctoChef spreads the batter in the grill like humans do: pouring it in one concavity at a time, which is inefficient, and in an imprecise manner, which is wasteful, because part of the liquid splashes and is lost [146]. Likewise, Alfred relies on vision to estimate the food quantity being picked, as humans do, which can be more difficult to learn and be precise than a direct measurement [151]. Naturally, in this case, the need for efficiency has to be balanced with the cost of adding another sensor just for a direct measurement of weight, since the camera can be used for multiple purposes (tools, or ingredients, or environment recognition and weighting). In turn, other $\mathrm{AE}$ seems to overcome the human efficiency. For example, with Dishcraft Robotics Inc., although one dish is cleaned at a time and the automatic cleaning proceeds similarly to the manual version (rinse, scrub, inspect, and re-clean if needed), it is performed in a standard and controlled manner, with faster mechanisms than human hands.

Regarding hygiene, it is expected that $\mathrm{AE}$ and, generally, automation lead to better hygiene because it avoids contact of human hands with food, preventing contaminations and disease spreading, like the latest Coronavirus SARS-CoV-2 (Covid-19) [214] [120]. However, advanced machines themselves must be designed with no food particle retention areas in their structure, to prevent bacteria growth, and must withstand wiping or rinsing processes (e.g. having sealant covers) [215]. To show their compliance with this [216], many AE is being certified with sanitation standards like the NSF mark [217]. Moreover, it is convenient that, just like most SAE already in the market, $i$ ) parts of the robotic platform or machine (e.g. an end-effector) 
are compatible with dishwashers and ii) if the machine includes a chamber, it can be self-cleaned automatically. All of this not only ensures sanitation, but also reduces the workers efforts.

With the recent Covid-19 pandemic, some machines that physically interact with customers included automatic mechanisms for disinfection with UV light (e.g. BreadBot). Others make available their graphical interface (for customer requests) in apps for mobile devices, so customers only touch their personal device (e.g. Makr Shakr ${ }^{\circledR}$ [147, p. OUR APP]). Similar solutions, as well as touchless interfaces, could be considered for the cases of staff-robot collaboration.

\section{Missing research on single actions}

In summary, the following categories of actions were found rarely automated:

i. separate solid/solid food parts (gut, pit, skin, trim);

ii. reduce food size to unspecific dimension (break, shred, chop, divide);

iii. move food between workstations or appliances in the kitchen (carry);

iv. move food (rotate, flip) that sticks or is slippery;

$\mathrm{v}$. introduce food into another solid food or a recipient (insert, pierce, stuff);

vi. clean food dirt stuck in surfaces (wipe);

vii. and other actions, like sew, roll or bread.

The manipulation actions among those in the list above (i.e. all actions except carry) seem too complex to automate robustly today, considering the variability of characteristics of the food that can be involved. Although there is AE in Section III.C that automates some of them, such $\mathrm{AE}$ handles limited types of food. For example, Miso Robotics developed a flipping method for hamburgers [218], not for e.g. vegetables, fish, eggs or chicken. These items are commonly grilled, too, but have different characteristics that affect slipperiness and stickiness [219] and could, then, affect the movement. Even with hamburgers, variable levels of grease can compromise the success of Miso Robotics' method [218]. Again, OctoChef is able to pierce the soft fried balls of Takoyaki, but e.g. the action of piercing fishes or meat, in multiple points, to prepare skewers for roasting/grilling (as in [59, pp. 178-180]) or for other tasks, is not found in FS automation or described in literature. Research, in fact, lacks a model of these manipulation actions for different food and conditions.

Furthermore, currently, there is no SAE or AE dedicated to carry items in kitchens. The AE that carries materials, does so within its own machine/installation. However, a solution seems to be missing to adaptively transfer outputs between independent kitchen workstations, like there is to transfer between the kitchen and the dining or dishwashing rooms (AMRs, conveyors belts), or even as there is for outdoor food delivery $^{23}$. As FS kitchens are usually small [220] [221], paths are often narrow, besides highly unstructured and marked by a dynamic human presence. Given the growing progress in indoor navigation methods [222] and control strategies to carry items [223] [197] [200] [199], the limited and dynamic space may be

\footnotetext{
${ }^{23}$ Although it is out of the scope of this article, it is worth mention that many startups, like Starship Technologies OÜ [306], Refraction AI, Inc. [305] or Kiwi
}

the major impediment preventing automation of these actions in the back-of-the-house. In alternative to ground robots, overhead rail robots are being considered by some companies, like Miso Robotics [224], to reduce the footprint occupied by the robot workstation. This solution could be studied also to transfer items between stations.

\section{E. "Robot Chef" or "Cobot Chef"?}

Despite the versatility of articulated robots, industrial cell robots could rarely be considered for FS until the rise of collaborative robotics, because of their large footprint and low mobility [225]. They would not fit the most common FS kitchens, that are small and tend to get smaller [220] [221], and would be fixed doing one task only. In turn, cobots (not being surrounded by safety fences) are easier to be displaced to another workstation, if needed, and occupy less space [225]. Moreover, human and cobot can collaborate in a task, with the actions distributed between them.

Human-robot collaboration (HRC) has been the strategy of few developers, such as Miso Robotics. Yet, this solution may not be the ideal for all tasks or circumstances in FS.

Working in the dishwashing room or at the grill/fryer, as well as in some food pre-processing tasks, was shown to have direct negative consequences on the workers' health (e.g. falls, noise exposure, burns, cuts [58] [12] [81]), which have not been changing over the years despite the literature suggestions on management and safety measures [7] [12] [226]. This indicates that, in those workstations and others of similar impact, a complete automation of the tasks should be more appropriate than HRC, so to eliminate the presence of the human in those detrimental environments. AE like that of Creator Inc., Spyce Inc. and Meiko Maschinenbau GmbH \& Co. KG, [73] or BratWurst bot, are in line with this perspective, although some of them use a custom machine instead of a robot. Blendid, Cafe $X$, Alfred and Makr Shakr ${ }^{\circledR}$ also eliminate the need for a human to stand for a long period doing repetitive tasks, which are very common in the preparation of drinks and cold dishes. Although there is no HRC in place, a cobot is used, saving space.

It should be noted, however, that it may not be possible, for all FS businesses, to completely automate a workstation (e.g. like BratWurst bot) or facility (e.g. like Creator Inc.), if some of the actions in that business are still too complex to automate (as discussed in Section IV.D). Here, the support to the staff could start with an HRC approach, in which humans would perform the complex actions and the cobot would perform the other actions, already reducing the staff workload. Miso Robotics implemented this option and, in fact, in their application, e.g. the action of picking the paper covers from the hamburger could be difficult to automate robustly.

Furthermore, tasks related to customer assistance and requests management carry much lower safety risks than cooking or dishwashing [58]. In these, the workers accomplish cognitive tasks (e.g. problem-solving or social interactions), while often performing physical actions, such as carrying

Campus Inc. [304], have been testing AMRs with thermally insulated compartments for food delivery off-premises. 
objects. In these conditions, a more reasonable strategy seems to be that where the machine handles the physical actions and the human puts attention on the social and creative tasks. In other food-unrelated service sectors, e.g. healthcare services, past studies found a successful human-machine collaboration where the machine is responsible for the complete technical action (in that case, get a requested pharmaceutical product) and the human is free to focus on the socio-emotional interactions with the customer [227]. This distribution of roles is also supported by other researchers, generally, for service robots and employees [228]. The case of intelligent robot-waiters is, in fact, in line with this: the robot (e.g. Penny [152]) carries dishes forward and backward, while the staff assists the customers. Even Spyce Inc. tested a similar distribution of roles, from the whole operation perspective: in the restaurant where the system was deployed, the machine performs all the cooking actions and the staff handles the social interactions with customers, inclusive during the final customization of their dish.

Notwithstanding, for particular FS businesses where customer incivility is frequent, a full automated solution may suit better, instead. For instance, in the United States, waiter staff frequently have to deal with customer incivility [229], which has been shown to lead employees to exhaustion, contributing to their intention to leave the job [230]. In places where managerial measures cannot overcome these issues and frontline staff is difficult to retain, also automating the interaction with the customer can be a solution. Typically, the acceptability of such a solution is assessed with respect to the customers' perspective [231], i.e. if customers prefer to be served by a machine or a human. However, it should be further assessed from the workers' perspective, i.e. if they prefer to deal with customers behavior or not, given the negative implications on their well-being.

Likewise, FS staff usually works in unsocial hours (i.e. meals time, holidays) and, often, for extra working hours [232]. These situations could be avoided by provisional automation of the workers' tasks in those hours, e.g. loaning robots/machines. For such cases, there should be an autonomous, multi-functional, and movable solution, i.e. one able to execute variable tasks (on an ad hoc basis), without human supervision or support, that can be easily displaced to the workstation in demand. However, again, several actions still need to be formally characterized before that is possible for the needs of every FS business.

Finally, on collaborative operations as defined by the ISO/TS 15066, the very few companies that implemented any of them, typically, opted for safety-rated monitored stop and, less commonly, power and force limiting [154].

\section{F. Social behaviors of FS equipment}

The integration of a social behavior in the control loop of a robot is a technique aimed to improve human-robot cooperation (mutual understandability, greater efficiency and robustness in communication) [233]. Robots become capable of establishing human-centric interactions with their teammates/users, through social signals that include the most obvious, verbal form, but also nonverbal cues (gaze, pose, facial expressions, gestures, nodding, among others) [233].

Despite its relevance, a social behavior was rarely and poorly included in the control of robots deployed in FS, so far. Among the AE here reviewed, only the robots of Pudu Technology, Cafe $X$ and BratWurst bot show any sort of social behavior, and this is limited to nonverbal cues. The robot of Cafe $X$ can simply react to a person exiting, after receiving the drink, through waving. The robots of Pudu Technology endow a small screen where a cat-like or human-like face (depending on the robot model) is displayed and expresses emotions (e.g., happiness when a meal is delivered and a new goal is set; neutral when carrying meals). BratWurst bot also integrates a screen with a friendly face (two eyes and a mustache), but it is almost static and does not map any emotion to any expression.

To what concerns SAE, no machine (not even those holding a screen) has been created, by the many searched suppliers in this review, with social capabilities.

There are other relevant social aspects, such as anticipatory actions by robots working with a human, that were previously demonstrated to improve efficiency and robustness to errors in cooperative tasks [234] [235]. Yet, for instance, none of the mobile robots deployed in FS included such behavior (e.g., estimation of a future need for help by the human waiters, estimation of the position of humans in the targeted path) neither Flippy, that was created for grill stations purposefully to cooperate with human staff (e.g., the robot stops by sensing, not by anticipating a need for a human to enter its workspace).

This lack of sociability of the present FS robots/machines may be due to the difficulty in implementing a robust dialogue system (concerning social verbal signals) [236] [237] and, possibly, a perceived low impact of including nonverbal cues, that should be further investigated.

\section{G. Artificial Intelligence for Foodservice Robotics}

Artificial Intelligence (AI) includes useful methods to design more autonomous and adaptive solutions for FS. Indeed, this has been noticed by suppliers of SAE and AE, to some extent.

To date, AI in SAE has been applied mostly to support cognitive tasks rather than physical tasks. A few suppliers added more sensors and machine learning methods to the userinterface of SAE, so that e.g. it automatically determines and suggests process parameters for the food to be cooked. Convotherm (a supplier of professional ovens), for instance, offers the ConvoSense function [238]. This uses an external camera in the oven door to identify the food entering in the oven and suggests the best cooking conditions (e.g. steam, time, temperature). As the algorithm learns the staff preferences, the suggestions are tailored [238], so, the staff puts less effort into the initial decision of process parameters and in interacting with the machine. Another example is a research work instead [239], in which an Artificial Neural Network (ANN) was trained to model the nonlinear relation between controllable factors of frying (time, temperature, oil amount) and nutritional quality indices of the fried food. With two optimization methods (Differential Evolution and Simulated Annealing) applied to the ANN, the researchers were able to determine the frying factors 
that maximize the nutritional quality of fried fish. This method could be integrated in the control of professional fryers or robots monitoring fryers, and it is also applicable to optimize other food processes [239]. In other studies, prototypes were created, like Chef Watson [240] or RecipeScape [241], to support cognitive tasks of food design i.e. creating recipes or menus, and the design of food presentation in dishes. All of these intelligent capabilities of SAE are, indeed, valuable because, in FS businesses, not only highly trained chefs work but also novices and workers with fewer knowledge on culinary techniques or short experience with FS equipment [13] [3].

On the other hand, less intelligence has been included in the control of the actuators of SAE, as observed in Section III.B. If the machine can perform multiple actions, the decision on which action to execute for a given food, the adjustment of the action to that food, as well as the exchange of the end-tool, nowadays, is dependent on a human for most marketed SAE.

On the contrary, eleven out of the seventeen AE that was found have implemented an adaptive control, at least, for some of the actions they automate. Creator Inc. patented a method for adjusting doneness, by controlling the actuator compressing the patties and the power of the grill [136]. Dishcraft Robotics Inc. machine and OctoChef use Computer Vision (CV) to assess the output of the system actions (cleanliness; complete plunging) and, accordingly, control the next actions of their actuators (e.g. with corrective steps) [166] [179]. Blendid uses AI to adjust the pouring movements in real-time [172]. Alfred uses machine learning to improve the picking actions in weight precision [189] [151], and PuduBot corrects its navigation plans to avoid collisions with obstacles detected through CV [153].

In fact, AI methods can contribute to plan motion under uncertainty, using inputs from environmental status (e.g. monitored food features) and from the interaction of the machine with the environment (e.g. exerted forces). Through AI, robotic manipulators can become truly autonomous and multi-functional like FS human staff. This way, they can be moved to different workstations, as needed, and support FS workers in a broader way. Research in this field has been progressing at a good pace, being this the reason for which several AE already implements adaptive control strategies. For instance, some researchers created CV procedures to classify liquids of different viscosity that are difficult to distinguish (using images of the liquid surface, in motion, as input to nearest neighbor and polynomial regression classifiers) [242] as well as to learn dynamical models of liquid flow (by applying the Lucas-Kanade CV method to images of two stereo cameras, for 2D liquid flow estimation, and a tailored $3 \mathrm{D}$ reconstruction method to obtain the 3D flow) [243], to adapt parameters in the control of pouring actions. Expectation Maximization-based Reinforcement learning (RL) was used by others to learn policies for tossing food and to, more generally, allow a robot to acquire new motor skills from Dynamic Movement Primitives encoding the skill demonstration by a human [209]. Inverse RL (specifically, Generative Adversarial Imitation Learning) was also used to plan the arrangement of food in serving plates like experts do [244]. Recurrent Neural Networks (6 fully connected layers and 2 recurrent layers with 30 units each) were used to learn/model the physical dynamics of cutting food (fruits, vegetables, cake) for a Model Predictive Controller [245], and other studies developed procedures fusing RGB-D image analysis (object segmentation, nearest neighbors correspondences) with physical modelling (finite element method) of non-rigid deformable food, like pizza dough, to track the object while it is being elastically deformed and, this way, support complex food manipulation [246]. Similar approaches could be studied to learn the policies, and identify the environmental inputs that modulate them, for the set of actions listed in Section IV.D, which, so far, are found difficult to automate. Organizing the studies by the clusters of our taxonomy may help finding common strategies among different actions, speeding up the discovery of policies.

Different fields of AI also open up the possibility to use touchless interfaces, like voice (e.g. through Natural Language Processing and Speech Recognition [247] [248]) or gestures (e.g. with CV [248] [249]), which favor hygiene. A number of attempts have been carried out to create RL-based dialogue systems, but training is still dependent on carefully engineered features (to describe the dialogue state, the set of action for the interaction, etc.) [236] [237], being inefficient and difficult to scaleup. So, other researchers have been studying Deep RL methods to learn both dialogue policies and features (e.g., [250] that share their dialogue system to public). Even though, to deal with multiple tasks, Deep RL also faces the scalability problem. So, for example, [251] proposed a three-stage training with a network of deep reinforcement learners (e.g., deep Q-networks [252]) instead of a single learner, which exhibited more scalability and yielded successful dialogues. Further to this is the extraction of emotions and opinions from natural speech, that is a large topic involving, e.g., sentiment analysis [253], with potential to improve human-machine dialogues including those on food evaluation [254]. Finally, despite the envisioned benefits of touchless interfaces, it is necessary to study if these are as effective and efficient as the current ones (i.e. mechanical buttons and text input), as well as robust enough to allow the exchange of information in the noisy and dirty FS environment. To this end, some studies gave the first steps, proving that tailored multimodal audio-tactile feedback related to virtual buttons [255] and haptic knobs [256] improve the robustness of the interaction in FS environments.

To conclude, it is worth noting the relevance (especially for the design of emotionally intelligent/responsive FS robots) of the past literature on Machine Learning [257] and Deep Learning [258] [259] strategies of facial expressions recognition. In addition, recent studies (under food emotion research) are of particular interest for FS robotics, for they have analyzed facial expressions (recognized with CV software applications like FaceReader ${ }^{\mathrm{TM}}$ ) and related these with food and beverage taste ratings [260] [261], identified ethnic differences in various facial expressions resulting from a same food tasting [262], and showed that facial expressions reflect the level of food-specific satiety [263]. These studies not only reveal the viability and usefulness of monitoring human facial expressions for robots that must interact with human FS workers/clients (e.g., to receive feedback on food prepared by the robot), but 
also give specific insights on how robots can interpretate facial expressions resulting from food stimuli.

\section{H. Core techniques of robotics used in AE for FS}

This article reviewed several AE that uses a number of core techniques of robotics, mentioned in previous sections with the description of the AE. These techniques are highlighted here in a nutshell:

- The use of flexible structures with multi-DoFs (articulated robotic arms, as Blendid, Cafe X, Pazzi, Flippy and others) - these can be more easily re-programmed than SAE to perform different actions; plus, the design of the structure itself is not tailored to specific actions; this allows to have a single machine (so, a smaller occupied space) performing various actions up to complete tasks;

- Perception - the use of multiple, embedded sensors (as in Penny, Alfred, OctoChef...) to monitor the environment and the objects with which the machine interacts, including sensors of force/torque, vision, temperature, and others;

- Force control [264] - the integration of contact forces in the machine control for compliant movements in contact with food, people, or tools (such as, e.g., Alfred does).

- Use of Artificial Intelligence in the machine control integration of adaptive algorithms, in the machine control (as with Blendid or Alfred), to increase the robustness of the action execution to different objects/food, or to navigate avoiding collision (as with Penny, HolaBot, PuduBot);

- Ground or ceiling mobile robots - flexible method to move materials (in contrast to, e.g., conveyor belts);

- SLAM technique [265] - environment mapping and selflocalization allow the navigation in unstructured, dynamic settings (again, in contrast to, e.g., conveyor belts);

- Advanced human/machine interfaces - using social features (e.g., an expressive face, like in PuduBot) or collaborative robots (like with Blendid, Flippy, Alfred, OctoChef...).

These techniques differentiate robotics from traditional automation and clearly lend superior attributes to $\mathrm{AE}$ in comparison to simply automatic SAE.

\section{Brief note on the potential impacts of FS automation in economy and employment}

Recent estimates show that $73 \%$ of accommodation and FS activities are automatable [266]. Interestingly, Ivanov et al. [267] observed that countries most interested in robotic labor are often those facing a demographic decline and, according to IFR [268], Asian-Pacific countries are the largest employers of robots in the world. The use of robots is often advocated as beneficial for the differentiation from competitors and to respond to high flows of customer needs/demands [267]. Hence, it has been often forecasted that investments in robotics will be advisable or even mandatory in the future, to remain competitive in the market [266]. Furthermore, automation does not carry some of the problems that work law poses today, such as occupational illness/injury, discrimination, retaliation, and excessive work hours [266].

Even so, studies effectively showing (rather than projecting or speculating) the impact of automation/robotics on economics and employment are rare (and even more if focused on FS).

For example, there are no studies [267] literally assessing the effects of adopting robots on redesign/re-structure of jobs. Only Tanizaki et al. [269] actually created a model to determine shift scheduling between robots and employees (accounting different trade-offs aimed at, simultaneously, meeting managerial needs and the satisfaction of the workers), but the method was not validated in a real FS establishment.

Likewise, [270] reported that around half of jobs' activities of today could be automated by 2055 , with a consequent shift of about 175 million jobs by 2022 [271]. However, these reports do not give specific numbers for the FS sector alone. Vermeulen et al. (2018) summarized three main scenarios on the advance of employment upon the introduction of robotics or AI, and found support for the scenario in which, after a first decrease, employment of humans returns to the previous level due to an higher advancement of the workers as compared to automation because of the generation of new jobs both directly linked to robotics (e.g., in the development of robotics technology) and indirectly linked (e.g., in components producers, education, leisure, traveling, sport, lifestyle, entertainment, arts, culture).

Ivanov et al. [267] reported that, while most scientific literature assumes a steep advance of robotics soon, newer papers show that robotic capabilities and costs of labor (manual versus robotic cost) will be major factors influencing automation deployment. Present low wages of automatable jobs lead to a slow adoption of robots but, as innovation proceeds, machines tend to inexorably get more capable and cheaper over time [266]. Additionally, some suppliers of the AE reviewed in this article offer options of distributed costs, that may be more affordable for FS businesses. For instances, Picnic provides their system and its maintenance with a monthly subscription fee rather than an upfront cost [140]. Likewise, Dexai Robotics Inc. only charges for every use [151]. In turn, Dishcraft Robotics Inc. offers a centralized dishwashing service, that provides clean dishes to FS businesses, instead of selling their system. Dishes are washed at Dishcraft Robotics Inc. facilities and, then, transported to the FS house (like tablecloths washing, that can be also outsourced) [141].

Finally, the economic benefit of automation seems to depend on the characteristics of the tasks, as well. For instance, Accorsi et al. [272] proposed a method to assess the payback of automation of the end-of-line in catering kitchens (manual and poorly added value tasks as weighting, packing, and labelling meals) by means of cobots. They concluded that the payback is influenced by the size of the production lot and the number of lots processed per day.

\section{CONCLUSION}

Foodservice staff often risk their health and well-being at work. This could be avoided if more autonomously actuated machines were available. Therefore, this article aimed to encourage the development of a new field of robotics research 
dedicated to design these type of machines for FS in a human/worker-centered framework.

Several basic actions compose the physical tasks of FS workers. Thus, a two-level taxonomy was proposed that systematically clusters these actions, primarily, by their purpose and, secondly, by a fundamental characteristic or status of the food involved. The resulting 16 categories may be useful to organize future studies on how FS workers execute these actions, to inspire the design of control strategies for FS robots. The structure of the taxonomy also guided our critical review of single-action equipment (SAE) and advanced equipment (AE) currently available for FS.

AE can execute complete tasks in a workstation or room and, thus, eliminate their dangers and negative effects on the workers' health. The most frequent benefit offered by AE is the avoidance of hot and humid environments, like the grill, fryer or stove, and the dishwashing rooms. Presently, the majority of $\mathrm{AE}$ is a custom-built machine, for which several novel mechanisms are being invented. When an industrial robot is included, typically, a cobot is chosen. Nevertheless, humanrobot collaboration is rarely implemented. Indeed, this option must be analyzed for the specific context, as it may not be the ideal solution for all scenarios. Lastly, rarely and very poor social behaviors have been implemented in FS robots, so far, despite the benefits envisioned by research. This is a robot skill that still lacks demonstration of usefulness in real FS scenarios.

$\mathrm{SAE}$ is, still, more common than AE, in FS businesses. However, SAE is marked by a low flexibility and a lack of autonomy, that could be improved if Artificial Intelligence (AI) would be applied in the control of its actuation. In turn, several AE already implements an adaptive control for, at least, some of the actions they automate. This is being possible due to the research advances in several disciplines of AI, including Computer Vision, Reinforcement and Deep Learning, applied to both food recognition and manipulation.

Still, we found evidences that some categories of actions are rarely automated (either in SAE as in AE), especially a few aimed at separating solid-solid food parts, moving food between workstations or independent appliances in the kitchen, introduce food into another solid food or recipient, and other specific actions, like e.g. sewing food. Research seems to be missing on the policies to automatically execute these complex actions under different conditions.

\section{ACKNOWLEDGMENT}

The authors sincerely thank all members of the Chef Academy and The Research Hub of Electrolux Professional SpA, and the Computer-Integrated Technology for Robotics Surgery laboratory of The BioRobotics Institute of Scuola Superiore Sant'Anna, for supporting this research.

\section{REFERENCES}

[1] US Department of Labor - Bureau of Labor Statistics, "Food Services and Drinking Places: NAICS 722 - Workforce Statistics," 2019. [Online]. Available: https://www.bls.gov/iag/tgs/iag722.htm. [Accessed 19 November 2019].
[2] National Restaurants Association, "National Statistics - The size and scope of the U.S. restaurant industry," 2019. [Online]. Available: https://restaurant.org/research/restaurant-statistics/restaurant-industryfacts-at-a-glance. [Accessed 28 October 2019].

[3] V. J. Wildes, "Attracting and retaining food servers: How internal service quality moderates occupational stigma," International Journal of Hospitality Management, vol. 26, no. 1, pp. 4-19, 32007.

[4] C. G. Beehner and M. J. Blackwell, "The impact of workplace spirituality on food service worker turnover intention," Journal of Management, Spirituality and Religion, vol. 13, no. 4, pp. 304-323, 1 102016.

[5] Bureau of Labor Statistics, "Hospitality industry turnover rate ticked higher in 2018," National Restaurant Association, 9 May 2019. [Online]. Available: https://restaurant.org/Articles/News/Hospitalityindustry-turnover-rate-ticked-higher. [Accessed 28 October 2019].

[6] K. Johnson, "Towards an Understanding of Labour Turnover," Service Industries Review, vol. 1, no. 1, pp. 4-17, 1981.

[7] G. Rowley and K. Purcell, "'As cooks go, she went': is labour churn inevitable?," International Journal of Hospitality Management, vol. 20, no. 2, pp. 163-185, 2001.

[8] S. Michie, "Causes and management of stress at work," Occupational and environmental medicine, vol. 59, no. 1, pp. 67-72, 2002.

[9] F. F. Chiang, T. A. Birtch and H. K. Kwan, "The moderating roles of job control and work-life balance practices on employee stress in the hotel and catering industry," International Journal of Hospitality Management, 2010.

[10] Y. Haruyama, H. Matsuzuki, S. Tomita, T. Muto, T. Haratani, S. Muto and A. Ito, "Burn and Cut Injuries Related to Job Stress among Kitchen Workers in Japan," Industrial Health, pp. 113-120, 2014.

[11] H. J. Chang, J. W. Kim, S. Y. Ju and E. S. Go, "How do the work environment and work safety differ between the dry and wet kitchen foodservice facilities?," Nutrition Research and Practice, vol. 6, no. 4, pp. 366-374, 82012.

[12] C. Achutan, "Assessment of noise exposure in a hospital kitchen," Noise and Health, vol. 11, no. 44, pp. 145-150, 172009.

[13] National Restaurants Association, "2019 Restaurant Industry fact sheet," 2019. [Online]. Available:

https://restaurant.org/Downloads/PDFs/Research/SOI/restaurant_indus try_fact_sheet_2019.pdf. [Accessed 28 October 2019].

[14] M. A. Bonn and L. R. Forbringer, "Reducing turnover in the hospitality industry: an overview of recruitment, selection and retention," International Journal of Hospitality Management, 1992.

[15] D. T. Jaffe, "The healthy company: Research paradigms for personal and organizational health.," in Organizational Risk Factors for Job Stress, 2 ed., S. M. L. Sauter, Ed., Washington, DC, American Psychological Association, 1996, p. 19.

[16] S. Cartwright and C. L. Cooper, "ASSET: An organisational stress screening tool-The management guide," Manchester, UK: Robertson/Cooper Ltd, 2002.

[17] P. Tongchaiprasit and V. Ariyabuddhiphongs, "Creativity and turnover intention among hotel chefs: The mediating effects of job satisfaction and job stress," International Journal of Hospitality Management, vol. 55, pp. 33-40, 152016.

[18] M. A. Kompier, C. L. Cooper and S. A. Geurts, "A multiple case study approach to work stress prevention in Europe," European Journal of Work and Organizational Psychology, vol. 9, no. 3, pp. 371-400, 92000.

[19] B. M. Noone and R. C. Coulter, "Applying modern robotics technologies to demand prediction and production management in the quick-service restaurant sector," Cornell Hospitality Quarterly, vol. 53, no. 2, pp. 122-133, 52012.

[20] Meticulous Research, "Food Robotics Market - Global Opportunity Analysis and Industry Forecast (2019-2025)," March 2019. [Online]. Available: https://www.meticulousresearch.com/product/foodrobotics-market-4957/. [Accessed 10 June 2019].

[21] International Federation of Robotics (IFR), "WR Service Robots 2019 - Contents," 2019. [Online]. Available: 
https://www.ifr.org/downloads/press2018/Contents_WR_Service_Rob ots_2019.pdf. [Accessed 20 November 2019].

[22] P. Y. Chua, T. Ilschner and D. G. Caldwell, Robotic manipulation of food products - A review, vol. 30, 2003, pp. 345-354.

[23] R. Bogue, "The role of robots in the food industry: A review," Industrial Robot, vol. 36, no. 6, pp. 531-536, 2009.

[24] J. O. Gray and S. T. Davis, "Robotics in the food industry: An introduction," in Robotics and Automation in the Food Industry: Current and Future Technologies, Elsevier Ltd., 2012, pp. 21-35.

[25] G. Ahmad Nayik, "Robotics and Food Technology: A Mini Review," Journal of Nutrition \& Food Sciences, vol. 05, no. 04, 2015.

[26] Z. H. Khan, A. Khalid and J. Iqbal, Towards realizing robotic potential in future intelligent food manufacturing systems, vol. 48, Elsevier Ltd, 2018, pp. 11-24.

[27] U.S. Department of Agriculture Food and Nutrition Service and National Food Service Management Institute, A Guide to Centralized Foodservice Systems, National Food Service Management Institute, 2002.

[28] P. M. Lin and T. Baum, "The Meaning of Applied Creativity in the Culinary Industry," International Journal of Hospitality and Tourism Administration, vol. 17, no. 4, pp. 429-448, 1102016.

[29] S. Y. Park, S. Kim and L. Leifer, "“Human Chef" to "Computer Chef": Culinary Interactions Framework for Understanding HCI in the Food Industry," in Kurosu M. (eds) Human-Computer Interaction. User Interface Design, Development and Multimodality. HCI 2017, Springer, Cham, 2017.

[30] A. Piselli, M. Simonato and B. Del Curto, "Holistic approach to materials selection in professional appliances industry," in $D S$ 84: Proceedings of the DESIGN 2016 14th International design conference, Dubrovnik, Croatia, 2016.

[31] S. H. Ivanov, C. Webster and K. Berezina, "Adoption of robots and service automation by tourism and hospitality companies," Revista Turismo \& Desenvolvimento, vol. 27, no. 28, pp. 1501-1517, 2017.

[32] J. Murphy, C. Hofacker, U. Gretzel and others, "Dawning of the age of robots in hospitality and tourism: challenges for teaching and research," European Journal of Tourism Research, vol. 15, pp. 104$111,2017$.

[33] J. Murphy, U. Gretzel and C. Hofacker, "Service Robots in Hospitality and Tourism: Investigating Anthropomorphism," 15th APacCHRIE Conference, 2017.

[34] C. Barrows and E. T. Vieira, "Recommendations for the Development of a New operational classification System For The Foodservice Industry," Journal of Hospitality and Tourism Research, vol. 37, no. 3, pp. 349-376, 82013.

[35] Executive Office Of The President Office Of Management And Budget, "North American Industry Classification System," 2017.

[36] S. R. Labensky, A. M. Hause, F. Malley, P. Martel, S. Sicoli, A. Bevan and R. Embery, On Cooking: A Textbook of Culinary Fundamentals, 5 ed., Pearson Education Limited, 2014.

[37] NSF International, "Commercial Food Equipment Standards," 2019. [Online]. Available: http://www.nsf.org/services/by-type/standardspublications/food-equipment-standards. [Accessed 09 December 2019].

[38] International Organization for Standardization, "ISO 8373: 2012 (en) Robots and robotic devices - Vocabulary," 2012.

[39] International Federation of Robotics (IFR), "Demystifying Collaborative Industrial Robots," International Federation of Robotics, Oct 2019. [Online]. Available:

https://ifr.org/downloads/papers/IFR_Demystifying_Collaborative_Ro bots_Update_2019.pdf. [Accessed July 2020].

[40] R. Lumia, J. Fiala and A. Wavering, "The NASREM robot control system standard," Robotics and Computer-Integrated Manufacturing, vol. 6, no. 4, p. 303-308, 1989.

[41] M. e. a. Beetz, "The Assistive Kitchen - A Demonstration Scenario for Cognitive Technical Systems," in The 17th IEEE International Symposium on Robot and Human Interactive Communication, 2008 RO-MAN, Munich, Germany, 2008.
[42] P. Turaga, R. Chellappa, V. S. Subrahmanian and O. Udrea, "Machine recognition of human activities: A survey," IEEE Transactions on Circuits and Systems for Video Technology, vol. 18, no. 11, pp. 14731488, 112008.

[43] M. Sadeghi, M. E. Andani, F. Bahrami and M. Parnianpour, "Trajectory of human movement during sit to stand: A new modeling approach based on movement decomposition and multi-phase cost function," Experimental Brain Research, vol. 229, no. 2, pp. 221-234, 2013.

[44] H. M. Schambra, A. Parnandi, N. J. Pandit, J. Uddin, A. Wirtanen and D. M. Nilsen, "A taxonomy of functional upper extremity motion," Frontiers in Neurology, vol. 10, no. JUL, 2019.

[45] P. Jones and A. Heulin, "Foodservice systems - generic types, alternative technologies and infinite variation," Journal of Foodservice Systems, vol. 5, p. 299, 1990.

[46] B. Davis, A. Lockwood, I. Pantelidis and P. Alcott, Food and Beverage Management, Routledge, 2013.

[47] O. Chadwicke Jenkins and M. J. Matarić, "Deriving Action and Behavior Primitives from Human Motion Data," in IEE/RSJ Conference on Intelligent Robots and Systems, Lausanne, Switzerland, 2002.

[48] D. Del Vecchio, R. M. Murray and P. Perona, "Decomposition of human motion into dynamics-based primitives with application to drawing tasks," Automatica, vol. 39, no. 12, pp. 2085-2098, 122003.

[49] S. Manschitz, M. Gienger, J. Kober and J. Peters, "Probabilistic Decomposition of Sequential Force Interaction Tasks into Movement Primitives," in IEEE/RSJ International Conference on Intelligent Robots and Systems (IROS), Daejeon, Korea, 2016.

[50] Y. P. Ivanenko, R. E. Poppele and F. Lacquaniti, "Five basic muscle activation patterns account for muscle activity during human locomotion," Journal of Physiology, vol. 556, no. 1, pp. 267-282, 14 2004.

[51] C. Alessandro, I. Delis, F. Nori, S. Panzeri and B. Berret, "Muscle synergies in neuroscience and robotics: From input-space to taskspace perspectives," Frontiers in Computational Neuroscience, no. APR 2013, 342013.

[52] M. Sanzari, V. Ntouskos and F. Pirri, "Discovery and recognition of motion primitives in human activities," PLoS ONE, vol. 14, no. 4, 14 2019.

[53] R. Hamada, I. Ide, S. Sakai and H. Tanaka, "Structural analysis of cooking preparation steps in Japanese," in Proceedings of the fifth international workshop on on Information retrieval with Asian languages, 2000.

[54] Y. Nakauchi, T. Suzuki, A. Tokumasu and S. Murakami, "Cooking Procedure Recognition and Inference in Sensor Embedded Kitchen," in The 18th IEEE International Symposium on Robot and Human Interactive Communication, Toyama, Japan, 2009.

[55] Y. Shidochi, T. Takahashi, I. Ide and H. Murase, "Finding replaceable materials in cooking recipe texts considering characteristic cooking actions," in Proceedings of the ACM multimedia 2009 workshop on Multimedia for cooking and eating activities, 2009.

[56] V. Marttila, "Mincing Words: A Diachronic View on English Cutting Verbs," in Proceedings of Symposium on New Approaches in English Historical Lexis Somerville, 2009.

[57] H. Nanba, Y. Doi, M. Tsujita, T. Takezawa and K. Sumiya, "Construction of a cooking ontology from cooking recipes and patents," in Proceedings of the 2014 ACM International Joint Conference on Pervasive and Ubiquitous Computing: Adjunct Publication, 2014.

[58] B. Y. Jeong, "Cooking processes and occupational accidents in commercial restaurant kitchens," Safety Science, vol. 80, pp. 87-93, 1 122015.

[59] S. Tsuji, Japanese Cooking: a simple art, 1 ed., Kodansha International, 1980.

[60] M. Hazan, Essentials of classic Italian cooking, 1 ed., New York: Alfred A. Knopf, 2010.

[61] K. J. Harris, "On cooking: A textbook of culinary fundamentals: by Sarah R. Labensky and Alan M. Hause, Prentice Hall, New Jersey. 
ISBN 0-13-194515-7," International Journal of Hospitality Management, vol. 14, no. 1, pp. 99-100, 131995.

[62] A. M. Tomei (Chef Instructor), "On Cooking: A Textbook of Culinary Fundamentals by Sarah R. Labensky and Alan M. House with Steven Labensky and Priscilla Martel," Food, Culture \& Society, vol. 11, no. 3, pp. 404-407, 192008.

[63] MathWorks, "Prepare Text Data for Analysis," [Online]. Available: https://www.mathworks.com/help/textanalytics/ug/prepare-text-datafor-analysis.html. [Accessed Dec 2019].

[64] "RecipeTips," [Online]. Available: https://www.recipetips.com/glossary.asp. [Accessed 03 2020].

[65] Oxford Dictionaries and Oxford University Press, Concise Oxford American Dictionary, Oxford University Press, USA, 2006.

[66] S. Rossi, G. Gai and R. De Benedetto, "Functional and perceptive aspects of non-stick coatings for cookware," Materials and Design, vol. 53, pp. 782-790, 2014.

[67] S. Rodgers, "The state of technological sophistication and the need for new specialised tertiary degrees in food services," International Journal of Hospitality Management, 2009.

[68] S. Rodgers, "Innovation in food service technology and its strategic role," International Journal of Hospitality Management, vol. 26, no. 4, pp. 899-912, 122007.

[69] Y. Sun, L. Guan, Z. Chang, C. Li and Y. Gao, "Design of a low-cost indoor navigation system for food delivery robot based on multisensor information fusion," Sensors (Switzerland), vol. 19, no. 22, 2019.

[70] A. Eksiri and A. Eksiri, "Restaurant Service Robots Development in Thailand and Their Real Environment Evaluation," Journal of Robotics and Mechatronics, vol. 27, no. 1, 2015.

[71] T. Shimmura, R. Ichikari, T. Okuma, H. Ito, K. Okada and K. Okada, "Service robot introduction to a restaurant enhances both labor productivity and service quality," in 13th CIRP Conference on Intelligent Computation in Manufacturing Engineering, Naples, Italy, 2019.

[72] P. Elinas, J. Hoey, D. Lahey, J. D. Montgomery, D. Murray, S. Se and J. J. Little, "Waiting with José, a vision-based mobile robot," in Proceedings - IEEE International Conference on Robotics and Automation, 2002.

[73] Z. Fu, W. X. Yan, W. Ma and Y. Zhao, "The auto-cooking system for Chinese traditional dishes," Assembly Automation, vol. 30, no. 1, pp. 75-81, 2010.

[74] B. Li, Y. Chen, Z. Deng and W. Xu, "Conceptual design and analysis of the 2T1R mechanism for a cooking robot," Robotics and Autonomous Systems, vol. 59, no. 2, pp. 74-83, 2011.

[75] Electrolux Professional SpA, "SkyLine Pro Forno digitale con iniettore di vapore, gas 20 GN 2/1 217985," [Online]. Available: https://www.electroluxprofessional.com/it/pd/cook-chill/forni-skylinepro/skyline-pro-gas/skyline-pro-20-gn-2-1-gas/skyline-pro-fornodigitale-con-iniettore-di-vapore-gas-20-gn-2-1-217985/\#attachments3. [Accessed Dec 2019].

[76] NSF International, "Testing, Inspection and Certification - Food," 2020. [Online]. Available: https://www.nsf.org/testing/food. [Accessed Aug 2020].

[77] Intertek Group plc, "Performance Testing - Benchmark and Comparison Testing," [Online]. Available: https://www.intertek.com/performance-testing/benchmark/. [Accessed ug 2020].

[78] B. M. Josiam, R. Malave, C. Foster and W. Baldwin, "Assessing quality of food, service and customer experience at a restaurant: The case of a student-run restaurant in the USA Movie Induced Tourism View project Culinary Tourism View project," Journal of Services Research, vol. 14, no. 1, 2014.

[79] F. Burlon, "Energy efficiency of combined ovens," in Energy Procedia, 2015.

[80] European Patent Office, "Espacenet Patent search," [Online]. Available: https://worldwide.espacenet.com/.

[81] S. K. Verma, W. R. Chang, T. K. Courtney, D. A. Lombardi, Y. H. Huang, M. J. Brennan, M. A. Mittleman and M. J. Perry, "Workers' experience of slipping in U.S. limited-service restaurants," Journal of Occupational and Environmental Hygiene, vol. 7, no. 9, pp. 491-500, 92010.

[82] Rational AG, "Mobile oven rack. Model 20-2/1.," 2019. [Online]. Available: https://www.rational-online.com/en_gb/accessories/mobileoven-rack/mobileovenrack-type-20-2-1.php . [Accessed Dec 2019].

[83] C. Hsin-I Feng, "The Tale of Sushi: History and Regulations," Comprehensive Reviews in Food Science and Food Safety, vol. 11, no. 2, pp. 205-220, 32011.

[84] Y. Shiraishi, "Circulative catering table". USA, Washington, DC: U.S. Patent and Trademark Office Patent US3895691A, 22071975.

[85] Meiko Maschinenbau GmbH \& Co. KG, "Conveying solutions," [Online]. Available: https://en.meiko.it/en/products/conveyingsolutions/. [Accessed Dec 2019].

[86] Kura Sushi Inc., "Comfort and fun," [Online]. Available: https://www.kurasushi.co.jp/quality/comfotable.php?SLANG=ja\&TL ANG $=$ en $\&$ XMODE $=0 \&$ XCHARSET $=U T F-8 \&$ XJSID $=0$. [Accessed Dec 2019].

[87] K.-C. LUO, "Apparatus for screening plate". Taiwan Patent M325055, 03082007.

[88] Hong Chiang Technology Industry Co., LTD., "Sushi Plate Slot System," 2019. [Online]. Available: https://www.hongchiang.com.tw/en/product/Sushi-Plate-SlotSystem/Sushi_Plate_Slot_System.html. [Accessed Dec 2019].

[89] A. Epple, "The "Automat". A History of Technological Transfer and the Process of Global Standardization in Modern Fast Food around 1900," Food and History, vol. 7, no. 2, pp. 97-118, 12009.

[90] Chowbotics ${ }^{\mathrm{TM}}$, "Sally The Robot," 2019. [Online]. Available: https://www.chowbotics.com/our-solutions/ .

[91] Henny Penny Corp., "Evolution Elite Brochure," 02 2015. [Online]. Available: https://www.hennypenny.com/wpcontent/uploads/2015/02/Evolution-Elite-Brochure-11-1-15.pdf. [Accessed Dec 2019].

[92] L2F Inc., "Kitchen Automation - Conveyor Oven Robotic Interface," [Online]. Available: https://www.12finc.com/kitchen-automation. [Accessed Jan 2020].

[93] Kenwood Ltd., "Major Size Potato Peeler AT445," 2017. [Online]. Available: https://www.kenwoodworld.com/en-id/products/foodmixers-kitchen-machines/chef-and-major-attachments/at445-potatopeeler-awat445001. [Accessed Dec 2019].

[94] Electrolux Professional SpA, "Product Catalog Food Preparation," 2019. [Online]. Available: https://tools.professional.electrolux.com/Mirror/Doc/BR/BR_BR9JE00129_1_5_1_1_brochure\%20Food\%20Preparation\%20LR.pdf. [Accessed 2711 2019].

[95] Electrolux Professional SpA, "Breading Station SmartSift MONO Breading station, 1 module with neutral base," [Online]. Available: https://www.electroluxprofessional.com/pl/pd/refrigerationequipment/refrigerated-and-freezer-counters/breadingstations/breading-station-smartsift-mono-breading-station-1-modulewith-neutral-base-727810/. [Accessed June 2021].

[96] Electrolux Professional SpA, "Electrolux Professional Fryers HP," [Online]. Available: https://tools.electroluxprofessional.com/Mirror/Doc/BR/BR_BR9JE00116_2_5_1_5_EPR_brochure_XP\%20Fryers\%20HP_LR.pdf?v ersion=1624144992. [Accessed Dec 2019].

[97] Sirman SpA, "Slow juicers - Ektor 37," 2013. [Online]. Available: https://www.sirman.com/en/product-list/slow-juicers/Ektor-37detail.html. [Accessed Dec 2019].

[98] Sirman SpA, "Ice Crusher," 2013. [Online]. Available: https://www.sirman.com/en/product-list/Ice-Crusher.html. [Accessed Dec 2019].

[99] Robot Coupe USA Inc., "Vegetable Preparation Machines - CL 50 Gourmet," 2018. [Online]. Available: https://www.robotcoupe.com/usa/en_US/p/vegetable-preparation-machines-cl-50gourmet/18352. [Accessed Dec 2019].

[100] Electrolux Professional SpA, "Food slicers $300 \mathrm{~mm}$ Gravity Slicer, gear transmission, semi-automatic," 2021. [Online]. Available: 
https://www.electroluxprofessional.com/pd/foodpreparation/slicers/gravity-food-slicers/gravity-slicers-geartransmission/food-slicers-300-mm-gravity-slicer-gear-transmissionsemi-automatic-601009/. [Accessed June 2021].

[101] Electrolux Professional SpA, "Stainless Steel Electric Bread Slicer (603265)," [Online]. Available: https://www.electroluxprofessional.com/pd/foodpreparation/slicers/bread-slicer-cpx/bread-slicers-stainless-steelelectric-bread-slicer-603265/. [Accessed May 2021].

[102] Sirman SpA, "Drake tenderizer and stripes cutting machine," [Online]. Available: https://www.sirman.com/en/productlist/tenderizer/drake/Drake-detail.html. [Accessed Dec 2020].

[103] Kenwood Ltd., "Trenette Metal Pasta Cutter AT973A," 2017. [Online]. Available: https://www.kenwoodworld.com/enid/products/food-mixers-kitchen-machines/chef-and-majorattachments/at973a-trenette-metal-pasta-cutter-awat973a01. [Accessed Dec 2019].

[104] Autec Inc., "Sushi Robots," 2019. [Online]. Available: https://www.sushimachines.com/all-sushi-robot-machine-models/. [Accessed Dec 2019].

[105] Henny Penny Corp., "Automatic Breading Machine datasheet," Jan 2019. [Online]. Available: https://www.hennypenny.com/wpcontent/uploads/2019/01/BM-110-data-sheet-12312018.pdf. [Accessed Dec 2019].

[106] Alto-Shaam Inc., "AR-6G VERTICAL GAS ROTISSERIE," 2020. [Online]. Available: https://www.altoshaam.com/en/products/rotisseries/ar-6g. [Accessed May 2020].

[107] Roto-Flex Oven Co., "Roto-Flex Pizza Ovens," [Online]. Available: https://www.rotoflexoven.com/. [Accessed May 2020].

[108] Electrolux Professional SpA, "Thermaline ProThermetic - Boiling and Braising Pans," 2017. [Online]. Available: https://profitex.ua/wpcontent/uploads/2021/01/Thermaline-Prothermetic-Boiling-BraisingPans-2017.pdf. [Accessed June 2021].

[109] Sirman SpA, "Drink mixers," 2013. [Online]. Available: https://www.sirman.com/en/product-list/drink-mixers.html. [Accessed Dec 2019].

[110] Rational AG, "Operating instructions SelfCooking Center®," [Online]. Available: https://www.rationalonline.com/media/downloads/en-xx/manuals/rational-originaloperating-instructions-scc-with-care-control-en-xx.pdf. [Accessed Dec 2019].

[111] Electrolux Professional SpA, "Vacuum packers \& sealer," [Online]. Available: https://www.electroluxprofessional.com/commercialkitchen-equipment/vacuum/. [Accessed Dec 2019].

[112] Kenwood Ltd., "Pasta Roller AT970A," 2021. [Online]. Available: https://www.kenwoodworld.com/en-id/products/food-mixers-kitchenmachines/chef-and-major-attachments/at970a-metal-pasta-rollerawat970a01. [Accessed June 2021].

[113] J. Yang, L. Wu and J. Liu, "Method for rapidly making a 3-D food object". USA Patent US6280784B1, 28082001.

[114] Natural Machines, "Foodini. Real Food Freshly Printed," 2020. [Online]. Available: https://www.naturalmachines.com/. [Accessed Jan 2020].

[115] 3D Systems Inc., "The Brill 3D Culinary Studio Powered by 3D Systems," 2020. [Online]. Available: https://www.3dsystems.com/culinary. [Accessed Jan 2020].

[116] byFlow, "3D Food Printer," 2020. [Online]. Available: https://www.3dbyflow.com/. [Accessed Jan 2020].

[117] Choc Edge Ltd., "The world of "3D Chocolate Printing", [Online]. Available: http://chocedge.com/home.html. [Accessed Jan 2020].

[118] Print2Taste GmbH, "3D Food Printer for professionals - Procusini Plug \& Play," [Online]. Available: https://www.procusini.com/. [Accessed Jan 2020].

[119] BeeHex Inc., "Bakery Equipment," [Online]. Available: https://www.beehex.com/bakery-equipment. [Accessed June 2021].

[120] J. I. Lipton, Printable food: the technology and its application in human health, vol. 44, Elsevier Ltd, 2017, pp. 198-201.
[121] H. Jiang, L. Zheng, Y. Zou, Z. Tong, S. Han and S. Wang, 3D food printing: main components selection by considering rheological properties, vol. 59, Taylor and Francis Inc., 2018, pp. 2335-2347.

[122] J. I. Lipton, M. Cutler, F. Nigl, D. Cohen and H. Lipson, Additive manufacturing for the food industry, vol. 43, Elsevier Ltd, 2015, pp. 114-123.

[123] M. Mizrahi, A. Golan, A. B. Mizrahi, R. Gruber, A. Z. Lachnish and A. Zoran, "Digital gastronomy: Methods \& recipes for hybrid cooking," in UIST 2016 - Proceedings of the 29th Annual Symposium on User Interface Software and Technology, 2016.

[124] Z. Liu, M. Zhang, B. Bhandari and Y. Wang, 3D printing: Printing precision and application in food sector, vol. 69, Elsevier Ltd, 2017, pp. 83-94.

[125] B. Pérez, H. Nykvist, A. F. Brøgger, M. B. Larsen and M. F. Falkeborg, "Impact of macronutrients printability and 3D-printer parameters on 3D-food printing: A review," Food Chemistry, vol. 287, pp. 249-257, 3072019.

[126] A. Derossi, M. Paolillo, R. Caporizzi and C. Severini, "Extending the $3 \mathrm{D}$ food printing tests at high speed. Material deposition and effect of non-printing movements on the final quality of printed structures," Journal of Food Engineering, vol. 275, 162020.

[127] N. Jonkers, J. A. van Dommelen and M. G. Geers, "Experimental characterization and modeling of the mechanical behavior of brittle 3D printed food," Journal of Food Engineering, vol. 278, 182020.

[128] Sirman SpA, "hand held mixer - Vortex 75," 2013. [Online]. Available: https://www.sirman.com/en/product-list/hand-heldmixer/vortex/Vortex-75.-detail.html\#. [Accessed 2711 2019].

[129] Hobart Corp., "CLeN Advansys ${ }^{\mathrm{TM}}$ Conveyor Type Commercial Dishwasher," [Online]. Available: https://www.hobartcorp.com/products/commercialdishwashers/conveyor-type/clen-advansys-conveyor-type. [Accessed Jan 2020].

[130] Spyce Inc., "Spyce - Culinary excellence elevated by technology," [Online]. Available: https://www.spyce.com/. [Accessed March 2020].

[131] M. S. Farid, B. E. Knight, L. S. Schlueter, K. T. Rogers, W. L. Ubellacker and S. N. Seidell, "Automated meal production system and apparatus". U.S. Patent 10,154,762, 18 Dec 2018.

[132] Spyce Inc., "Spyce media kit," [Online]. Available: https://www.dropbox.com/s/ibgoanvxl4m13vm/Spyce_Media_Kit_Ro botic_Kitchen_Restaurant_BostonV2.pdf?dl=0. [Accessed Dec 2019].

[133] W. Yan, E. Guan, E. Guan, Z. Fu and Y. Zhao, "Automatic Cooking Robot with a Novel Feeding System," in International Conference on Intelligent Robotics and Applications, 2010.

[134] W. Yan, Z. Fu, Y. Liu, Y. Zhao, X. Zhou, J. Tang and X. Liu, "A novel automatic cooking robot for Chinese dishes," Robotica, vol. 25, no. 4, pp. 445-450, 2007.

[135] Creator Inc., "Imagining a new culinary possibility," [Online]. Available: http://creator.rest/. [Accessed March 2020].

[136] S. Frehn, A. Vardakostas, M. Balsamo, N. Esparza and M. Williams, "System and method for cooking a meat patty". U.S. Patent 9,788,687, 17 Oct 2017.

[137] A. Engel-hall, A. Vardakostas, J. L. McDonald, M. Williams, S. Frehn and A. Soong, "Systems for buttering and toasting bread". U.S. Patent 10,427,313, 1 Oct 2019.

[138] P. Sherman, T. Nicholson, B. Shih and A. Soong, "Modular coveyor apparatus". United States Patent US20190389665A1, 19 Dec 2019.

[139] A. K. Bogard, C. C. Fuller, V. Radke, C. A. Selman and K. E. Smith, "Ground beef handling and cooking practices in restaurants in eight states," Journal of Food Protection, vol. 76, no. 12, pp. 2132-2140, 1 2013.

[140] Otto Robotics Inc. (dba Picnic), "See our system in action," 2020. [Online]. Available: https://www.hellopicnic.com/. [Accessed 30 July 2020].

[141] Dishcraft Robotics Inc., "Dishcraft Solutions," [Online]. Available: https://dishcraft.com/solutions. [Accessed March 2020].

[142] Meiko Maschinenbau GmbH \& Co. KG, "Conveyor dishwashing machines, Automatic dishwashers - Fully automatic," [Online]. 
Available: https://www.meiko.us/en_us/knowledge-base/video/\#1-11. [Accessed March 2020].

[143] Wilkinson Baking Company LLC, "BreadBot, the mini bakery," [Online]. Available: https://www.wilkinsonbaking.com/the-minibakery. [Accessed May 2020].

[144] Blendid, "Blendid," [Online]. Available: https://www.blendid.com/. [Accessed May 2020].

[145] Cafe X Technologies Ltd., "Robotic Coffee Bar," [Online]. Available: https://cafexapp.com/. [Accessed January 2020].

[146] Connected Robotics Inc., "Products," [Online]. Available: https://connected-robotics.com/en/. [Accessed April 2020].

[147] Makr Shakr, "Your robotic bartender," [Online]. Available: https://www.makrshakr.com/. [Accessed January 2020].

[148] Pazzi, "Our Pazzirias," [Online]. Available: https://www.pazzi.co/en/pazzirias/. [Accessed May 2020].

[149] F. Mauch, A. Roennau, G. Heppner, T. Buettner and R. Dillmann, "Service robots in the field: The BratWurst Bot," 2017 18th International Conference on Advanced Robotics, ICAR 2017, no. July, pp. 13-19, 2017.

[150] Miso Robotics, "Miso Robotics - The Future of Food Starts Here," 2018. [Online]. Available: https://misorobotics.com. [Accessed January 2020].

[151] Dexai Robotics Inc., "Meet Alfred," [Online]. Available: https://www.dexai.com. [Accessed January 2020].

[152] Bear Robotics, Inc., "Meet Penny," [Online]. Available: https://www.bearrobotics.ai/products/. [Accessed June 2020].

[153] Pudu Technologies Co. Ltd, "Pudu Products," 2020. [Online]. Available: https://www.pudutech.com/en/product. [Accessed June 2020].

[154] ISO/TC 299 Robotics, "ISO/TS 15066:2016 Robots and robotic devices - Collaborative robots," International Organization for Standardization, 2016.

[155] Industrial Truck Standards Development Foundation (ITSDF), "ANSI/ITSDF B56.5 - 2019, Safety Standard for Driverless, Automatic Guided Industrial Vehicles and Automated Functions of Manned Industrial Vehicles EFFECTIVE 08/12/20," Washington DC USA, 2019.

[156] ISO/TC 110/SC 2 Safety of powered industrial trucks, "ISO 36914:2020 Industrial trucks - Safety requirements and verification Part 4: Driverless industrial trucks and their systems," International Organization for Standardization.

[157] International Federation of Robotics (IFR), "New U.S. Standard Sets the Bar for Industrial Mobile Robot Safety," 13 Feb 2019. [Online]. Available: https://ifr.org/post/new-u.s.-standard-sets-the-bar-forindustrial-mobile-robot-safety. [Accessed Aug 2020].

[158] A. Markis, M. Papa, D. Kaselautzke, M. Rathmair, V. Sattinger and M. Brandstötter, "Safety of Mobile Robot Systems in Industrial Applications," in Proc. of ARW \& OAGM Workshop, 2019.

[159] G. Ochs, C. Anderson, K. Han, B. DeVitis, K. Reinecke, N. Wright, D. Soike and J. M. Turner, "Distributed machine cooperation in assembly". U.S. Patent 10,437,220 B1, 8 Oct 2019.

[160] P. K. M. Birkmeyer Paul M, "Automatic Magnetic Gripper For NonMagnetic Objects". U.S. Patent US10562193B2, 18 Feb 2020.

[161] K. Y. MA, A. E. SOONG, K. M. ANDERSON, P. M. BIRKMEYER, K. M. PETERS, J. C. DOORIS, S. N. BAHL and T. Y. LEE, "Dishwashing conveyance system and method". WO Patent 2020/112909A1, 04 June 2020.

[162] J. Fujimoto, I. Mizuuchi, Y. Sodeyama, K. Yamamoto, N. Muramatsu, S. Ohta, T. Hirose, K. Hongo, K. Okada and M. Inaba, "Picking up dishes based on active groping with multisensory robot hand," in The 18th IEEE International Symposium on Robot and Human Interactive Communication, Toyama, Japan, 2009.

[163] K. Kosuge and et al., "Development of an automatic dishwashing robot system," in IEEE International Conference on Mechatronics and Automation, Changchun, Jilin, China, 2009.
[164] A. Saxena, J. Driemeyer and A. Y. Ng, "Robotic Grasping of Novel Objects using Vision," International Journal of Robotics Research, vol. 27, no. 2, pp. 157-173, 2008.

[165] T. Y. Lee, J. C. Dooris, A. E. Soong, K. B. Sheehy, M. W. Tschudy and T. J. CONE, "Dish stacking cart.". U.S. Patent 10,654,504 B1, 19 May 2020.

[166] K. B. Choi, B. P. P. M. and K. M. Peters, "Intelligent Dishwashing Systems And Methods". U.S. Patent 15/887,686, 08 Aug 2019.

[167] E. Ackerman, "Dishcraft Robotics Takes Over Dishwashing From Humans," IEEE Spectrum, 18 June 2019. [Online]. Available: https://spectrum.ieee.org/automaton/robotics/industrialrobots/dishcraft-robotics-takes-over-dishwashing-from-humans. [Accessed Dec 2019].

[168] Meiko Maschinenbau GmbH \& Co. KG, "Conveyor dishwashing machines, Automatic dishwashers - Fully automatic," [Online]. Available: https://www.youtube.com/watch?v=L-iJDQbnBt4. [Accessed March 2020].

[169] H. A. F. Larsen, "Automated production processes and associated systems, including automated bread making processes". U.S. Patent 8,091,471, 10 Jan 2012.

[170] Wilkinson Baking Company LLC, "Quick Intro to Machine (video)," [Online]. Available: https://www.wilkinsonbaking.com/media-photos.

[171] V. Jain, V. Ayalur and V. Doddabalapur, "Delivery Apparatus For Autonomous System". US Patent 10,676,269, 10102019.

[172] K. Shaw, "How Blendid Blends AI, Robots and Vision to Create a Better Smoothie," Robotics Business Review, 8 Aug 2019. [Online]. Available: https://www.roboticsbusinessreview.com/news/howblendid-blends-ai-robots-and-vision-to-create-a-better-smoothie/. [Accessed June 2020].

[173] X. H. Hu, H. H. J. Sun and P. Y. Kwan, "Method and system for automated food and beverage serving". Patent U.S. 15/201,599, 12 Jan 2017.

[174] W. M. Swartz, "Drink shaker". U.S. Patent 4,003,555, 18 Jan 1977.

[175] Royal Caribbean, "Bionic Bar," 2019. [Online]. Available: https://www.royalcaribbean.com/cruise-dining/bionic-bar. [Accessed Dec 2019].

[176] Robotic Innovations, Inc., "Tipsy Robot," 2017. [Online]. Available: http://thetipsyrobot.com/ . [Accessed Dec 2019].

[177] Makr Shakr, "Makr Shakr - How it works?," [Online]. Available: https://www.youtube.com/watch?v=EivBxP3kqWs.

[178] Y.-L. Chen, Shih-Kai Hsu and Yin-Sheng Ou, "Musculoskeletal Disorders of the Handmade Drinks Workers: A Case Report," in International Conference on Industrial Engineering, Management Science and Application (ICIMSA), 2017.

[179] S. TETSUYA, "Food producing device, food producing system, food producing method, and control program". Japan Patent JP2019180289A (B1), 17 Oct 2019.

[180] Noriko and Yuko, "Takoyaki Recipe," Japanese Cooking 101, 26 Jan 2013. [Online]. Available: https://www.japanesecooking101.com/takoyaki-recipe/. [Accessed Aug 2020].

[181] C. HAMON, S. Roverso and F. CALVARIN, "Automate pour la confection de pizzas". France Patent 3,047,149 B1, 14 Sept 2018.

[182] C. HAMON, S. ROVERSO and F. CALVARIN, "Device for forming a sheeted dough from a dough piece by pressing". U.S. Patent 10,681,916 B2, 16 June 2020 .

[183] C. HAMON, S. ROVERSO and D. RASCLE, "System for handling culinary preparations". U.S. Patent 10,701,943 B2, 07 July 2020.

[184] C. HAMON, S. Roverso and F. CALVARIN, "Device for individually cooking a plurality of culinary preparations". U.S. Patent 10,548,327 B2, 04 Feb 2020.

[185] Connected Robotics, "ロボット食洗システム動作フロー概要 ～\# ロボット\#調理＃お血洗い\#井ぶり," 6 April 2020. [Online]. Available: https://www.youtube.com/watch?v=Z5dcJ18V3dk\&t=3s. [Accessed July 2020].

[186] M. Quigley, B. Gerkey, K. Conley, J. Faust, T. Foote, J. Leibs, E. Berger, R. Wheeler and A. Ng, "ROS: an open-source Robot 
Operating System," in ICRA workshop on open source software, Kobe, Japan, 2009.

[187] R. W. Sinnet, R. Anderson, Z. Z. Vinegar, W. Werst, D. Zito and S. Olson, "Multi-sensor array including an ir camera as part of an automated kitchen assistant system for recognizing and preparing food and related methods". U.S. Patent 2018 / 0345485 A1, 06122018.

[188] R. Sinnet, R. Anderson and W. Werst, "Robotic kitchen assistant including universal utensil gripping assembly". U.S. Patent 2020/0047349 A1, 13022020

[189] "The Tech Of Food - BBC Click," BBC Click, 3 July 2020. [Online]. Available: https://www.youtube.com/watch?v=Ebf28XV8hdw. [Accessed July 2020].

[190] B. Ang, "Robot Lucy at your service at newly opened Rong Heng Seafood," The Strait Times Lifestye, 7 Feb 2016. [Online]. Available: https://www.straitstimes.com/lifestyle/food/robot-lucy-at-yourservice-at-newly-opened-rong-heng-seafood. [Accessed June 2020].

[191] M. Asif, M. Sabeel, Mujeeb-ur-Rahman and Z. H. Khan, "Waiter Robot - Solution to Restaurant Automation," in Proceedings of the 1st student multi disciplinary research conference (MDSRC), Wah, Pakistan, 2015.

[192] J. Fullerton, "Robots Cooked and Served My Dinner," Munchies Food by Vice, 30 August 2017. [Online]. Available: https://www.vice.com/en_us/article/aey9na/robots-cooked-andserved-my-dinner. [Accessed Dec 2019].

[193] "[Money Monster] Rise of autonomous robots amid COVID-19 outbreak," Arirang TV, 24 March 2020. [Online]. Available: https://www.bearrobotics.ai/press/. [Accessed June 2020].

[194] N. Karlsson, E. Di Bernardo, J. Ostrowski, L. Goncalves, P. Pirjanian and M. E. Munich, "The vSLAM algorithm for robust localization and mapping," in Proceedings - IEEE International Conference on Robotics and Automation, 2005.

[195] G. Csorvási, Á. Nagy and I. Vajk, "Near Time-Optimal Path Tracking Method for Waiter Motion Problem," IFAC-PapersOnLine, 2017

[196] F. G. Flores and A. Kecskeméthy, "Time-optimal path planning for the general waiter motion problem," in Mechanisms and Machine Science, vol. 14, Springer Netherlands, 2013, pp. 189-203.

[197] K. Terashima and G. Schmidt, "Motion control of a cart-based container considering suppression of liquid oscillations," in IEEE International Symposium on Industrial Electronics, 1994.

[198] H. Leonpacher, "Trajectory optimisation to reduce sloshing in open liquid filled containers.," 2000.

[199] T. A. Permadi, J. Halomoan and S. Hadiyoso, "Balancing system of tray on waiter robot using complementary filter and fuzzy logic," in Proceedings - International Conference on Industrial Automation, Information and Communications Technology, IAICT 2014, 2014.

[200] J. Lorente, J. M. García, S. Martínez, J. Hernández, C. Balaguer, U. Roboticslab, I. Carlos and M. De, "Waiter robot: advances in humanoid robot research at uc3m," in Open Conference on Future Trends in Robotics, 2016.

[201] S.-Y. Chung and H.-P. Huang, "Predictive Navigation by Understanding Human Motion Patterns," International Journal of Advanced Robotic Systems, www.intechweb.org, vol. 8, no. 1, pp. 5264, 2011.

[202] Hobart Corp., "Food Wrapping Equipment," 2019. [Online]. Available: https://www.hobartcorp.com/products/weighwrap/wrapping-equipment. [Accessed Dec 2019].

[203] Sirman SpA, "Tenderizer T-rex Automec XP," 2013. [Online]. Available: https://www.sirman.com/en/product-list/ tenderizer/t-rex/Trex-Automec-XP-detail.html . [Accessed Dec 2019].

[204] Sirman SpA, "Shell washer LCJ," 2013. [Online]. Available: https://www.sirman.com/en/product-list/shell-washer.html. [Accessed Dec 2019].

[205] Frontline International, "Indoor Waste Cooking Oil Tanks," [Online]. Available: https://www.frontlineii.com/indoor-waste-cooking-oiltanks-frontline. [Accessed Jan 2020].

[206] Restaurant Technologies Inc., "Total Oil Management," 2020. [Online]. Available: https://www.rti-inc.com/solutions/total-oilmanagement. [Accessed Jan 2020].
[207] McDonald's Corporation, "Products Grills (by Welbilt Corp.)," 2019. [Online]. Available: https://mcd.welbilt.us/Products/Grills.. [Accessed Dec 2019].

[208] McDonald's Corporation, "Clamshell Grill Model 38 Manufactured exclusively for McDonald's®," 2001. [Online]. Available: https://static-pt.com/modelManual/TAF38Clamshell_spm.pdf?v=1532466740963. [Accessed Dez 2019].

[209] P. Kormushev, S. Calinon and D. G. Caldwell, "Robot motor skill coordination with EM-based reinforcement learning," in IEEE/RSJ 2010 International Conference on Intelligent Robots and Systems, IROS 2010 - Conference Proceedings, 2010.

[210] W. X. Yan, Z. Fu and Y. Z. Zhao, "Realization of turn-over-wok movement for cooking robot," Industrial Robot, vol. 40, no. 1, pp. 67 76, 2013.

[211] Robotics Business Review (RBR), "Robotics Restaurant Spyce to Renovate Boston Location, Revamp Menu," Robotics Business Review, 15 Nov 2019. [Online]. Available: https://www.roboticsbusinessreview.com/news/robotics-restaurantspyce-to-renovate-boston-location-revamp-menu/. [Accessed Jan 2020]

[212] Universal Robots A/S, "History of the Cobots," [Online]. Available: https://www.universal-robots.com/about-universal-robots/newscentre/the-history-behind-collaborative-robots-cobots/. [Accessed May 2021].

[213] International Federation of Robotics (IFR), "WR Industrial Robots 2019 - Sources \& Methods," 2019. [Online]. Available: https://ifr.org/downloads/press2018/WR\%20Industrial\%20Robots\%20 2019_Chapter_1.pdf. [Accessed Feb 2020].

[214] E. C. Todd, J. D. Greig, C. A. Bartleson and B. S. Michaels, "Outbreaks where food workers have been implicated in the spread of foodborne disease. Part 5. Sources of contamination and pathogen excretion from infected persons," Journal of Food Protection, vol. 71, no. 12, pp. 2582-2595, 2008.

[215] NSF International, "Food Equipment Certification," NSF, 2020. [Online]. Available: https://www.nsf.org/testing/food/productcertification/food-equipment/food-equipment-certification.

[216] Joesel, Bob (North American Association of Food Equipment Manufacturers - Technical Liaison Committee), "What is Certification?," 2017. [Online]. Available: https://www.nafem.org/wpcontent/uploads/2017/01/WhatIsCertification.pdf. [Accessed 09 December 2019].

[217] NSF International, "The NSF Mark," 2020. [Online]. Available: https://www.nsf.org/about-nsf/nsf-mark. [Accessed June 2020].

[218] S. Kolathaya, W. Guffey, R. W. Sinnet and A. D. Ames, "Direct Collocation for Dynamic Behaviors With Nonprehensile Contacts: Application to Flipping Burgers," IEEE Robotics and Automation Letters, vol. 3, no. 4, pp. 3677-3684, 2018.

[219] A. Nussinovitch, Adhesion in foods: Fundamental principles and applications, John Wiley \& Sons, 2017.

[220] R. Ghiselli, B. A. Almanza and S. Ozaki, "Foodservice design: trends, space allocation, and factors that influence kitchen size," Foodservice Research International, vol. 10, no. 2, 1998.

[221] A. D. Alonso and M. A. O'Neill, "Exploring consumers images of open restaurant kitchen design," Journal of Retail and Leisure Property, vol. 9, no. 3, pp. 247-259, 82010.

[222] G. N. Desouza and A. C. Kak, "Vision for Mobile Robot Navigation: A Survey," IEEE Transactions On Pattern Analysis And Machine Intelligence, vol. 24, no. 2, 2002.

[223] N. van Duijkeren, F. Debrouwere, G. Pipeleers and J. K. Swevers Leuven, "Cartesian constrained time-optimal point-to-point motion planning for robots: the waiter problem," in Benelux Meeting on Systems and Control, Date: 2015/03/24-2015/03/26, Lommel, Belgium, 2015.

[224] Miso Robotics, "The Rail System, Future Innovations," 2019. [Online]. Available: https://invest.misorobotics.com/. [Accessed July 2020]. 
[225] C. S. Franklin, E. G. Dominguez, J. D. Fryman and M. L. Lewandowski, "Collaborative robotics: New era of human-robot cooperation in the workplace," Journal of Safety Research, 72020.

[226] P. T. Lee, "Hotels and Restaurants," ILO Encyclopaedia of Occupational Health and Safety, June 29 2011. [Online]. Available: https://www.iloencyclopaedia.org/part-xvii-65263/hotels-andrestaurants. [Accessed June 2020].

[227] M. Barrett, E. Oborn, W. J. Orlikowski and J. A. Yates, "Reconfiguring boundary relations: Robotic innovations in pharmacy work," Organization Science, vol. 23, no. 5, pp. 1448-1466, 2012.

[228] V. N. Lu, J. Wirtz, W. H. Kunz, S. Paluch, T. Gruber, A. Martins and P. G. Patterson, "Service robots, customers and service employees: what can we learn from the academic literature and where are the gaps?," Journal of Service Theory and Practice, 2020.

[229] H. Kim and H. Qu, "The Effects of Experienced Customer Incivility on Employees' Behavior Toward Customers and Coworkers," Journal of Hospitality and Tourism Research, vol. 43, no. 1, pp. 58-77, 11 2019.

[230] S. J. Han, M. A. Bonn and M. Cho, "The relationship between customer incivility, restaurant frontline service employee burnout and turnover intention," International Journal of Hospitality Management, vol. 52, pp. 97-106, 112016.

[231] S. Ivanov and C. Webster, "Adoption of robots, artificial intelligence and service automation by travel, tourism and hospitality companies a cost-benefit analysis," in International Scientific Conference "Contemporary Tourism - Traditions and Innovations", 2017.

[232] K.-E. Lee and K.-H. Shin, "Job Burnout, Engagement and Turnover Intention of Dietitians and Chefs at a Contract Foodservice Management Company," Journal of Community Nutrition, vol. 7, no. 2, pp. 100-106, 2005.

[233] C. Breazeal, K. Dautenhahn and T. Kanda, "Social Robotics," in Handbook of Robotics, Springer, 2016.

[234] G. Hoffman and C. Breazeal, "Effects of anticipatory perceptual simulation on practiced human-robot tasks," Autonomous Robots, vol. 28, no. 4, pp. 403-423, 2010.

[235] L. Y. Morales Saiki, S. Satake, T. Kanda and N. Hagita, "Modeling environments from a route perspective," in Proceedings of the 6th international conference on Human-robot interaction, 2011.

[236] T. Paek and R. Pieraccini, "Automating spoken dialogue management design using machine learning: An industry perspective," Speech communication, vol. 50, no. 8-9, pp. 716-729, 2008.

[237] H. Cuayáhuitl, S. Yu, A. Williamson and J. Carse, "Scaling up deep reinforcement learning for multi-domain dialogue systems," in International Joint Conference on Neural Networks (IJCNN), 2017.

[238] Convotherm Elektrogerate GmbH, "ConvoSense, The world's first AI-powered combi oven for fully automated cooking," 2020. [Online]. Available: https://www.convotherm.com/ConvoSense. [Accessed Dec 2019].

[239] T. Sadhu, I. Banerjee, S. K. Lahiri and J. Chakrabarty, "Modeling and optimization of cooking process parameters to improve the nutritional profile of fried fish by robust hybrid artificial intelligence approach," Journal of Food Process Engineering, vol. 43, no. 9, 2020.

[240] F. Pinel, L. R. Varshney and D. Bhattacharjya, "A Culinary Computational Creativity System," 2015, pp. 327-346.

[241] M. Chang, L. V. Guillain, H. Jung, V. M. Hare, J. Kim and M. Agrawala, "RecipeScape: An interactive tool for analyzing cooking instructions at scale," in Conference on Human Factors in Computing Systems - Proceedings, 2018.

[242] C. Elbrechter, J. Maycock, R. Haschke and H. Ritter, "Discriminating Liquids Using a Robotic Kitchen Assistant," in IROS IEEE/RSJ International Conference on Intelligent Robots and Systems , Hamburg, Germany, 2015.

[243] A. Yamaguchi and C. G. Atkeson, "Stereo Vision of Liquid and Particle Flow for Robot Pouring," in EEE-RAS 16th International Conference on Humanoid Robots (Humanoids), 2016.

[244] J. Matsuoka, Y. Tsurumine, Y. Kwon, T. Matsubara, T. Shimmura and S. Kawamura, "Learning Food-arrangement Policies from Raw
Images with Generative Adversarial Imitation Learning," in 17th International Conference on Ubiquitous Robots (UR), 2020.

[245] I. Mitsioni, Y. Karayiannidis, J. A. Stork and D. Kragic, "Data-Driven Model Predictive Control for the Contact-Rich Task of Food Cutting," in IEEE-RAS 19th International Conference on Humanoid Robots (Humanoids), 2019.

[246] A. Petit, V. Lippiello, G. A. Fontanelli and B. Siciliano, "Tracking elastic deformable objects with an RGB-D sensor for a pizza chef robot," Robotics and Autonomous Systems, vol. 88, pp. 187-201, 12 2017.

[247] A. A. Osuwa, E. B. Ekhoragbon and L. T. Fat, "Application of artificial intelligence in Internet of Things," in 2017 9th International Conference on Computational Intelligence and Communication Networks (CICN), 2017.

[248] Program-Ace, "The Future of Touchless Technologies: Voice or Gesture," 2020. [Online]. Available: https://programace.com/blog/the-future-of-touchless-technologies-voice-or-gesture/. [Accessed Aug 2020].

[249] T. Vuletic, A. Duffy, L. Hay, C. McTeague, G. Campbell and M. Grealy, "Systematic literature review of hand gestures used in human computer interaction interfaces," International Journal of HumanComputer Studies, vol. 129, pp. 74-94, 2019.

[250] H. Cuayáhuitl, "SimpleDS: A simple deep reinforcement learning dialogue system," in Dialogues with social robots, Singapore, Springer, 2017, pp. 109-118.

[251] H. Cuayahuitl and S. Yu, "Deep reinforcement learning of dialogue policies with less weight updates," in International Conference of the Speech Communication Association (INTERSPEECH), Stockholm, Sweden, 2017.

[252] V. Mnih, K. Kavukcuoglu, D. Silver, A. A. Rusu, J. Veness, M. G. Bellemare, A. Graves, M. Riedmiller, A. K. Fidjeland, G. Ostrovski, S. Petersen, C. Beattie, A. Sadik, I. Antonoglou, H. King and D. Ku, "Human-level control through deep reinforcement learning," Nature, vol. 518, p. 529-533, 2015.

[253] B. Liu and L. Zhang, "A Survey of Opinion Mining and Sentiment Analysis," in Mining Text Data, Springer, 2012, pp. 415-463.

[254] P. Q. Tran, N. Thanh, N. Vu, H. Thanh and H. Xuan, "Effective opinion words extraction for food reviews classification," International Journal of Advanced Computer Science and Applications, vol. 11, no. 7, 2020.

[255] Y. De Pra, S. Papetti, F. Fontana, H. Järveläinen and M. Simonato, "Tactile discrimination of material properties: application to virtual buttons for professional appliances," Journal on Multimodal User Interfaces, vol. 14, no. 3, pp. 255-269, 2020.

[256] Y. De Pra, F. Fontana and S. Papetti, "Endless knob with programmable resistive force feedback," in Human-Computer Interaction - INTERACT2021, 2021.

[257] A. Fathima and K. Vaidehi, "Review on facial expression recognition system using machine learning techniques," in Advances in Decision Sciences, Image Processing, Security and Computer Vision, Springer, 2020, pp. 608-618.

[258] M. Ghayoumi, "A quick review of deep learning in facial expression," Journal of Communication and Computer, vol. 14, no. 1, 2017.

[259] S. M. S. Abdullah and A. M. Abdulazeez, "Facial expression recognition based on deep learning convolution neural network: A review," Journal of Soft Computing and Data Mining, vol. 2, no. 1, pp. 53-65, 2021.

[260] T. Yamamoto, H. Mizuta and K. Ueji, "Analysis of facial expressions in response to basic taste stimuli using artificial intelligence to predict perceived hedonic ratings," Plos one, vol. 16, no. 5, 2021.

[261] R. Zhi, J. Wan, D. Zhang and W. Li, "Correlation between hedonic liking and facial expression measurement using dynamic affective response representation," Food research international, vol. 108, pp. 237-245, 2018.

[262] W. He, S. Boesveldt, S. Delplanque, C. de Graaf and R. A. De Wijk, "Sensory-specific satiety: Added insights from autonomic nervous system responses and facial expressions," Physiology \& behavior, vol. 170, pp. 12-18, 2017. 
[263] D. D. Torrico, S. Fuentes, C. G. Viejo, H. Ashman and F. R. Dunshea, "Cross-cultural effects of food product familiarity on sensory acceptability and non-invasive physiological responses of consumers," Food research international, vol. 115, pp. 439-450, 2019.

[264] B. Siciliano, L. Sciavicco, L. Villani and G. Oriolo, "Force Control," in Robotics: modelling, planning and control, Springer Science \& Business Media, 2010.

[265] B. Siciliano and O. Khatib, "Simultaneous Localization and Mapping," in Springer handbook of robotics, Springer, 2016.

[266] C. Estlund, "What Should We Do after Work: Automation and Employment," Yale LJ, vol. 128, 2018.

[267] S. Ivanov, U. Gretzel, K. Berezina, M. Sigala and C. Webster, "Progress on robotics in hospitality and tourism: a review of the literature," Journal of Hospitality and Tourism Technology, 2019

[268] International Federation of Robotics (IFR), "Robot density rises globally," 2018. [Online]. Available: https://ifr.org/ifr-pressreleases/news/robot-density-rises-globally. [Accessed June 2021].

[269] T. Tanizaki, T. Shimmura and N. Fujii, "Shift scheduling to improve customer satisfaction, employee satisfaction and management satisfaction in service workplace where employees and robots collaborate," in International Conference on Serviceology, 2017.

[270] McKinsey Global Institute (McKinsey \& Company), "A future that works: automation, employment, and productivity," 2017. [Online]. Available:

https://www.mckinsey.com/ /media/mckinsey/featured\%20insights/D igital\%20Disruption/Harnessing\%20automation $\% 20$ for $\% 20 \mathrm{a} \% 20$ futur e\%20that\%20works/MGI-A-future-that-works-Executivesummary.ashx. [Accessed June 2021].

[271] World Economic Forum, "The future of jobs report 2018," 2018. [Online]. Available: http://www3.weforum.org/docs/WEF_Future_of_Jobs_2018.pdf. [Accessed June 2021].

[272] R. Accorsi, A. Tufano, A. Gallo, F. G. Galizia, G. Cocchi, M. Ronzoni, A. Abbate and R. Manzini, "An application of collaborative robots in a food production facility," Procedia Manufacturing, pp. 341-348, 2019.

[273] V. E. Reese and R. A. Schwierking, "Sifter for breading apparatus". Washington, DC Patent 4,550,677, 1985.

[274] A. Ambroset, O. Fracas, D. Longo and M. Scacco, "Foodstuff sieve station". Washington, DC Patent 10,245,619, April 2019.

[275] Henny Penny Corp., "Evolution Elite® Open Fryers," [Online]. Available: https://www.hennypenny.com/wpcontent/uploads/2019/01/EEG-241-244-data-sheet-06182020.pdf. [Accessed May 2021].

[276] Henny Penny Corp., "Service manual register warranty split/full vat open fryer (gas)," 02 2018. [Online]. Available: https://www.hennypenny.com/wp-content/uploads/2018/02/FM06040-B_LVG-10x_Tech._Mc-1.pdf. [Accessed June 2021].

[277] Electrolux Professional SpA, "Fryers User maintenance guide," [Online]. Available: https://tools.electroluxprofessional.com/Mirror/Doc/UM/UM_05UMA _D_ENG00_1_5_1_1_05UMA_D_ENG00_\%20EPR_umg_Fry ers_ENG_LR.pdf?version=1623675320. [Accessed June 2021].

[278] Sirman SpA, "Meat grinders / graters," [Online]. Available: https://www.sirman.com/en/product-list/meat-grinders---graters.html. [Accessed April 2021].

[279] Electrolux Professional SpA, "Stainless Steel Electric Bread Slicer COD 603265," [Online]. Available: https://www.electroluxprofessional.com/pd/foodpreparation/slicers/bread-slicer-cpx/bread-slicers-stainless-steelelectric-bread-slicer-603265/. [Accessed May 2021].

[280] Sirman SpA, "Sinfonia 2," [Online]. Available: https://www.sirman.com/en/product-list/pastamachines/sinfonia/Sinfonia-2-detail.html\#. [Accessed June 2021].

[281] Autec Inc., "Chain conveyor belt," [Online]. Available: https://www.sushimachines.com/chain-conveyor-belt/. [Accessed Dez 2020].
[282] V. Kwok, "The Appeal of Conveyor-belt Sushi," Discovery, 22 May 2019. [Online]. Available: https://discovery.cathaypacific.com/appealconveyor-belt-sushi/. [Accessed May 2021].

[283] Autec Inc., "Sushi Train Monorail," [Online]. Available: https://www.sushimachines.com/sushi-train-monorail/. [Accessed Dez 2020].

[284] Hong Chiang Technology Industry Co., LTD., "Optional accessories for optimizing your conveyor," [Online]. Available: https://www.hong-chiang.com.tw/en/category/Optional-Function-OfSushi-Conveyor-Belt/B03.html. [Accessed May 2021].

[285] Meiko Maschinenbau GmbH \& Co. KG, "Round belt conveyor RF with VF Operating instructions," [Online]. Available: https://partnernet.meiko-global.com/download/3117/en. [Accessed May 2021].

[286] Sirman SpA, "Forcella 20-35-50," [Online]. Available: https://www.sirman.com/it/catalogo-prodotti/impastatricipizza/forcella/Forcella-20-35-50-detail.html\#. [Accessed June 2021].

[287] Electrolux Professional SpA, "Food preparation: knead, wheep and sheet," 2021. [Online]. Available: https://www.electroluxprofessional.com/commercial-kitchenequipment/knead-whip-sheet/. [Accessed May 2021].

[288] Electrolux Professional SpA, "Lavastoviglie a cesto trascinato green\&clean," 2020. [Online]. Available: https://tools.electroluxprofessional.com/Mirror/Doc/BR/BR_BR9JE00124_1_5_0_15_RT\%20green\&clean\%20Multirisciacquo.pdf. [Accessed May 2021].

[289] Electrolux Professional SpA, "green\&clean Lavabicchieri e Lavastoviglie sottotavolo," 2020. [Online]. Available: https://tools.electroluxprofessional.com/Mirror/Doc/BR/BR_BR9JE00171_1_5_0_5_green\&clean\%20Lavabicchieri\%20\&\%20Sottota volo\%20LR.pdf. [Accessed May 2021].

[290] Nilma SpA, "Vegetable washers ATIR," [Online]. Available: https://nilma.com/eng/preparation-products/atir. [Accessed June 2021].

[291] Electrolux Professional SpA, "Dito Sama Vegetable Washer Tilting Basket Vegetable Washer 10/40kg," [Online]. Available: https://tools.electroluxprofessional.com/Mirror/Doc/MAD2/Dito\%20S ama/English/Tilting\%20Basket\%20Vegetable\%20Washer\%201040kg_660034.pdf?version=1605279837. [Accessed June 2021].

[292] Electrolux Professional SpA, "Range Overview 700XP \& 900XP Accessories," [Online]. Available: https://tools.electroluxprofessional.com/Mirror/Doc/RAN/RAN_RAN

9JE00011_1_5_1_5_RO\%20XP\%20accessories_ENG_20201221.pdf ?version=1624744275. [Accessed May 2021].

[293] Electrolux Professional SpA, "Fryer HP demo recipe book," [Online]. Available: https://tools.electroluxprofessional.com/Mirror/Doc/REC/REC_REC2_1_5_1_2_EPR_Recipe\%20book_Fryers\%20HP_LR.pdf?version=1 624744816. [Accessed June 2021].

[294] Sirman SpA, "IS 15 Idra," [Online]. Available: https://www.sirman.com/en/product-list/sausage-stuffers/idra/IS-15Idra-detail.html\#. [Accessed June 2021].

[295] Sirman SpA, "Vacuum packaging machines," [Online]. Available: https://www.sirman.com/en/product-list/vacuum-packagingmachines.html\#. [Accessed May 2021].

[296] Natural Machines, "Natural Machines Foodini Brochure," [Online]. Available: https://static.naturalmachines.com/images/NaturalMachines-Foodini-Brochure.pdf. [Accessed May 2021].

[297] Electrolux Professional SpA, "Dough Sheeter, table standing - 500 mm," 2020. [Online]. Available:

https://tools.electroluxprofessional.com/Mirror/Doc/MAD2/Electrolux $\% 20$ Professional/English/Dough\%20Sheeter\%20\%20table\%20standing\%20-\%20500\%20mm_603532-603533603534.pdf?version=1625361275. [Accessed May 2021].

[298] C. Sachs, P. Allen, A. R. Terman, J. Hayden and C. Hatcher, "Front and back of the house: socio-spatial inequalities in food work," Agriculture and Human Values, vol. 31, no. 1, pp. 3-17, 32014. 
[299] ItaliaGroup Corporate, "The gastronorm measures," [Online]. Available: https://www.gastronorm.it/en/The-Gastronormmeasures.d766. [Accessed 1012 2019].

[300] G. Trigatti, P. Boscariol, L. Scalera, D. Pillan and A. Gasparetto, "A new path-constrained trajectory planning strategy for spray painting robots - rev.1," International Journal of Advanced Manufacturing Technology, vol. 98, no. 9-12, pp. 2287-2296, 1102018.

[301] N. Asakawa and Y. Takeuchi, "Teachingless Spray-Painting of Sculptured Surface by an Industrial Robot," in Proceedings of the International Conference on Robotics and Automation, Albuquerque, New Mexico, 1997.

[302] C. D. Derby, "Cephalopod ink: production, chemistry, functions and applications.," Marine drugs, vol. 12, no. 5, pp. 2700-2730, 2014.

[303] Â. G. de Lima, M. T. Barum, R. P. Ramirez, S. F. Fonseca, S. Pieniz and K. L. \& Rodrigues, "Acceptability, nutritional composition, and protein digestibility of food produced with black rice.," Journal of culinary science \& technology, vol. 16, no. 1, pp. 30-39, 2018.

[304] Kiwi Campus Inc., "Technology," [Online]. Available: https://www.kiwibot.com/technology. [Accessed June 2020].

[305] Refraction AI, Inc., "Say hello to the REV-1," [Online]. Available: https://refraction.ai/. [Accessed June 2020].

[306] Starship Technologies OÜ, "Starship," [Online]. Available: https://www.starship.xyz/. [Accessed June 2020].

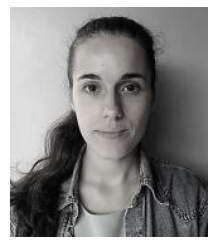

Débora Pereira is a Ph.D. student in BioRobotics, at the BioRobotics Institute of Scuola Superiore Sant'Anna, Pisa, Italy. Electrolux Professional SpA is funding her research on the study of bio-inspired control methods for robotic systems to support the work in foodservice. She received her MSc in Bioengineering, with specialization in Biomedical Engineering (2017), from the University of Porto, Portugal. Her research interests include collaborative robotics, biorobotics, design and control of mechatronic systems.

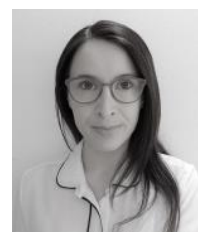

Arianna Bozzato is a Ph.D. student in Food and Human Health at the department of Agricultural, Food, Environmental and Animal Sciences at the University of Udine. She is employed in the Advanced Development and Technologies team at Electrolux Professional. She has a master degree in Food Quality Management and Control at the University of Udine with a thesis in inactivation treatments for biofilm forming bacteria.

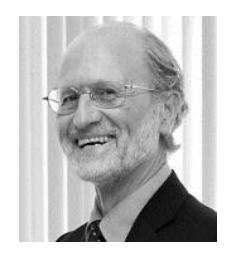

Paolo Dario received the Dr. Eng. degree in Mechanical Engineering from the University of Pisa (Pisa, Italy) in 1977 and the Honorary Dr. Eng. degree in Biomedical Engineering from the Campus Bio-Medico University (Rome, Italy) in 2018. He is Professor of Biomedical Robotics and he has been and is a Visiting Researcher, Professor, and Fellow at various universities and scientific institutions in Europe, the U.S., the Middle East, and Asia. Dr. Dario has co-authored 400+ journal publications (Scopus) and his h-index is 64 (Scopus). He has co-authored 50+ international patents and is the co-founder of 6 start-up companies. Dr. Dario has been the coordinator of many large national and European projects and he has served and serves as Editor-in-Chief, Associate Editor, and member of the Editorial Board of many international journals, such as he is Editor-in-Chief of the new IEEE Transactions on Medical Robotics and Bionics. He served as President of the IEEE Robotics and Automation Society and was the recipient of many prizes and awards, including the 1996 Joseph Engelberger Robotic Award for merits in Biomedical Robotics, the 2014 IEEE RAS George Saridis Leadership Award, and the 2017 IEEE RAS Pioneer Award in Biorobotics.

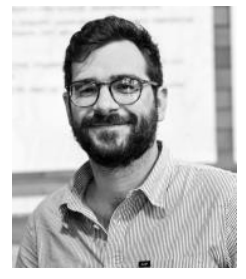

Gastone Ciuti received the Master's degree (with honours) in Biomedical Engineering from the University of Pisa (Pisa, Italy) in 2008, with a thesis entitled "Study and development of endoscopic robot with locomotion based on permanent magnetic field", carried out at the Center for Research in Microengineering Lab of Scuola Superiore Sant'Anna (Pisa, Italy). He obtained the $\mathrm{PhD}$ in BioRobotics (with honours) in 2012. Currently, he is an Associate Professor in Bioengineering at The BioRobotics Institute of Scuola Superiore Sant'Anna, Surgical Robotics and Allied Technologies area, and head of the Computer-Integrated Technologies for Robotic Surgery laboratory. Dr. Ciuti is co-author of more $75+$ scientific publications on computer-integrated platforms and innovative devices for medical robotic intervention and treatment (50+ in ISI journals) and he is also the holder of more than 10 international patents. 


\section{APPENDIX A}

TABLE 3. TECHNICAL DETAILS OF SINGLE-ACTION EQUIPMENT (SAE).

\begin{tabular}{|c|c|c|c|c|c|c|c|c|}
\hline \multicolumn{2}{|c|}{$\begin{array}{l}\text { Machine (SAE) } \\
\text { and its actions }{ }^{\text {a }}\end{array}$} & $\begin{array}{c}\text { Format } \\
\text { size }^{b}\end{array}$ & $\begin{array}{c}\text { Actuated } \\
\text { mechanism } \\
\text { (type, as in Fig. 3) }\end{array}$ & $\begin{array}{l}\text { Capacity and } \\
\text { Productivity }^{c}\end{array}$ & $\begin{array}{l}\text { Accessories } \\
\text { (for additional } \\
\text { functions) } \\
\end{array}$ & $\begin{array}{l}\text { Typical food } \\
\text { (examples) }\end{array}$ & $\begin{array}{c}\text { Usefulness } \\
\text { and advantages }\end{array}$ & Drawbacks \\
\hline $\begin{array}{l}\bar{\Xi} \\
\approx\end{array}$ & $\begin{array}{l}\text { Vegetables' } \\
\text { peeler } \\
\text { machine [93] } \\
\text { [94, p. 40] } \\
\text { (video) }\end{array}$ & $\begin{array}{l}\text { Tabletop; } \\
\text { floor }\end{array}$ & $\begin{array}{l}\text { Container with } \\
\text { rotating plate, at the } \\
\text { bottom; the plate has } \\
\text { an abrasive surface (1) }\end{array}$ & $\begin{array}{l}\text { C: } 1.5-25 \mathrm{~kg} \\
\text { P: } 80-400 \mathrm{~kg} / \mathrm{h}\end{array}$ & $\begin{array}{c}\text { Alternative } \\
\text { rotating plates } \\
\text { with blades or } \\
\text { brushes. }\end{array}$ & $\begin{array}{l}\text { Potato, garlic, } \\
\text { onion, carrot, } \\
\text { shellfish }\end{array}$ & $\begin{array}{l}\text { - Reduces waste of food } \\
\text { with the peel; } \\
\text { - Fast processing of large } \\
\text { quantities; } \\
\text { - Workers avoid repeated } \\
\text { manipulation of } \\
\text { dangerous utensils, and } \\
\text { avoid a dull, longtime- } \\
\text { standing action. }\end{array}$ & $\begin{array}{l}\text { Plates manually exchanged; } \\
\text { - Need to sharpen the plates } \\
\text { with blades regularly; } \\
\text { - Need to manually } \\
\text { disassemble blades to clean } \\
\text { in the dishwasher (no self- } \\
\text { cleaning); } \\
\text { - Heavy loads manually lifted } \\
\text { to fill the machine. }\end{array}$ \\
\hline$\stackrel{\rightleftarrows}{=}$ & $\begin{array}{l}\text { Automatic } \\
\text { sifting system } \\
\text { for breading } \\
\text { workstations } \\
\text { [95] [273] } \\
\underline{\underline{\text { video at }}} \\
\underline{\underline{00: 35)}}\end{array}$ & Floor & $\begin{array}{l}\text { Rotating drum with } \\
\text { sieve, where the used } \\
\text { breading enters and the } \\
\text { residual lumps get } \\
\text { stuck (ending up in a } \\
\text { container); the re- } \\
\text { usable sifted breading } \\
\text { falls from the sieve } \\
\text { into a collector basin } \\
\text { (1) }\end{array}$ & $\begin{array}{l}\text { Information not } \\
\text { available }\end{array}$ & No & $\begin{array}{c}\text { Breading } \\
\text { preparation } \\
\quad \text { (i.e., } \\
\text { breadcrumbs- } \\
\text { or flour-based) }\end{array}$ & $\begin{array}{l}\text { Reduces the time needed } \\
\text { to sift the flour/crumbs, } \\
\text { which increases } \\
\text { productivity and } \\
\text { encourages the re-use of } \\
\text { the flour/crumbs (less } \\
\text { waste). }\end{array}$ & $\begin{array}{l}\text { - Noisy ( } 49 \text { / } 57 \mathrm{~dB} \text {, still } \\
\text { under the NIOSH } \\
\text { recommended limits) [95] } \\
\text { - Need to manually pickup } \\
\text { and lift the basin with sifted } \\
\text { breading from the bottom of } \\
\text { the machine to reuse the } \\
\text { breading [274]; } \\
\text { - The system tends to clog and } \\
\text { is not easy to clean [274]. }\end{array}$ \\
\hline \multirow[t]{2}{*}{ 墕 } & $\begin{array}{l}\text { Oil filtering } \\
\text { system for } \\
\text { fryers [96, p. } \\
\text { 7] [275] } \\
\text { ( } \underline{\text { video })}\end{array}$ & $\begin{array}{l}\text { Built-in } \\
\text { (into } \\
\text { fryers) }\end{array}$ & $\begin{array}{l}\text { Recirculation pump } \\
\text { leads the oil to pass } \\
\text { through metal and } \\
\text { paper filters and } \\
\text { pumps the oil back to } \\
\text { the fryer well (9) }\end{array}$ & $\begin{array}{l}\text { C: NA } \\
\text { P: } 13.6 \mathrm{~L} \text { in } 4 \\
\min [275]\end{array}$ & $\begin{array}{l}\text { Drain tube to } \\
\text { pump the oil out } \\
\text { of the fryer }\end{array}$ & Oil & $\begin{array}{l}\text { - Allows a healthier re-use } \\
\text { of frying oil (less burnt } \\
\text { particles than with } \\
\text { manual straining) and } \\
\text { reduces the wasted oil; } \\
\text { - Encourages the workers } \\
\text { not to filter or drain the } \\
\text { oil manually while it's } \\
\text { still hot }\end{array}$ & $\begin{array}{l}\text { Need to replace the filters } \\
\text { recurrently - from daily to } \\
\text { weekly depending on oil } \\
\text { usage [276] [277] (in } \\
\text { addition to the generated } \\
\text { waste, the procedure is not } \\
\text { very ergonomic). }\end{array}$ \\
\hline & $\begin{array}{l}\text { Vegetables' } \\
\text { dryer machine } \\
\text { e.g., [94, p. } \\
\text { 45] (video) }\end{array}$ & Floor & $\begin{array}{c}\text { Basket (with } \\
\text { vegetables inside) } \\
\text { rotating inside a } \\
\text { container that receives } \\
\text { the drained water (1) }\end{array}$ & $\begin{array}{l}\text { C: } 5-10 \mathrm{~kg} \\
\text { P: } 1-2 \mathrm{~min} \text { to dry }\end{array}$ & No & $\begin{array}{c}\text { Washed } \\
\text { vegetables }\end{array}$ & $\begin{array}{l}\text { Workers avoid a } \\
\text { repetitive and tiring } \\
\text { action. }\end{array}$ & $\begin{array}{l}\text { Bulky machine with large } \\
\text { footprint }(e . g . \text {. } \\
0.46 \times 0.54 \times 0.8 \mathrm{~m}) \text { for a } \\
\text { single use/few applications. }\end{array}$ \\
\hline 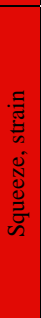 & 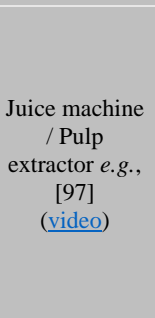 & Tabletop & $\begin{array}{c}\text { Endless screw rotating } \\
\text { inside a container that } \\
\text { presses } \\
\text { fruits/vegetables } \\
\text { against a rotating } \\
\text { perforated surface }(7)\end{array}$ & $\begin{array}{l}\text { C: } 0.5 \text { L [97] } \\
\text { P: specific } \\
\text { information not } \\
\text { available }\end{array}$ & $\begin{array}{c}\text { Different } \\
\text { perforated } \\
\text { surfaces/strainer; } \\
\text { optional filter }\end{array}$ & $\begin{array}{c}\text { Fruits, } \\
\text { vegetables }\end{array}$ & $\begin{array}{l}\text { - Large food-introduction } \\
\text { hopper reduces the need } \\
\text { of pre-cutting food; } \\
\text { - Professional-grade } \\
\text { powerful motor } \\
\text { squeezes food more } \\
\text { effectively, wasting less } \\
\text { juice; } \\
\text { - Workers avoid a } \\
\text { repetitive and tiring } \\
\text { action. }\end{array}$ & $\begin{array}{l}\text { Difficult to clean the parts; } \\
\text { - Slow movement (e.g., } 37 \\
\text { rpm [97]) and limited } \\
\text { capacity requires care to not } \\
\text { overfeed the machine, } \\
\text { otherwise, output juice will } \\
\text { contain pulp - consequent } \\
\text { low productivity. }\end{array}$ \\
\hline \multirow{2}{*}{$\frac{\text { जี }}{\sum_{i}^{ \pm}}$} & $\begin{array}{c}\text { Food } \\
\text { processor } \\
{[94, \text { pp. 22-23] }}\end{array}$ & Tabletop & $\begin{array}{l}\text { Container with } \\
\text { rotating blades at the } \\
\text { bottom (1) }\end{array}$ & $\begin{array}{l}\text { C: small formats } \\
\text { from } 2.5 \mathrm{~L} \text { to } 7 \\
\mathrm{~L} \text {; big formats of } \\
11.5 \mathrm{~L} \text { (up to } 6 \\
\mathrm{~kg} \text { ) or } 17.5 \mathrm{~L} \text { (up } \\
\text { to } 8 \mathrm{~kg} \text { ) } \\
\text { P: NA }\end{array}$ & Bowl scraper & $\begin{array}{l}\text { Liquid/solid } \\
\text { mixtures }(e . g ., \\
\text { with milk, } \\
\text { yogurt, water); } \\
\text { solids (e.g., dry } \\
\text { cheese, bread, } \\
\text { chocolate, nuts) }\end{array}$ & $\begin{array}{l}\text { Fast processing of large } \\
\text { quantities of many } \\
\text { different ingredients and } \\
\text { preparations. }\end{array}$ & $\begin{array}{l}\text { - No-self-cleaning, so, need to } \\
\text { manually disassemble blades } \\
\text { to clean in the dishwasher; } \\
\text { - Need to sharpen the blades } \\
\text { regularly or even to replace } \\
\text { them. }\end{array}$ \\
\hline & $\begin{array}{c}\text { Immersion } \\
\text { blender } \\
\text { [94, pp. 24-29] } \\
\text { [128] }\end{array}$ & $\begin{array}{c}\text { Floor; } \\
\text { handheld }\end{array}$ & $\begin{array}{l}\text { Rotating arm with } \\
\text { blades, inserted on a } \\
\text { container with food ( } 2 \text { ) }\end{array}$ & $\begin{array}{l}\text { C: } 30-290 \mathrm{~L} \\
\text { P: information } \\
\text { not available }\end{array}$ & $\begin{array}{l}\text { Adjustable holder } \\
\text { to sustain the } \\
\text { blender up inside } \\
\text { the container [94, } \\
\text { p. } 25] \text {; whisk; } \\
\text { purée tube } \\
\text { attachment. }\end{array}$ & $\begin{array}{l}\text { Mixture for } \\
\text { soup or purée; } \\
\text { liquids, } \\
\text { emulsions, } \\
\text { semi-liquids. }\end{array}$ & $\begin{array}{l}\text { Fast processing of large } \\
\text { quantities of many } \\
\text { different ingredients and } \\
\text { preparations. }\end{array}$ & $\begin{array}{l}\text { - Can be bulky and heavy (1- } \\
4 \mathrm{~kg} \text { [94, pp. 24-27] [128]) - } \\
\text { it is particularly too heavy } \\
\text { for a handheld solution; } \\
\text { - Need to manually } \\
\text { disassembly the blades to } \\
\text { clean. }\end{array}$ \\
\hline \multirow[t]{2}{*}{ 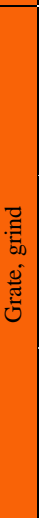 } & $\begin{array}{l}\text { Meat mincer } \\
\text { machine } \\
{[94, \text { p. } 49]} \\
{[278]} \\
\text { (video) } \\
\\
\text { Grater } \\
\text { machine } \\
\text { [94, p. 49] } \\
\text { [278] } \\
\text { (video) }\end{array}$ & Tabletop & $\begin{array}{l}\text { Endless screw or } \\
\text { perforated cylindrical } \\
\text { surface rotating inside } \\
\text { a horizontal pipe, that } \\
\text { presses and drives } \\
\text { meat parts against } \\
\text { rotating blades and a } \\
\text { perforated surface }(7)\end{array}$ & $\begin{array}{l}\text { C: NA } \\
\text { P: up to } 150 \\
\mathrm{~kg} / \mathrm{h} \text { bread, up to } \\
130 \mathrm{~kg} / \mathrm{h} \text { cheese }\end{array}$ & $\begin{array}{l}\text { Different shaper } \\
\text { attachments } \\
\text { (molds for } \\
\text { hamburgers or } \\
\text { other shapes) } \\
\text { [278] }\end{array}$ & $\begin{array}{l}\text { Cheese; bread; } \\
\text { nuts }\end{array}$ & $\begin{array}{l}\text { - Fast processing of large } \\
\text { quantities; } \\
\text { - Workers avoid a } \\
\text { repetitive and tiring } \\
\text { action. }\end{array}$ & $\begin{array}{l}\text { - Needs proper storage space } \\
\text { - too limited use for the } \\
\text { occupied space; } \\
\text { - Cleaning and (un)mounting } \\
\text { are not practical; } \\
\text { - Not completely autonomous } \\
\text { action - need to manually } \\
\text { guide and pull the meat to } \\
\text { enter the machine and need } \\
\text { to take care with the quantity } \\
\text { to avoid overfeeding the } \\
\text { machine. }\end{array}$ \\
\hline & $\begin{array}{l}\text { Ice crusher } \\
\text { [98] } \\
\text { (video) }\end{array}$ & Tabletop & $\begin{array}{l}\text { Container with a disc, } \\
\text { at the bottom, that } \\
\text { embeds blades (1) }\end{array}$ & $\begin{array}{l}\text { C: (bowl) } 2 \mathrm{~L} \text {; } \\
\text { crushes ice up to } \\
4 \times 4 \mathrm{~cm} \text { at }-3^{\circ} \mathrm{C} \\
\text { P: information } \\
\text { not available }\end{array}$ & No & $\begin{array}{l}\text { Ice (for drinks } \\
\text { and for fresh } \\
\text { food } \\
\text { preservation) }\end{array}$ & $\begin{array}{l}\text { - Faster processing of } \\
\text { large quantities than by } \\
\text { hand; } \\
\text { - Workers avoid } \\
\text { manipulating the ice } \\
\text { with hands, reducing }\end{array}$ & $\begin{array}{l}\text { Very limited use, similar to } \\
\text { the action of a } \\
\text { grinder/grater/food } \\
\text { processor. }\end{array}$ \\
\hline
\end{tabular}




\begin{tabular}{|c|c|c|c|c|c|c|c|c|}
\hline & & & & & & & $\begin{array}{l}\text { burns, and improving } \\
\text { hygiene. }\end{array}$ & \\
\hline \multirow{3}{*}{ 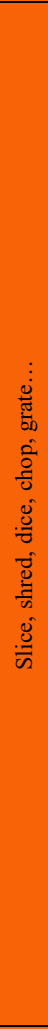 } & $\begin{array}{l}\text { Food cutter } \\
\text { machine } \\
\text { e.g., [99] [94, } \\
\text { pp. 4-17] } \\
\text { (video) }\end{array}$ & $\begin{array}{l}\text { Tabletop; } \\
\text { floor (on } \\
\text { mobile } \\
\text { stand) }\end{array}$ & $\begin{array}{l}\text { Container with } \\
\text { rotating discs, at the } \\
\text { bottom, that embed } \\
\text { blades, or have a } \\
\text { perforated surface (i.e., } \\
\text { with holes having } \\
\text { sharp edges) (1) }\end{array}$ & $\begin{array}{l}\text { C: NA } \\
\text { P: } 250-2500 \\
\mathrm{~kg} / \mathrm{h}[94] ; 100- \\
250 \mathrm{~kg} / \mathrm{h}[99]\end{array}$ & $\begin{array}{l}\text { Discs for } \\
\text { different cuts } \\
\text { (slice, grate, } \\
\text { julienne, dice, } \\
\text { brunoise, waffle } \\
\text { and ripple); } \\
\text { Automatic large } \\
\text { feed hopper for a } \\
\text { load of } 6 \mathrm{~kg} \text { [94]; } \\
132 \mathrm{~cm}^{2} \text { feed } \\
\text { hopper [99]; long } \\
\text { feed hoppers for } \\
\text { long vegetables. }\end{array}$ & $\begin{array}{c}\text { Cabbage, } \\
\text { potato, } \\
\text { chocolate, } \\
\text { cheese, tomato }\end{array}$ & $\begin{array}{l}\text { - Precise cuts (specific } \\
\text { dimensions); } \\
\text { - Large variety of cuts' } \\
\text { type/dimensions; } \\
\text { - Large discs (e.g., 30mm- } \\
\text { diameter) allow high } \\
\text { productivity; } \\
\text { - Workers avoid repeated } \\
\text { manipulation of } \\
\text { dangerous utensils and } \\
\text { repetitive actions. }\end{array}$ & $\begin{array}{l}\text { - Dangerous and can be } \\
\text { difficult to (dis)assembly the } \\
\text { blades; } \\
\text { - Need to sharpen the blades } \\
\text { regularly; } \\
\text { - Discs manually exchanged; } \\
\text { - For each cut type/dimension, } \\
\text { a different disc/accessory is } \\
\text { needed. } \\
\text { - Food can accumulate } \\
\text { between blades. }\end{array}$ \\
\hline & $\begin{array}{l}\text { Vertical or } \\
\text { gravity } \\
\text { food slicer } \\
\text { e.g., [100] } \\
\text { (video) }\end{array}$ & Tabletop & $\begin{array}{l}\text { Rotating circular saw } \\
\text { with a tightening arm } \\
\text { to push the food } \\
\text { against the saw, and a } \\
\text { moving tray to re- } \\
\text { position the food in } \\
\text { front of the saw (1) }\end{array}$ & $\begin{array}{l}\text { C: } N A \\
\text { P: } 2400 \text { slices/h } \\
\text { with gravity } \\
\text { slicer }\end{array}$ & No & $\begin{array}{c}\text { Salamis and } \\
\text { raw/pressed } \\
\text { meat }\end{array}$ & $\begin{array}{l}\text { - Adjustable thickness } \\
\text { (e.g., } 0-24 \text { or } 0-15 \mathrm{~mm} \\
\text { slices, depending on the } \\
\text { machine model); } \\
\text { - Precise slice } \\
\text { dimensions; } \\
\text { - Workers avoid repeated } \\
\text { manipulation of } \\
\text { dangerous utensils and a } \\
\text { repetitive action. }\end{array}$ & $\begin{array}{l}\text { - Dangerous and sometimes } \\
\text { difficult to (dis)assembly the } \\
\text { blades; } \\
\text { - Need to sharpen the blades } \\
\text { regularly. }\end{array}$ \\
\hline & $\begin{array}{l}\text { Shredder } \\
\text { machine } \\
\text { (strips cutter) } \\
\text { e.g., }[102] \\
\text { (video) }\end{array}$ & Tabletop & $\begin{array}{l}\text { Two rolls with blades, } \\
\text { rotating in opposite } \\
\text { direction, side by side; } \\
\text { the food passes in } \\
\text { between the rolls, from } \\
\text { the top, being cut in } \\
\text { strips (3) }\end{array}$ & $\begin{array}{l}\text { Information not } \\
\text { available }\end{array}$ & $\begin{array}{c}\text { Rolls with } \\
\text { tenderizing } \\
\text { blades (make } \\
\text { holes in the meat } \\
\text { instead of cutting } \\
\text { it) }\end{array}$ & Meat, fish & $\begin{array}{l}\text { - Faster processing of } \\
\text { large quantities than by } \\
\text { hand; } \\
\text { - Workers avoid repeated } \\
\text { manipulation of } \\
\text { dangerous utensils and } \\
\text { repetitive actions. }\end{array}$ & $\begin{array}{l}\text { - Accessories (tenderizing or } \\
\text { cutting blades assembly) } \\
\text { manually exchanged; } \\
\text { - Limited use/applications; } \\
\text { - Heavy for a tabletop } \\
\text { machine ( } 35 \mathrm{~kg}-\text { e.g., vs. } \\
\text { 21-Kg food cutter [99], or } \\
\text { 18-kg sushi rolls cutter } \\
\text { [104], or } 1.3-\mathrm{kg} \text { pasta } \\
\text { divider type \#3 [103]); } \\
\text { - Fixed thickness (10 or } \\
\text { 15mm with a different } \\
\text { accessory). }\end{array}$ \\
\hline \multirow{3}{*}{$\begin{array}{l}\frac{8}{\pi} \\
\frac{0}{2} \\
\frac{0}{2} \\
0\end{array}$} & $\begin{array}{c}\text { Bread slicer } \\
\text { [279] } \\
(\underline{\text { video at }} \\
\underline{00: 25)}\end{array}$ & Tabletop & $\begin{array}{l}\text { An arm with a serrated } \\
\text { half-disc rotates below } \\
\text { the hopper where the } \\
\text { bread is inserted; while } \\
\text { the half-disc rotates, } \\
\text { the bread slides down } \\
\text { and, then, it is cut by } \\
\text { the half-disc when the } \\
\text { disc passes through (1) }\end{array}$ & $\begin{array}{l}\text { C: } 1 \text { or } 2 \text { rolls } \\
\text { P: } 60 \text { rolls/h (or } \\
120 \text {, if small- } \\
\text { diameter } \\
\text { standard rolls, } \\
\text { because } 2 \text { rolls } \\
\text { can be cut in } \\
\text { simultaneous) in } \\
6,8 \text { or } 10 \text { slices. } \\
\text { C: } 175 \times 110 \mathrm{~mm} \\
\text { (input bread } \\
\text { max. } \\
\text { dimensions) } \\
\text { P: } 7000 \text { to } \\
14000 \text { bread } \\
\text { slices/h (cutting } \\
2 \text { baguettes in } \\
\text { simultaneous) }\end{array}$ & $\begin{array}{l}\text { Sushi cutter: } \\
\text { different cutting } \\
\text { grids to cut } 6,8 \\
\text { or } 10 \text { slices. }\end{array}$ & Sushi rolls & $\begin{array}{l}\text { - Precise slice } \\
\text { dimensions; } \\
\text { - Adjustable thickness of } \\
\text { bread slices (e.g., 8-60 } \\
\text { mm [279]); } \\
\text { - Workers avoid repeated } \\
\text { manipulation of } \\
\text { dangerous utensils and } \\
\text { repetitive actions; } \\
\text { - Faster processing of } \\
\text { large quantities than by } \\
\text { hand. }\end{array}$ & $\begin{array}{l}\text { - Limited use (so far, only for } \\
\text { bread or sushi rolls). } \\
\text { - Need to manually } \\
\text { disassemble blades to clean } \\
\text { them in the dishwasher (no } \\
\text { self-cleaning). } \\
\text { - (For the bread slicer) Heavy } \\
\text { machine ( } 31 \mathrm{~kg} \text { ). }\end{array}$ \\
\hline & \multirow[t]{2}{*}{$\begin{array}{l}\text { Pasta divider } \\
\text { like } \text { e.g., }[103] \\
\quad \text { (video) }\end{array}$} & \multirow[b]{2}{*}{ Tabletop } & $\begin{array}{l}\text { Two rolls with sharp } \\
\text { teeth, fitting each other } \\
\text { and rotating in } \\
\text { opposite direction, side } \\
\text { by side; the pasta sheet } \\
\text { passes in between the } \\
\text { rolls being cut in strips } \\
\text { or strings (3) }\end{array}$ & $\begin{array}{l}\text { C: NA } \\
\text { P: Information } \\
\text { not available }\end{array}$ & $\begin{array}{l}\text { Alternative rolls } \\
\text { with different } \\
\text { teeth for different } \\
\text { pastas }(e . g ., \\
\text { spaghetti, } \\
\text { tagliatelle...) }\end{array}$ & Pasta & \multirow{2}{*}{$\begin{array}{l}\text { - Frees workers from a } \\
\text { repetitive action; } \\
\text { - Avoids long training to } \\
\text { master the skill, } \\
\text { especially to shape the } \\
\text { complex pasta types; } \\
\text { - Repeatability in pasta } \\
\text { dimensions. }\end{array}$} & $\begin{array}{l}\text { - Limited flexibility in the } \\
\text { output pasta dimensions. }\end{array}$ \\
\hline & & & $\begin{array}{l}\text { Endless screw rotating } \\
\text { inside a horizontal } \\
\text { pipe, that presses and } \\
\text { drives the dough } \\
\text { against a perforated } \\
\text { surface (and } \\
\text { optionally, a blade - to } \\
\text { cut pasta in pieces like, } \\
\text { e.g., fusilli) (7) } \\
\end{array}$ & $\begin{array}{l}\text { C: } 2.1 \mathrm{~kg} \\
\text { P: } 4.2 \mathrm{~kg} / \mathrm{h}\end{array}$ & $\begin{array}{l}\text { Alternative } \\
\text { perforated } \\
\text { surfaces for } \\
\text { different pastas } \\
\text { (e.g., spaghetti, } \\
\text { pasta sheet, } \\
\text { fusilli, shells...) }\end{array}$ & Pasta & & $\begin{array}{l}\text { - Heavy for a tabletop } \\
\text { machine }(28 \mathrm{~kg}-e . g ., \text { vs. } \\
\text { 21-Kg food cutter [99], or } \\
18-\mathrm{kg} \text { sushi rolls cutter } \\
\text { [104], or } 1.3-\mathrm{kg} \text { pasta } \\
\text { divider type \#3 [103]); } \\
\text { - Too many parts and steps to } \\
\text { mount or disassembly for } \\
\text { cleaning. }\end{array}$ \\
\hline 胥 & $\begin{array}{c}\text { Breading } \\
\text { machine } \\
\text { e.g., }[105] \\
\text { (video at } 1: 28 \text { ) }\end{array}$ & $\begin{array}{l}\text { The same } \\
\text { machine } \\
\text { fits both } \\
\text { on the } \\
\text { floor and } \\
\text { at a table }\end{array}$ & $\begin{array}{l}\text { Rotating drum with } \\
\text { paddle that tumbles } \\
\text { food in order to } \\
\text { promote even breading } \\
\text { (1) }\end{array}$ & $\begin{array}{l}\text { C: } 4.5 \mathrm{~kg} \\
\text { P: } 180 \mathrm{~kg} / \mathrm{h} \\
(\text { e.g., } 400 \\
\text { chicken } \\
\text { pieces/h) }\end{array}$ & No & $\begin{array}{l}\text { Meat parts } \\
\text { (e.g., chicken } \\
\text { wings), fish, } \\
\text { shrimp, } \\
\text { vegetable } \\
\text { pieces }\end{array}$ & $\begin{array}{l}\text { - Frees workers from a } \\
\text { repetitive, dirty, and } \\
\text { longtime-standing } \\
\text { action; } \\
\text { - Fast processing of large } \\
\text { quantities; } \\
\text { - Smaller footprint } \\
(0.8 \times 0.4 \times 0.5 \mathrm{~m}) \text { than the } \\
\text { workstation for a manual } \\
\text { breading }(e . g ., 1.3 \times 1 \times 0.8 \\
\text { m [95]). }\end{array}$ & $\begin{array}{l}\text { - Noisy machine - listen here; } \\
\text { - No self-cleaning and manual } \\
\text { cleaning can be difficult. }\end{array}$ \\
\hline
\end{tabular}




\begin{tabular}{|c|c|c|c|c|c|c|c|c|}
\hline \multirow[t]{2}{*}{ 己̇ } & $\begin{array}{l}\text { Bidirectional } \\
\text { conveyor } \\
\text { belt, e.g., } \\
\text { [281] } \\
\text { (video) }\end{array}$ & $\begin{array}{l}\text { "tabletop" } \\
\text { (i.e., built } \\
\text { on } \\
\text { counters) }\end{array}$ & $\begin{array}{l}\text { Chain of discs that fit } \\
\text { each other in a } \\
\text { horizontal sequence, } \\
\text { moving in a horizontal } \\
\text { closed path, to carry } \\
\text { dishes on top (6) }\end{array}$ & $\begin{array}{l}\text { C: length, width } \\
\text { and height are } \\
\text { usually } \\
\text { customizable } \\
\text { P: } 0.04 \mathrm{~m} / \mathrm{s} \\
{[282]}\end{array}$ & $\begin{array}{l}\text { Conveyor to } \\
\text { deliver special } \\
\text { requests to } \\
\text { specific tables } \\
\text { [283]; accessory } \\
\text { ("belt transfer } \\
\text { system") to guide } \\
\text { plates to a } \\
\text { conveyor belt } \\
\text { aside [284] }\end{array}$ & $\begin{array}{l}\text { Dishes of } \\
\text { prepared food } \\
\text { (to move them } \\
\text { food from } \\
\text { kitchen to } \\
\text { dining room, } \\
\text { and backwards) }\end{array}$ & $\begin{array}{l}\text { The curved plates, } \\
\text { fitting one after the } \\
\text { other, allow the forward } \\
\text { movement along any } \\
\text { straight or circular path; } \\
\text { - Frees workers from a } \\
\text { repetitive action, from } \\
\text { the risk of falls and from } \\
\text { carrying loads. }\end{array}$ & $\begin{array}{l}\text { Fixed space occupied in the } \\
\text { facilities (requires the } \\
\text { kitchen to stop operations } \\
\text { for modifications to the } \\
\text { layout) } \\
\text { - Not adequate for all types of } \\
\text { food (e.g. liquids) }\end{array}$ \\
\hline & $\begin{array}{l}\text { Unidirectional } \\
\text { conveyor belt, } \\
\text { e.g., [85] } \\
\text { (video) }\end{array}$ & $\begin{array}{l}\text { "tabletop" } \\
\text { (i.e., built } \\
\text { on top of } \\
\text { counters) }\end{array}$ & $\begin{array}{c}\text { Two rubber cords } \\
\text { moving synchronously } \\
\text { in parallel (on a table } \\
\text { with structures that } \\
\text { align the cords with } \\
\text { the desired path), } \\
\text { while carrying on trays } \\
\text { (6) }\end{array}$ & $\begin{array}{l}\text { C: up to } 5 \mathrm{~kg} / \mathrm{m} \\
\text { P: up to } 1800 \\
\text { trays } / \mathrm{h}(1200 \\
\mathrm{m} / \mathrm{h})[285]\end{array}$ & $\begin{array}{c}\text { Accessory to } \\
\text { deviate trays to a } \\
\text { conveyor aside; } \\
\text { vertical chain to } \\
\text { transfer trays to a } \\
\text { higher conveyor } \\
\text { [85] }\end{array}$ & $\begin{array}{l}\text { Trays with } \\
\text { plates of } \\
\text { finished meals } \\
\text { (to transfer to } \\
\text { the } \\
\text { dishwashing } \\
\text { area) }\end{array}$ & $\begin{array}{l}\text { Reduces the need for the } \\
\text { workers to push trolleys } \\
\text { or from carrying trays, } \\
\text { reducing the risk of slips } \\
\text { and falls. }\end{array}$ & $\begin{array}{l}\text { Not always can keep up with } \\
\text { the influx of trays, so the } \\
\text { system is commonly } \\
\text { complemented with trolleys } \\
\text { that are manually pushed. }\end{array}$ \\
\hline$\stackrel{\Xi}{0}$ & $\begin{array}{l}\text { Automatic- } \\
\text { tilting system } \\
\text { for pans and } \\
\text { kettle } \\
\text { e.g., [108, pp. } \\
\text { 18-20] (video) }\end{array}$ & $\begin{array}{l}\text { Floor; } \\
\text { wall- } \\
\text { mounted }\end{array}$ & $\begin{array}{l}\text { Shaft attached to the } \\
\text { lateral wall of } \\
\text { pans/kettles, that } \\
\text { rotates, tilting them (6) }\end{array}$ & $\begin{array}{l}\text { C: NA } \\
\text { P: information } \\
\text { not available }\end{array}$ & NA & $\begin{array}{l}\text { Any solid and } \\
\text { liquid food }\end{array}$ & $\begin{array}{l}\text { - Workers avoid handling } \\
\text { heavy loads; } \\
\text { - Adjustable tilting speed; } \\
\text { - Variable tilting angle; } \\
\text { - Tilting angle over } 90^{\circ} \\
\text { allows complete } \\
\text { emptying and facilitates } \\
\text { cleaning. }\end{array}$ & $\begin{array}{l}\text { Not available/compatible } \\
\text { for/to all the appliances } \\
\text { associated to a pouring } \\
\text { action (e.g., mixers, to pour } \\
\text { from the bowls) }\end{array}$ \\
\hline \multirow[b]{2}{*}{$\begin{array}{l}\frac{0}{\pi} \\
\frac{\pi}{2}\end{array}$} & $\begin{array}{l}\text { Rotating spit } \\
\text { for rotisserie } \\
\text { e.g., [106] } \\
\text { (video) }\end{array}$ & Floor & $\begin{array}{c}\text { Several skewers } \\
\text { connected to a rotating } \\
\text { shaft }(\mathbf{6})\end{array}$ & $\begin{array}{l}\text { C: } \text { e.g., } 36-42 \\
\text { chickens } \\
\text { P: NA }\end{array}$ & $\begin{array}{l}\text { Basket and } \\
\text { skewers for } \\
\text { different food } \\
\text { types }\end{array}$ & $\begin{array}{l}\text { Chicken, pork } \\
\text { loin, meat, } \\
\text { vegetables }\end{array}$ & $\begin{array}{l}\text { Frees workers from a } \\
\text { repetitive and long } \\
\text { action; } \\
\text { - Reduces the workers' } \\
\text { presence in a hot and } \\
\text { humid environment and } \\
\text { the risk of burns. }\end{array}$ & $\begin{array}{l}\text { Limited use for such large } \\
\text { footprint (e.g., } 1.98 \times 1.6 \times \\
0.8 \mathrm{~m}) \text {. }\end{array}$ \\
\hline & $\begin{array}{l}\text { Rotating floors } \\
\text { of deck ovens } \\
\text { e.g., [107] } \\
\text { (video) }\end{array}$ & Floor & $\begin{array}{c}\text { Decks stacked at } \\
\text { different levels inside } \\
\text { an oven, connected to } \\
\text { a central rotating shaft } \\
\text { (1) }\end{array}$ & $\begin{array}{l}\text { C: } \text { e.g., } 24 \\
\text { pizzas with } \\
0.45 \mathrm{~m} \text { diameter } \\
\text { P: NA }\end{array}$ & No & $\begin{array}{c}\text { Pizza, } \\
\text { sandwiches, } \\
\text { pasta, beef }\end{array}$ & $\begin{array}{l}\text { - Frees workers from a } \\
\text { repetitive action of } \\
\text { changing the pizza } \\
\text { orientation; } \\
\text { - Allows faster loading } \\
\text { and unloading and easy } \\
\text { reaching the pizzas; } \\
\text { - Reduces the workers' } \\
\text { presence in a hot and } \\
\text { humid environment and } \\
\text { the risk of burns }\end{array}$ & $\begin{array}{l}\text { Large footprint (e.g., 3.4-m² } \\
\text { area, } 1.4 \mathrm{~m} \text {-diameter decks) }\end{array}$ \\
\hline \multirow[t]{2}{*}{$\begin{array}{l}\vec{\Xi} \\
\stackrel{D}{n}\end{array}$} & $\begin{array}{c}\text { Fork } \\
\text { kneader/mixer } \\
\text { e.g., }[94, \mathrm{p} . \\
\text { 50] [286] } \\
\text { (video at } \\
\underline{00: 48)}\end{array}$ & $\begin{array}{l}\text { Tabletop; } \\
\text { floor }\end{array}$ & $\begin{array}{l}\text { Arm with a two-teeth } \\
\text { fork at the tip, } \\
\text { vertically tilted, } \\
\text { rotating inside a bowl. } \\
\text { The bowl rotates to } \\
\text { help in even mixing. } \\
\text { (2) }\end{array}$ & $\begin{array}{l}\text { C: } 25-40 \mathrm{~L}(15- \\
24 \mathrm{~kg} \text { of dough) } \\
\text { [94]; 20/35/50 } \\
\mathrm{kg}[286] \\
\text { P: NA }\end{array}$ & No & Dough & \multirow{3}{*}{$\begin{array}{l}\text { - Frees workers from a } \\
\text { repetitive, tiring, and } \\
\text { long action; } \\
\text { - Fast processing of both } \\
\text { large and small } \\
\text { quantities. }\end{array}$} & \multirow{3}{*}{$\begin{array}{l}\text { - For the larger models, tools } \\
\text { and bowl are heavy (e.g., 1- } \\
3 \mathrm{~kg} \text { ); } \\
\text { - Heavy machine (100-151 kg } \\
\text { [286]); } \\
\text { - Unloading is manual - a } \\
\text { tiring action especially if the } \\
\text { bowl doesn't tilt; } \\
\text { - Need to disassembly tools } \\
\text { and bowl to clean (no self- } \\
\text { cleaning). }\end{array}$} \\
\hline & $\begin{array}{l}\text { Spiral } \\
\text { kneader/mixer } \\
\text { e.g. }[94, \text { p. } 50] \\
\text { (video) }\end{array}$ & Floor & $\begin{array}{l}\text { Arm with a spiral tool } \\
\text { at the tip, vertically } \\
\text { oriented, rotating } \\
\text { inside a bowl. The } \\
\text { bowl rotates to help in } \\
\text { even mixing. (2) }\end{array}$ & $\begin{array}{l}\text { C: } 50-90 \mathrm{~L}(26- \\
48 \mathrm{~kg} \text { of dough }) \\
\text { P: NA }\end{array}$ & No & Dough & & \\
\hline 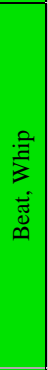 & $\begin{array}{c}\text { Planetary } \\
\text { mixer } \\
\text { e.g. }[94, \text { p. } 50] \\
(\underline{\text { video at }} \\
\underline{00: 20)}\end{array}$ & $\begin{array}{l}\text { Tabletop; } \\
\text { floor }\end{array}$ & $\begin{array}{l}\text { Rotating arm with tool } \\
\text { at the tip, attached at a } \\
\text { top structure, and } \\
\text { inserted in a container } \\
\text { which optionally } \\
\text { rotates, too. The tool } \\
\text { revolves fast on its } \\
\text { own vertical axis and } \\
\text { also rotates more } \\
\text { slowly in a planetary } \\
\text { motion }(i . e ., \text { around } \\
\text { the center of the } \\
\text { bowl).e }(2)\end{array}$ & $\begin{array}{l}\text { C: } 5-80 \mathrm{~L} \mathrm{[287]} \\
\text { P: } e . g ., 10 \mathrm{~min} \\
\text { for } \sim 7.5 \mathrm{~kg} \text { of } \\
\text { dough (for sweet } \\
\text { bread) }\end{array}$ & $\begin{array}{l}\text { Different hooks } \\
\text { and whisks, } \\
\text { paddle, beater, } \\
\text { bowl scraper }\end{array}$ & Dough, cream & & \\
\hline \multirow[t]{2}{*}{ 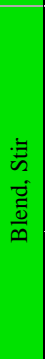 } & $\begin{array}{c}\text { Rotating } \\
\text { scraper system } \\
\text { for boiling } \\
\text { pans, e.g., } \\
\text { [108, p. } 19 ; \\
27](\text { video } 1 \text { at } \\
\underline{0: 57 ; \text { video } 2} \\
\text { at } 0: 36)\end{array}$ & $\begin{array}{l}\text { Built-in } \\
\text { (inside } \\
\text { floor-pan) }\end{array}$ & $\begin{array}{l}\text { Rotating arm with } \\
\text { stirrers, that scrape the } \\
\text { bottom of the pan }(\mathbf{1})\end{array}$ & $\begin{array}{l}\text { C: boiling pans } \\
60-500 \mathrm{~L}[108] \\
\text { P: information } \\
\text { not available }\end{array}$ & $\begin{array}{l}\text { Scrapers, } \\
\text { mashing stirrer }\end{array}$ & $\begin{array}{c}\text { Sauces, } \\
\text { goulash, soups, } \\
\text { puree }\end{array}$ & $\begin{array}{l}\text { - Frees workers from a } \\
\text { repetitive, tiring, and } \\
\text { long action; } \\
\text { - Reduces the risk of } \\
\text { burns. }\end{array}$ & \\
\hline & $\begin{array}{l}\text { Drinks mixer, } \\
\text { e.g. [109] } \\
\text { (video })\end{array}$ & $\begin{array}{l}\text { Tabletop; } \\
\text { wall- } \\
\text { mounted }\end{array}$ & $\begin{array}{c}\text { Rotating stirrers } \\
\text { (similar to a blender } \\
\text { but with non-cutting } \\
\text { blades) (2) }\end{array}$ & $\begin{array}{l}\text { C: } 0.5-0.9 \mathrm{~L} \\
\text { P: a few seconds } \\
\text { (as shown in the } \\
\text { video) }\end{array}$ & $\begin{array}{l}\text { Round agitator } \\
\text { for frozen coffees } \\
\text { or for creamier } \\
\text { results }\end{array}$ & $\begin{array}{l}\text { Coffee, } \\
\text { cocktails, } \\
\text { milkshakes }\end{array}$ & $\begin{array}{l}\text { Frees workers from a } \\
\text { repetitive action. }\end{array}$ & \\
\hline
\end{tabular}




\begin{tabular}{|c|c|c|c|c|c|c|c|c|}
\hline & $\begin{array}{c}\text { Automatic } \\
\text { stirring system } \\
\text { for woks [74] }\end{array}$ & $\begin{array}{l}\text { Built-in } \\
\text { (on a wok } \\
\text { at a stove) }\end{array}$ & $\begin{array}{c}2 \mathrm{~T} 1 \mathrm{R}^{\mathrm{f}} \text { parallel } \\
\text { manipulator with a } 1- \\
\text { DoF linear feed } \\
\text { mechanism connected } \\
\text { to a wok }(\mathbf{5})\end{array}$ & $\begin{array}{l}\text { C: One wok pan } \\
\text { P: NA }\end{array}$ & No & $\begin{array}{l}\text { Vegetables, } \\
\text { eggs, pasta, } \\
\text { meat }\end{array}$ & $\begin{array}{l}\text { - Reduces risk of burns; } \\
\text { - Reduces complex and } \\
\text { not always ergonomic } \\
\text { manual wok } \\
\text { moving/stirring. } \\
\end{array}$ & $\begin{array}{l}\text { - Although tested in realistic } \\
\text { conditions, it is still a } \\
\text { research prototype }\end{array}$ \\
\hline \multirow{3}{*}{$\stackrel{\mathscr{E}}{\approx}$} & Dishwasher & Floor & $\begin{array}{l}\text { Rotating water nozzles } \\
\text { (1) }\end{array}$ & $\begin{array}{l}\text { C: } e . g ., \text { each } \\
\text { basket with } 18 \\
\text { flat plates }[288] \\
\text { P: } \text { e.g., } 1000 \\
\text { coffee cups/h } \\
\text { [289] or up to } \\
300 \text { baskets/h } \\
{[288]}\end{array}$ & No & $\begin{array}{l}\text { Any food dirty } \\
\text { (except large } \\
\text { leftovers) on } \\
\text { crockery, trays, } \\
\text { cups, and } \\
\text { cutlery }\end{array}$ & $\begin{array}{l}\text { - Performs autonomously } \\
\text { repetitive and long } \\
\text { action; } \\
\text { - Automatic sanitization }\end{array}$ & $\begin{array}{l}\text { - Pre-scrubbing/scraping } \\
\text { action is most frequently } \\
\text { manual (an exceptional case } \\
\text { is [129]); } \\
\text { - Sorting serviceware into/out } \\
\text { of the dishwasher is } \\
\text { frequently manual. }\end{array}$ \\
\hline & 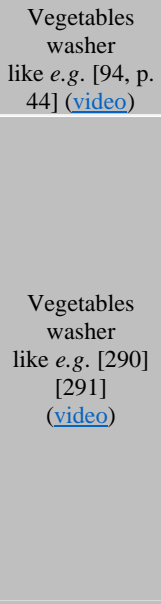 & Floor & $\begin{array}{l}\text { Water pump that } \\
\text { creates an adjustable } \\
\text { whirl/vortex and a } \\
\text { continuous flow of } \\
\text { clean water, inside a } \\
\text { well where the } \\
\text { vegetables are loaded } \\
\text { (9) }\end{array}$ & $\begin{array}{l}\text { C: } 5-16 \mathrm{~kg} / 20- \\
60 \mathrm{~kg} \text { of light / } \\
\text { heavy } \\
\text { vegetables, } \\
\text { respectively } \\
\text { P: (fixed time) } \\
\text { 2-3min }\end{array}$ & No & Vegetables & $\begin{array}{l}\text { - Frees workers from a } \\
\text { repetitive and long } \\
\text { action; } \\
\text { - Fast processing of large } \\
\text { quantities; } \\
\text { - More accurate cleaning } \\
\text { [290]: the vortex } \\
\text { replaces rinsing and } \\
\text { brushing; being } \\
\text { adjustable, it allows } \\
\text { cleaning more dirty and } \\
\text { more irregular } \\
\text { vegetables; } \\
\text { - Includes automatic } \\
\text { sanitization; } \\
\text { - Different programs } \\
\text { available for soft or hard } \\
\text { vegetables; } \\
\text { - Includes the automatic } \\
\text { tilting system to unload } \\
\text { the machine. }\end{array}$ & $\begin{array}{l}\text { Bulky machine with large } \\
\text { footprint (e.g., } 1.5 \times 0.85 \times 0.9 \\
\mathrm{~m}[291]) \text { for a single use/few } \\
\text { applications; } \\
\text { - Tall machine }(e . g ., 0.85 \mathrm{~m})- \\
\text { need to lift a vegetables } \\
\text { container to pour them } \\
\text { inside the machine. }\end{array}$ \\
\hline & $\begin{array}{c}\text { Appliances } \\
\text { self-cleaning } \\
\text { mechanisms } \\
\text { e.g. [110, p. } \\
52] \\
\text { (video at 5:50) }\end{array}$ & $\begin{array}{l}\text { Tabletop } \\
\text { or floor } \\
\text { (inside } \\
\text { appliance) }\end{array}$ & $\begin{array}{c}\text { Rotating water nozzles } \\
\text { (1) }\end{array}$ & $\begin{array}{l}\text { C: adapted to } \\
\text { the size of the } \\
\text { specific } \\
\text { appliance } \\
\text { P: dependent on } \\
\text { the appliance } \\
\text { and selected } \\
\text { cleaning } \\
\text { program }\end{array}$ & No & $\begin{array}{l}\text { Any food dirty } \\
\text { (except large } \\
\text { pieces) }\end{array}$ & $\begin{array}{l}\text { - Frees workers from a } \\
\text { repetitive, tiring and } \\
\text { long action; } \\
\text { - Workers avoid recurrent } \\
\text { contact with strong } \\
\text { chemicals. } \\
\text { - Cleans difficult-to- } \\
\text { access interior zones }\end{array}$ & \\
\hline$\stackrel{\substack{\infty \\
\Xi}}{\Xi}$ & $\begin{array}{l}\text { Automatic } \\
\text { immersion and } \\
\text { lifting system } \\
\text { in } \\
\text { fryers and } \\
\text { rice/pasta } \\
\text { cookers [292] } \\
\text { (video) }\end{array}$ & $\begin{array}{l}\text { Built-in } \\
\text { (on fryer); } \\
\text { add-in } \\
\text { (cooker, } \\
\text { side } \\
\text { module) }\end{array}$ & $\begin{array}{l}\text { Linear actuator with } \\
\text { shaft where the baskets } \\
\text { are hanged (5) }\end{array}$ & $\begin{array}{l}\text { C: can include } \\
\text { as many arms as } \\
\text { baskets on the } \\
\text { fryer/cooker; can } \\
\text { lift, at least } 3.4 \\
\mathrm{~kg} \text { of food [293] } \\
\text { P: speed } \\
\text { information not } \\
\text { available }\end{array}$ & No & No & $\begin{array}{l}\text { - Workers avoid manually } \\
\text { lifting heavy loads; } \\
\text { - Standardized food } \\
\text { quality (lower risk of } \\
\text { overcooking food with } \\
\text { the automatic timed } \\
\text { lifting) } \\
\text { - Reduces the risk of } \\
\text { workers' burns. }\end{array}$ & \\
\hline 岌 & $\begin{array}{l}\text { Meat stuffing } \\
\text { machine } \\
\text { e.g., [294] } \\
\text { (video) }\end{array}$ & $\begin{array}{l}\text { Tabletop; } \\
\text { floor }\end{array}$ & Hydraulic piston (5) & $\begin{array}{l}\text { C: } \text { e.g., } 15-55 \mathrm{~L} \\
\text { P: variable } \\
\text { speed (max. time } \\
\text { to empty the } \\
\text { largest tank: } \\
\text { 6min; min. time } \\
\text { to empty the } \\
\text { smallest tank: } \\
\text { 35sec) }\end{array}$ & No & Sausages & $\begin{array}{l}\text { - Workers avoid repetitive } \\
\text { and tiring action. }\end{array}$ & $\begin{array}{l}\text { - Still requires a lot of hand } \\
\text { work; } \\
\text { - Limited use (sausages-like } \\
\text { food). }\end{array}$ \\
\hline चँ & $\begin{array}{c}\text { Vacuum/aired } \\
\text { sealer machine } \\
\text { e.g. }[111] \\
{[295]} \\
\text { (video) }\end{array}$ & $\begin{array}{l}\text { Tabletop; } \\
\text { floor }\end{array}$ & $\begin{array}{l}\text { Air pump and heated } \\
\text { sealing bar (9) }\end{array}$ & $\begin{array}{l}\text { C: sealing bar } \\
\text { length of } 0.45- \\
0.65 \mathrm{~m} \text { (different } \\
\text { models) } \\
\text { P: From } 10 \text { to } \\
60 \mathrm{~m}^{3} / \mathrm{h} \text { ( } 100 \text { to } \\
800 \text { meals/day) }\end{array}$ & $\begin{array}{l}\text { Adaptor for } \\
\text { vacuuming } \\
\text { external } \\
\text { containers }\end{array}$ & $\begin{array}{l}\text { Liquid or solid } \\
\text { foods in proper } \\
\text { plastic bags }\end{array}$ & $\begin{array}{l}\text { - Fast packages' closure; } \\
\text { - Adjustable vacuum } \\
\text { degree; } \\
\text { - Possibility to have inert } \\
\text { gas for delicate foods; } \\
\text { - Effective bags sealing } \\
\text { for cooking food by } \\
\text { sous-vide. }\end{array}$ & $\begin{array}{l}\text { - Bulky and heavy, even for } \\
\text { the smaller tabletop models } \\
(32 \mathrm{~kg}) \text { [295]. }\end{array}$ \\
\hline$\sum^{\frac{\pi}{0}}$ & $\begin{array}{c}\text { 3D food } \\
\text { printers } \\
\text { e.g. }[114] \\
{[117]} \\
\text { (video) }\end{array}$ & Tabletop & $\begin{array}{l}\text { Nozzle that moves in } \\
\text { three directions in } \\
\text { space, while extruding } \\
\text { a food paste }(\mathbf{8})\end{array}$ & $\begin{array}{l}\text { C: } 1-5 \text { capsules } \\
\text { of ingredients } \\
(0.1 \mathrm{~L}) ; \text { max. } \\
\text { printable height } \\
0.11 \mathrm{~m} \text { and } \\
0.257 \mathrm{~m} \\
\text { diameter [114]; } \\
1 \text { capsule of } 0.03 \\
\mathrm{~L}, \text { max. } \\
\text { printable height } \\
0.04 \mathrm{~m} \text { and } \\
0.17 \mathrm{~m} \text { width } \\
{[117]} \\
\text { P: depends on } \\
\text { ingredients, }\end{array}$ & $\begin{array}{l}\text { Different nozzles' } \\
\text { diameters }\end{array}$ & $\begin{array}{l}\text { Purees, sauces, } \\
\text { semi-liquid } \\
\text { doughs, melted } \\
\text { chocolate }\end{array}$ & $\begin{array}{l}\text { - Avoids long training to } \\
\text { master the skill; } \\
\text { - Workers avoid repetitive } \\
\text { action. }\end{array}$ & $\begin{array}{l}\text { - Final food product is often } \\
\text { not 3D but } 2.5 \mathrm{D} \text {, more } \\
\text { similar to extruded products; } \\
\text { - Low productivity; } \\
\text { - Not suitable for all types of } \\
\text { ingredients and dishes. } \\
\text { - Final texture reported to be } \\
\text { sometimes not appealing. }\end{array}$ \\
\hline
\end{tabular}




\begin{tabular}{|c|c|c|c|c|c|c|c|c|}
\hline & & & & $\begin{array}{l}\text { shape, quantity - } \\
\text { e.g., few minutes } \\
\text { for crackers or } \\
\text { simple } \\
\text { decorations, } \\
\text { 20min or more } \\
\text { for chocolate } \\
\text { sculptures [296] }\end{array}$ & & & & \\
\hline & $\begin{array}{c}\text { Rice balls } \\
\text { press } \\
\text { machine [104] } \\
\text { (video) }\end{array}$ & Tabletop & $\begin{array}{l}\text { Rotating gears drive } \\
\text { and press the rice } \\
\text { against rotating molds } \\
\text { that shape the rice }(\mathbf{8})\end{array}$ & $\begin{array}{l}\text { C: Approx. } \\
6.6 \mathrm{~kg} \text { hopper } \\
\text { P: Up to } 2400 \\
\text { rice balls/h; }\end{array}$ & $\begin{array}{l}\text { Rice ball sizes } \\
\text { can be changed } \\
\text { by switching } \\
\text { forming Rollers }\end{array}$ & Sushi rice & $\begin{array}{l}\text { - Avoids long training to } \\
\text { master the skill; } \\
\text { - Fast processing of large } \\
\text { quantities; } \\
\text { - Workers avoid repetitive } \\
\text { action; } \\
\text { - Exchangeable molds for } \\
\text { other shapes. }\end{array}$ & $\begin{array}{l}\text { - Limited use; } \\
\text { - Short number of shapes } \\
\text { available. }\end{array}$ \\
\hline $\begin{array}{l}\frac{5}{5} \\
\overline{\bar{c}} \\
\check{\Sigma}\end{array}$ & $\begin{array}{l}\text { Japanese Maki } \\
\text { wrapper [104] } \\
\text { (video) }\end{array}$ & Tabletop & $\begin{array}{l}\text { Set of actuated plates } \\
\text { that get aligned and } \\
\text { pushed towards one } \\
\text { another, to close a } \\
\text { sheet of food in } \\
\text { between the plates (4) }\end{array}$ & $\begin{array}{l}\text { C: } 70-80 \text { rolls } \\
\text { (hopper } \\
\text { capacity) } \\
\text { P: } 450 \text { rolls } / \mathrm{h} \text {; }\end{array}$ & $\begin{array}{c}\text { Different } \\
\text { wrapping units }\end{array}$ & $\begin{array}{l}\text { Sushi roll } \\
\text { assembly }\end{array}$ & $\begin{array}{l}\text { - Avoids long training to } \\
\text { master the skill; } \\
\text { - Fast processing of large } \\
\text { quantities; } \\
\text { - Workers avoid repetitive } \\
\text { action; } \\
\text { - Customizable wrap } \\
\text { strength. }\end{array}$ & - Limited use. \\
\hline $\begin{array}{l}\frac{5}{0} \\
\frac{0}{0} \\
\text { के }\end{array}$ & $\begin{array}{c}\text { Rice/dough/pa } \\
\text { sta sheeter, } \\
\text { e.g., [104] } \\
{[112] \text { [94, p. }} \\
51] \\
\text { (video) }\end{array}$ & Tabletop & $\begin{array}{l}\text { Two rolls rotating in } \\
\text { opposite direction, side } \\
\text { by side; the rice/dough } \\
\text { passes in between the } \\
\text { rolls becoming a sheet } \\
\text { (3) }\end{array}$ & $\begin{array}{l}\text { C: } 70-80 \text { rolls } \\
\text { (hopper } \\
\text { capacity) [104]; } \\
\text { max. dough } \\
\text { width } 0.5 \mathrm{~m} \text { [94] } \\
\text { P: } 720 \text { rice } \\
\text { sheets/h [104] }\end{array}$ & $\begin{array}{l}\text { Different rice } \\
\text { sheet sizes [104]; } \\
\text { remote foot pedal } \\
\text { to change rolling } \\
\text { direction [297] }\end{array}$ & $\begin{array}{c}\text { Rice, } \\
\text { dough/pasta }\end{array}$ & $\begin{array}{l}\text { - Avoids long training to } \\
\text { master the skill; } \\
\text { - Fast processing of large } \\
\text { quantities; } \\
\text { - Workers avoid repetitive } \\
\text { action; } \\
\text { - Adjustable sheet } \\
\text { thickness (e.g., 0.1-27 } \\
\text { mm [94]). }\end{array}$ & - Limited use. \\
\hline
\end{tabular}

${ }^{a}$ A link for a video, when available, is suggested, for the reader to watch an example of the mechanism in action.

${ }^{\mathrm{b}}$ Formats: built-in, floor, handheld, on stand, tabletop, wall-mounted.

${ }^{\mathrm{c}}$ Presented values of capacity and productivity are typical values, found in the references cited near the respective machine name - only suppliers in our search list (see section III.A).

${ }^{\mathrm{d}}$ As a reference, this corresponds to six times faster than slicing by hand. [279]

e The planetary movement is produced by a gear pinion mounted on the shaft of the tool (the beater or whisk), that moves along the teeth of a stationary external gear ring.

f $2 \mathrm{~T} 1 \mathrm{R}$ refers to the type of joints of the manipulator: 2 translational joints and 1 rotational joint. DoF stands for degrees of freedom.

Additional notes:

(i) $\mathrm{kg}$ stands for kilogram, $\mathrm{m}$ for meter, $\mathrm{h}$ for hour, $\mathrm{m}$ for minute(s), L for liter(s), min. for minimum, max. for maximum, NA for "not applicable".

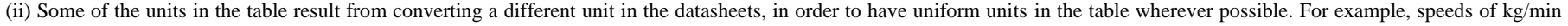
were converted to $\mathrm{kg} / \mathrm{h}$, and volumes in pounds (lb) converted to $\mathrm{L}$.

\section{APPENDIX B}

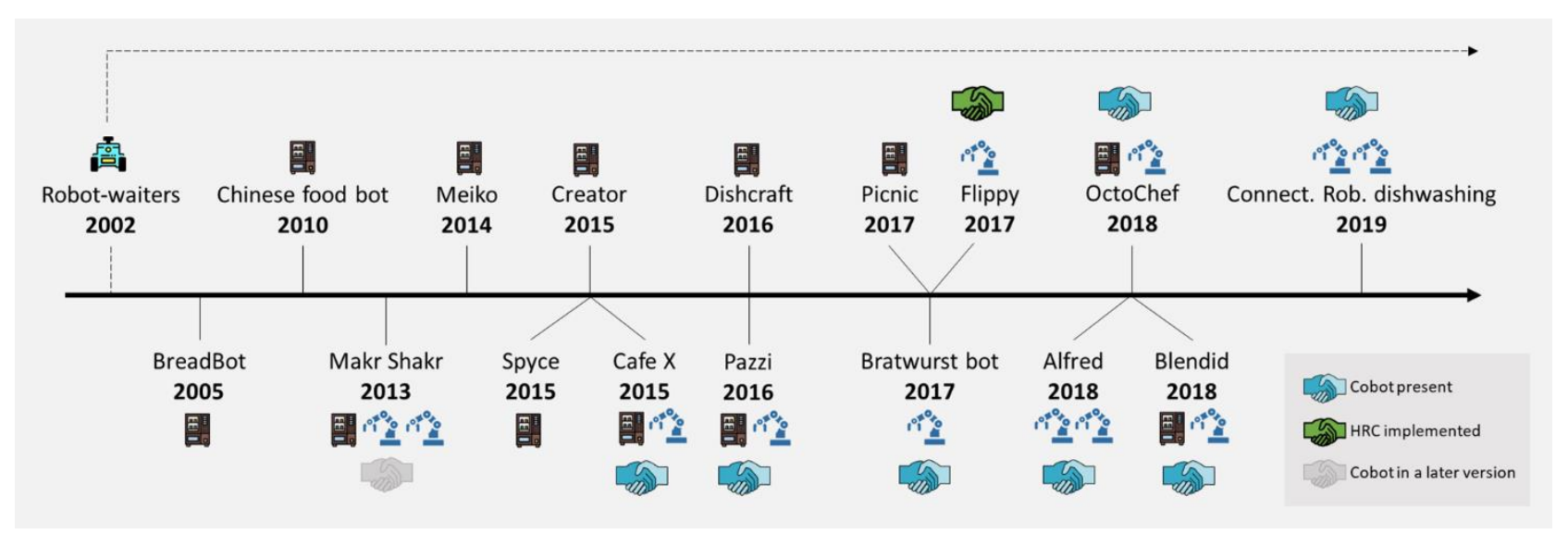

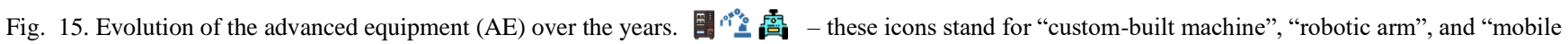
robot", respectively, like in Table 2 . The arrow on top of the mobile robot indicates that, at least, since 2002 and over the years, different mobile waiter robots have created. The indicated year concerns the invention or the release to the market if the first was not available. 